University of San Diego

Digital USD

Spring 5-27-2017

\title{
The Effect of Watershed Runoff and Sediment Resuspension on Turbidity and Sediment Deposition in St. John, US Virgin Islands: Implications for Watershed and Marine Development and Restoration in Bays with Coral Reefs
}

Stephen E. Campbell

University of San Diego

Follow this and additional works at: https://digital.sandiego.edu/theses

Part of the Geology Commons, Geomorphology Commons, Hydrology Commons, Oceanography Commons, and the Other Environmental Sciences Commons

\section{Digital USD Citation}

Campbell, Stephen E., "The Effect of Watershed Runoff and Sediment Resuspension on Turbidity and Sediment Deposition in St. John, US Virgin Islands: Implications for Watershed and Marine Development and Restoration in Bays with Coral Reefs" (2017). Theses. 22.

https://digital.sandiego.edu/theses/22

This Thesis: Open Access is brought to you for free and open access by the Theses and Dissertations at Digital USD. It has been accepted for inclusion in Theses by an authorized administrator of Digital USD. For more information, please contact digital@sandiego.edu. 


\title{
UNIVERSITY OF SAN DIEGO
}

\author{
San Diego
}

The Effect of Watershed Runoff and Sediment Resuspension on Turbidity and Sediment Deposition in St. John, US Virgin Islands: Implications for Watershed and Marine Development and Restoration in Bays with Coral Reefs

A thesis submitted in partial satisfaction of the

requirements for the degree of

Master of Science in Marine Science

by

Stephen Campbell

Thesis Committee

Sarah Gray, Ph.D., Chair

Jennifer Prairie, Ph.D.

James Whinney, Ph.D. 
The thesis of Stephen Campbell is approved by:

Sarah Gray, Ph.D., Chair

University of San Diego

Jennifer Prairie, Ph.D.

University of San Diego

James Whinney, Ph.D.

James Cook University

University of San Diego

San Diego

2017 
Copyright 2017 Stephen Campbell 


\section{Dedication}

This thesis is dedicated to my grandparents, Berdelle and Ernest Campbell, who instilled in me the value of education and hard work, and my parents, Paul and Virginia Campbell, who inspired my curiosity and fascination with the natural world.

Thanks for encouraging me to pursue what I love. 


\section{ACKNOWLEDGMENTS}

I would first like to thank my thesis advisor Dr. Sarah Gray who allowed for all of this to happen. She was instrumental in helping me design and conduct my research, and write my thesis. She provided me with numerous opportunities to grow as a scientist, and has always been dedicated to the success of her graduate students. I would also like to thank my committee members; Dr. Jennifer Prairie, for helping me though my data analysis and statistics, and Dr. James Whinney for providing the nephelometers and helping with the interpretation of the data.

There are numerous lab mates, field assistants, and graduate students that deserve a thank you for their contributions to this thesis. My lab mates, Whitney Sears and Bobby Harrington, spent many many hours passing on their knowledge of the St. John Sediment project to me, training me in lab protocols, and helping me get oriented in San Diego. My field help, Heidi Hirsh and Tyler Barnes, made long days of field work not only productive but also endlessly entertaining. My cohort, Elizabeth Smith, Megan Slack, and Dustin Chen, who could always relate to my experiences, both good and bad, as a graduate student. Sean Campbell for his patience in explaining the nephelometer data, and answering my numerous questions during the data analysis phase. There's a unique friendship that evolves from spending countless hours together working on a common goal, and I can't thank those enough who have worked with me on this project.

Finally, I would like to acknowledge the funding sources that made this project possible: 1) NOAA Coral Reef Conservation Program, 2) National Fish and Wildlife Foundation, 3) The Geological Society of America Graduate Student Research Grant, 4) The Stephen Sullivan Memorial Scholarship, and 5) the University of San Diego. Without the generous financial support from these organizations, I would not have been able to conduct this research. 


\section{Table of Contents}

List of Figures

VIII

List of Tables .IX

Chapter 1: Introduction . 1

1.1 Land-based sedimentation and coral reefs ............................................ 1

1.2 Gray Lab Research.................................................................... 3

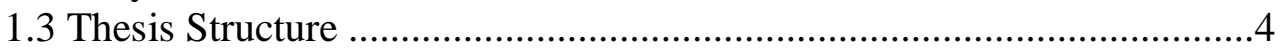

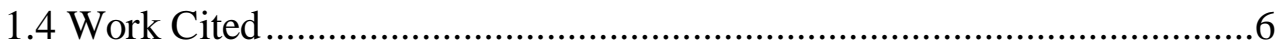

Chapter 2: Monitoring sediment dynamics using Nephelometers and Sediment Traps: Challenges and Considerations

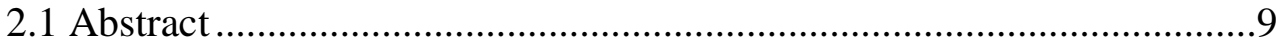

2.2 Introduction ................................................................................. 10

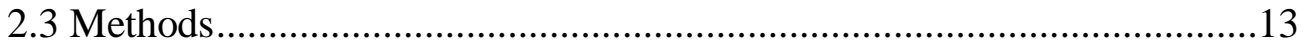

2.3.1 Study Area: St. John, USVI ............................................13

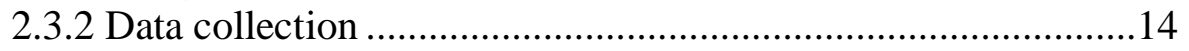

2.3.3 Laboratory methods ......................................................16

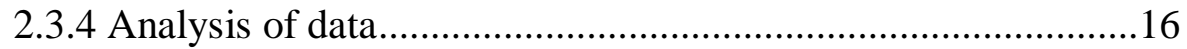

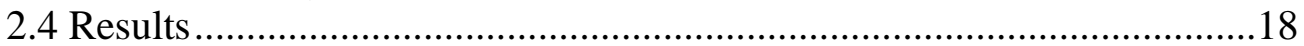

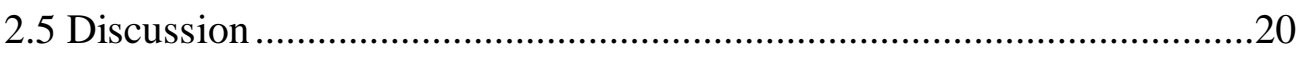

2.5.1 Interpretation of sediment trap data ..................................20

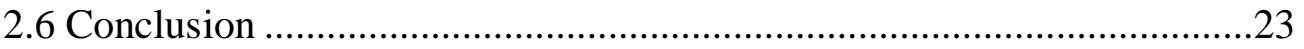

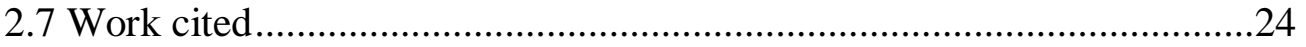

Chapter 3: Watershed Runoff and Sediment Resuspension: Factors Affecting

Turbidity and Sedimentation in Bays with Coral Reefs, St. John, USVI .................28

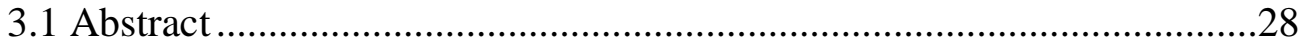

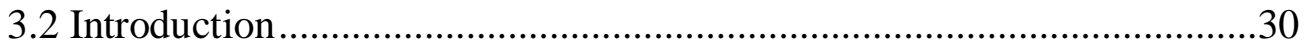

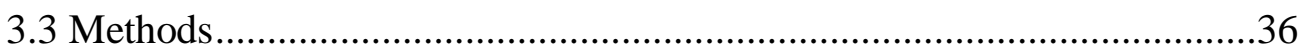

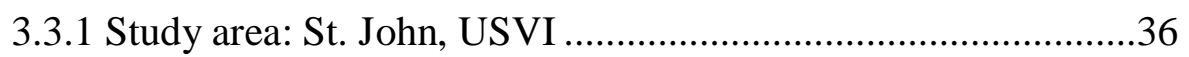

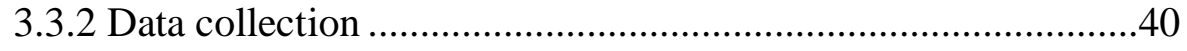

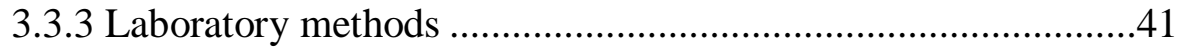

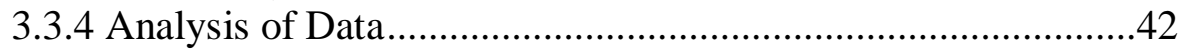

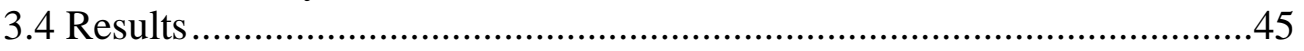

3.4.1 General spatial variability of turbidity and deposition .............45

3.4.2 Runoff induced sedimentation ...........................................48

3.4.2.1 Rainfall and runoff at the Shipwreck ephemeral stream...............................................48

3.4.2.2 Sedimentary response to runoff .............................48

3.4.3 Factors affecting resuspension ..........................................55

3.4.3.1 Benthic sediment grain size ..................................55

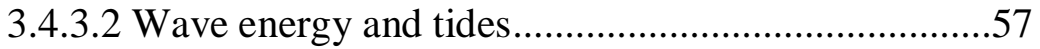


3.4.4 Contributions to turbidity and deposition from runoff vs.

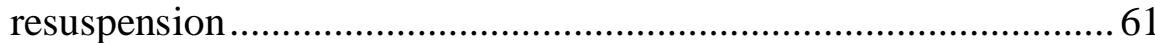

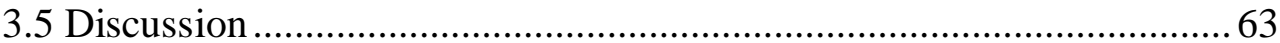

3.5.1 Processes affecting sediment dynamics at the shore and reef in

St. John. 63

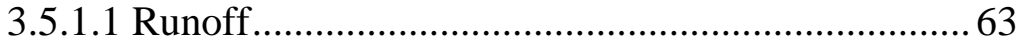

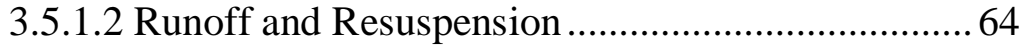

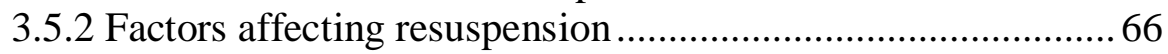

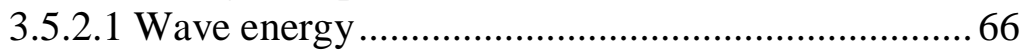

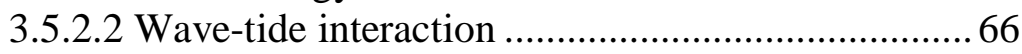

3.5.2.3 Benthic sediment grain size................................. 68 3.5.3 Contributions to turbidity and deposition from runoff vs. resuspension 69 3.5.4 Impact of watershed development and restoration, and environmental implications of a proposed mega-yacht marina ....... 70

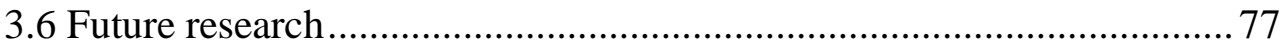

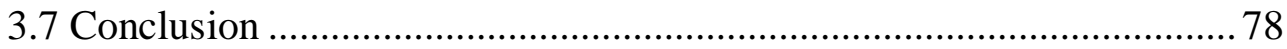

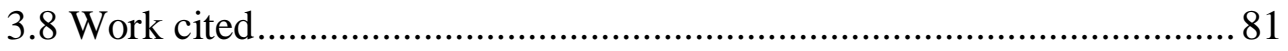

Chapter 4: Conclusion

Appendix A: Deployment intervals and data availability of sediment traps, nephelometers, crest gauges, and the stream gauge during the Fall of 2013 90

Appendix B: Deployment intervals of sediment traps, time averaged nephelometer turbidity and deposition values, variance and range of turbidity and deposition values, and sediment trap accumulate rates at each site during the Fall of 2013 ....91

Appendix C: Timing, total duration, max stage height, mean stage height, and rainfall during runoff events in the Fall of 2013

Appendix D: Location, water depth, environment, watershed classification, and runoff monitoring instruments at each monitoring site.

Appendix E: $\%$ of benthic sediment $<63 \mu \mathrm{m}$ (silt+clay) at each site during each collection/deployment

Appendix F: Crest gauge periods with and without runoff 


\section{List of Figures}

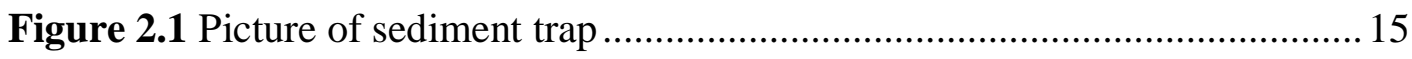

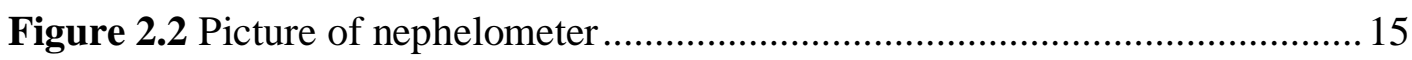

Figure 3.1 Study Area: Instrument package deployment locations in Coral and Lameshur Bay

Figure 3.2 Range of turbidity and deposition at developed and minimally developed shore and reef sites .46

Figure 3.3 Turbidity, deposition, and runoff stage height vs. local time during the 11/21/13 runoff event at the Shipwreck site

Figure 3.4 Turbidity, deposition, and runoff stage height vs. local time during the 11/4/13 runoff event at the Shipwreck site 52

Figure 3.5 Turbidity, deposition, and runoff stage height vs. local time during the 12/24/13 runoff event at the Shipwreck site 53

Figure 3.6 Median and max turbidity and deposition during crest gauge runoff and resuspension periods 54

Figure 3.7 Mean turbidity vs. mean \% silt and clay in benthic sediment during the

Fall of 2013 .56

Figure 3.8 Wave energy vs. turbidity during stream gauge runoff and resuspension periods at the Shipwreck site 59

Figure 3.9 Turbidity, deposition, and tides from 12/15/13 through 12/21/13 at the Shipwreck site 60

Figure 3.10 Contributions to turbidity and deposition from runoff and resuspension 


\section{List of Tables}

Table 2.1 Correlation between nephelometer and sediment trap data ................... 19

Table 3.1 Physical characteristics of watersheds in the study area .......................39

Table 3.2 Ratio of turbidity and deposition between pairs of developed and

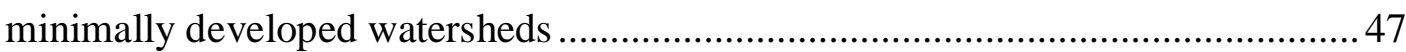




\section{Chapter 1: Introduction}

\subsection{Land-based sedimentation and coral reefs}

For decades, coral condition and abundance have been declining throughout the Caribbean (Gardner et al., 2003; Alvarev-Filip et al., 2009). Coral reef degradation is a product of direct and indirect anthropogenic activity, such as overfishing (McManus, 1997), dredging and trawling (Bak, 1978; Brown et al., 1990; McManus, 1997), ocean acidification (Anthony et al., 2008), ocean warming (Anthony et al., 2011), and in coastal environments, terrigenous runoff and sedimentation (Fabricius, 2005; Bartley et al., 2013; Ertfemeijer et al., 2012; Bartley et al., 2013; Bégin et al., 2016). Terrigenous runoff and sedimentation affect coral health in four distinct ways: 1) elevated concentrations of dissolved inorganic nutrients increase the abundance of macroalgae which can overgrow corals (Loya, 2004); 2) increased concentration of particulate organic matter provide a competitive advantage to heterotrophic filter feeders over corals (Fabricius, 2005; Edmunds and Gray, 2014); 3) increased turbidity reduces light availability for photosynthetic zooxanthellae (Anthony and Fabricius, 2000); 4) increased sedimentation can smother corals, particularly affecting growth and recruitment in early life stages, reduce the availability of hard benthic substrate (Fabricius et al., 2003; Fabricius, 2005; Yeemin et al., 2013; Browne et al., 2015), and reduce reef fish herbivory (Goatley and Bellwood, 2012).

On the island of St. John, in the U.S. Virgin Islands (USVI), anthropogenic activity in steep coastal watersheds, specifically the construction of unpaved roads, has been associated with increased watershed erosion, sediment 
yield (Macdonald et al., 1997; Ramos-Scharrón and Macdonald, 2007b; RamosScharrón and McDonald, 2012; Ramos-Scharrón and LaFevor, 2016), and marine terrigenous sedimentation of up to an order of magnitude above background levels (Brooks et al., 2007; Gray et al., 2008; Gray et al., 2012).

To reduce the transport of land based sediment to the reef in St. John, watershed restoration funded by the American Reinvestment and Recovery Act (ARRA) was completed in 2011. Watershed restoration consisted of paving unpaved roads to reduce the availability of easily erodible sediment, installing water-bars on unpaved roads to divert water and reduce erosion, and constructing retention ponds to allow sediment to settle out of runoff water before entering the marine environment (Ramos-Scharrón et al., 2012). 


\subsection{Gray Lab Research}

The National Oceanic and Atmospheric Administration (NOAA) Coral Reef Conservation Program, in addition to other agencies, funded S. Gray's Marine Sedimentation Project to link watershed processes with marine sedimentation, and assess the effect of watershed development and restoration on marine sediment dynamics. S. Gray's marine sedimentation research has shown that sediment trap accumulation rates below developed watershed were significantly greater than below minimally developed watersheds (Gray et al., 2008; Gray et al., 2012). Additionally, they found that the highest rates of terrigenous sediment accumulation were associated with major storm events such as Hurricane Otto in October 2010 (Gray et al., 2012; Sears, 2015). However, due to the typically long deployment intervals ( 26 days) of sediment traps, and short duration (minutes to days) of runoff and resuspension processes, it has not been possible to separate primary deposition (particles that undergo deposition for the first time after being introduced to the marine environment) from runoff events, and secondary deposition (particles that are resuspended from the seafloor and redeposit) from resuspension. The complexity of separating runoff vs. resuspension processes using sediment trap data alone has made it challenging to evaluate the effectiveness of watershed restoration. 


\subsection{Thesis Structure}

Building on previous studies from Gray’s Marine Sedimentation Project

(Gray et al., 2008; Gray et al., 2012; Sears, 2015), this thesis addresses knowledge gaps regarding the effect of watershed development, runoff, and resuspension on marine turbidity and sedimentation. In Chapter 2, I evaluate the efficacy of timeintegrated ( 26 day) sediment trap monitoring in relation to high-resolution (10minute) turbidity and deposition monitoring. This was accomplished by deploying 10-min resolution nephelometers (measuring turbidity and deposition) adjacent to 26-day resolution sediment traps. Relative changes in data collected from the nephelometer were compared to relative changes in data collected by the sediment trap. At the majority of sites, nephelometers and sediment traps recorded similar relative changes in marine sediment dynamics. This chapter, which is based on data from the 2013 field season, will be expanded to integrate data from subsequent monitoring field seasons for submission as an article. In Chapter 3, I describe the spatial and temporal variability of marine turbidity and deposition in relation to resuspension, and watershed development, restoration, and runoff, and separate contributions to turbidity and deposition from runoff vs. resuspension. Turbidity and deposition measurements were greater below developed watersheds compared to minimally developed watersheds, during short duration (minuteshours) runoff events, and over longer periods (months). Resuspension contributed significantly more than runoff to turbidity and deposition. As resuspension is the primary mechanism contributing to turbidity and deposition, watershed restoration may not immediately result in measurable improvements in water 
quality until previously deposited terrigenous sediment has been worked out of the system and is no longer available for resuspension.

By revealing the roles of resuspension compared to runoff in contributing to water quality degradation, the results of this study help us better understand the complex watershed-marine interaction in St. John, and better inform management decisions that policies that intend to protect corals and other marine resources. 


\subsection{Work Cited}

Alvarez-Filip, L., N.K. Dulvy, J.A. Gill, I.M. Cote, and A.R. Watkinson, 2009. Flattening of Caribbean coral reefs: region-wide declines in architectural complexity. Proceedings of the Royal Society 1822:1-7.

Anthony, K.R.N., and K.E. Fabricius, 2000. Shifting roles of heterotrophy and autotrophy in coral energetic under varying turbidity. Journal of Experimental Marine Biology and Ecology 252:221-253.

Anthony, K.R.N., J.A. Maynard, G. Diaz-Pulido, P.J. Mumby, P.A. Marshall, L. Cao, and O. Hoegh-Guldberg. 2011. Ocean acidification and warming will lower coral reef resilience. Global Change Biology17:1798-1808.

Anthony, KRN., D.I. Kline, G. Diaz-Pulido, S. Dove, and O. Hoegh-Guldberg. 2008. Ocean acidification causes bleaching and productivity loss in coral reef builders. PNAS 105(45): 17442-17446.

Bak, R.P.M. 1978. Lethal and sublethal effects of dredging on reef corals. Marine Pollution Bulletin 9, 14-16.

Bartley R., Z.T. Bainbridge, S.E. Lewis, F.J. Kroon, S.N. Wilkinson, J.E. Brodie, and D.M. Silburn. 2014. Relating sediment impacts on coral reefs to watershed sources, processes and management: A review. Science of the Total Environment 468-469:1138-1153

Bégin, C., C.K. Schelten, M.M. Nugues, J. Hawkins, C. Roberts, and I.M. Coté. 2016. Effects of protection and sediment stress on coral reefs in Saint Lucia. PLOS 1-16.

Brooks, G.R., B. Devine, R.A. Larson, and B.P. Rood. 2007. Sedimentary development of Coral Bay, St. John, USVI: A shift from natural to anthropogenic influences. Caribbean Journal of Science 43:226-243.

Brown, B.E., Le Tissier, M.D.A., Scoffin, T.P., and A.W. Tudhope. 1990. Evaluation of the environmental impact of dredging on intertidal coral reefs at Ko Phuket, Thailand, using ecological and physiological parameters. Marine Ecology Progress Series 65:273-281.

Browne, N.K., Tay, J., and P.A. Todd. 2015. Recreating pulsed turbidity events to determine coral-sediment thresholds for active management. Journal of Experimental Marine Biology and Ecology 466:98-109.

Edmunds, P.J., and S.C. Gray, 2014. The effects of storms, heavy rain, and sedimentation on the shallow coral reefs of St. John, US Virgin Islands. Hydrobiologia.

Erftemeijer, P.L.A, B. Riegl, B.W. Hoeksema, P.A. Todd. 2012. Environmental 
impacts, of dredging and other sediment disturbances of corals: A review. Marine Pollution Bulletin 64(9):1737-1765.

Fabricius, K.E., C. Wild, E. Wolanski, and D. Abele. 2003. Effects of transparent exopolymer particles and muddy terrigenous sediments on the survival of hard coral recruits. Estuarine, Coastal and Shelf Science 57:613-621.

Fabricius, K.E. 2005. Effects of terrestrial runoff on the ecology of corals and coral reefs: review and synthesis. Marine Pollution Bulletin 50:125-146.

Gardner, T.A., I.M. Côté, J.A. Gill, A. Grant, and A.R. Watkinson. 2003. LongTerm Region-Wide Declines in Caribbean Corals. Science 301:958-960.

Goatley, C.H., and D.R. Bellwood. 2012. Sediment suppresses herbivory across a coral reef depth gradient. Biology Letters 8, 1016-1018.

Gray, S.C., K.L. Gobbi, and P.V. Narwold. 2008. Comparison of Sedimentation in Bays and Reefs Below Developed versus Undeveloped Watersheds on St. John, US Virgin Islands. Proceedings of the $11^{\text {th }}$ International Coral Reef Symposium, $1-5$.

Gray, S.C., W. Sears, M.L. Kolupski, Z.C. Hastings, N.W. Przyuski, M.D. Fox, and A. DeGrood. 2012. Factors affecting land-based sedimentation in coastal bays, US Virgin Islands. Proceedings of the $12^{\text {th }}$ International Coral Reef Symposium, 9-13.

Loya, Y. 2004. The coral reefs of Eilat — past, present and future: three decades of coral community structure studies. In: Rosenberg, E., Loya, Y. (Eds.), Coral Reef Health and Disease. Springer, Berlin, p. 396.

MacDonald, L.H., D.M. Anderson, and W.E. Dietrich. 1997. Paradise threatened: Land use and erosion on St. John, US Virgin Islands. Environmental Management 21:851-863.

McManus, J.W. 1997, Tropical marine fisheries and the future of coral reefs: a brief review with emphasis on Southeast Asia. Coral Reefs 16:121-127.

Ramos-Scharrón, C.E., and L.H. MacDonald, 2007b. Runoff and suspended sediment yields from an unpaved road segment, St John, US Virgin Islands. Hydrological Processes 21:35-50.

Ramos-Scharrón, C.E., S. Atkinson, K. Day, B. Devine, K.R. Munroe, and B. Swanson. 2012. USVI Coastal Habitat Restoration through Watershed Stabilization Project, NOAA-ARRA: 2009-2012 Terrestrial Monitoring Component Final Report. 
Ramos-Scharrón, C.E., and M. LaFevor. 2016. The role of unpaved roads as active source areas of precipitation excess in small watersheds drained by ephemeral streams. Journal of Hydrology 553:168-179

Sears, W. 2015. Factors Affecting Terrigenous Sedimentation in Coastal Bays with Coral Reefs: Implications for Monitoring the Effective of Watershed Restoration. Thesis. University of San Diego.

Yeemin, T., S. Pengsakun, M. Yucharoen, W. Klinthong, K. Sangmanee, M. Sutthacheep. 2013. Long-term changes in coral communities under stress from sediment. Deep Sea Research Part II: Topical Studies in Oceanography 96:32-40. 


\section{Chapter 2: Monitoring sediment dynamics using Nephelometers and Sediment Traps: Challenges and Considerations}

\subsection{Abstract}

In the US Virgin Islands, sediment stress due to poor watershed management practices has been identified as a major cause of the decline in coastal coral reefs. Identifying effective methods to monitor marine sediment dynamics is crucial for researchers and policy makers to make appropriate management decisions regarding the protection of coral reefs. Here we compare two monitoring approaches: time-integrated ( 26-day) sediment trap monitoring, and highresolution (10-min) nephelometer turbidity and deposition monitoring. While previous studies have compared high-resolution sediment monitoring approaches to time-integrated sediment trap monitoring in laboratory flume studies, no studies have done this comparison with field deployed instruments. Between late July 2013 and January 2014, nephelometers were deployed adjacent to sediment traps at three offshore reef sites and five shoreline sites. We found monthly mean sediment trap accumulation rates and nephelometer data were strongly correlated at the majority of sites, and nephelometer turbidity measurements were more strongly correlated with sediment trap accumulation rates than nephelometer deposition measurements. While this indicates sediment traps are effectively recording relative changes in marine sedimentation over longer periods, sediment traps cannot record important short-time scale variability, and cannot separate contributions to sediment trap accumulation from runoff vs. resuspension. 


\subsection{Introduction}

In coastal marine environments throughout the Caribbean, the abundance and condition of corals are declining (Gardner et al., 2003, Alvarev-Filip et al., 2009). Though numerous confounding factors contribute to coral stress and mortality, increased sedimentation due to poor land use practices has been identified as a major cause of the decline in coral reefs. Sediment introduced into the water column through watershed runoff can initially negatively affect corals by decreasing light availability for photosynthetic zooxanthellae (Anthony and Fabricius, 2000; Browne et al., 2015). As suspended sediment settles out of the water column it can smother corals, particularly affecting their early life stages, and reduce the availability of hard benthic substrate needed for coral recruits (Fabricius et al., 2003; Fabricius, 2005; Browne et al., 2015). The same sediment can then undergo repeated cycles of resuspension and deposition, further stressing corals after its initial introduction to the marine environment and settlement on the seafloor. To assess the exposure of corals to sediment related stressors and make appropriate management decisions to protect corals, the measurement of turbidity, suspended sediment concentrations, sediment deposition, and the composition and texture of sediment are necessary.

Due to their low cost and ease of construction, sediment traps have been used for decades in coastal and coral reef environments to provide an estimate of marine sedimentation rates (Rogers, 1983; Bastidas et al., 1999; Almada-Villela et al., 2003; Hill and Wilkinson, 2004; Gray et al., 2008). However, due to variations in trap design and deployment duration, hydrodynamic disturbance 
around the trap mouth in turbulent or laminar flows (Hargrave and Burns, 1979), preferential collection of coarser particles (Baker et al., 1988), variation in trap collection efficiency under varying flow conditions (Baker et al., 1988) coupled with significant variation in hydrodynamic conditions over short temporal and spatial scales, the interpretation of sediment trap data is contentious. Essentially, sediment traps deployed in areas with differing environmental conditions, such as hydrodynamic energy, sediment availability, or sediment texture, may measure different aspects of marine sediment dynamics. For example, data derived from a sediment trap deployed in quiescent area may represent sediment settling out of the water column and accumulating on the seafloor, while data derived from a sediment trap deployed in a highly energetic and erosional environment may represent suspended sediment that was siphoned into the trap. In light of this, sediment traps can be useful for tracking relative changes in marine sediment dynamics if standardized sediment trap design and deployment duration is adopted (Storlazzi et al., 2011).

Sediment traps, along with compositional and textural analysis of trapped sediments, have been commonly used in the USVI to monitor relative spatial and temporal changes in marine sediment dynamics (Nemeth and Nowlis, 2001; Gray et al., 2008; Gray et al., 2012; Edmunds and Gray, 2014; Sears, 2015). In St. John, USVI, development in steep coastal watersheds has been associated with increased watershed erosion, sediment yield (Macdonald et al., 1997; RamosScharrón and Macdonald, 2007b; Ramos-Scharron and McDonald, 2012), and marine terrigenous sedimentation of up to an order of magnitude above 
background levels (Brooks et al., 2007; Gray et al., 2008; Gray et al., 2012). To reduce the transport of land based sediment to the reef, watershed restoration funded by the American Reinvestment and Recovery Act (ARRA) was completed in 2011. However, due to the typically long deployment intervals (weeks to months) of sediment traps, and short duration (minutes to days) of runoff and resuspension processes, it has not been possible to separate primary deposition (particles that undergo deposition for the first time after being introduced to the marine environment) caused by runoff events from secondary deposition (particles that are resuspended from the seafloor and redeposit) caused by resuspension. Even with sediment trap data starting in 2009, the complexity of separating primary and secondary deposition has made it difficult to assess the effectiveness of watershed restoration. Knowing the relative contribution of primary deposition (from runoff) vs. secondary deposition (from resuspension), is necessary to determine if sediment loads were reduced after watershed restoration was completed.

The specific objective of this study was to compare data collected from time-integrated ( monthly-resolution) sediment trap monitoring to data collected from high-resolution (10-min) nephelometer monitoring. This was accomplished by deploying nephelometers adjacent to sediment traps at eight marine shore and reef locations for five months during the fall of 2013. By verifying that sediment traps and nephelometers are recording similar relative changes in marine sedimentation over longer periods (months), this study may help with the interpretation of sediment trap data by providing insight into how runoff and 
resuspension processes impact sediment trap accumulation. This may improve our understanding of the sensitivity of sediment traps to record changes in land-based sediment input to the marine environment.

\subsection{Methods}

\subsubsection{Study Area: St. John, USVI}

St. John is a small $\left(50.8 \mathrm{~km}^{2}\right)$ high relief island surrounded by fringing coral reefs, patch reefs, mangroves, and seagrass beds. The island is part of the U.S. Virgin Islands, and is located $\sim 90 \mathrm{~km}$ east of Puerto Rico. In 1956, the Virgin Islands National Park was established, and now protects over $28 \mathrm{~km}^{2}$ of land on St. John, and additionally more than $30 \mathrm{~km}^{2}$ of coastal waters surrounding the island. With a variety of marine environments including coral reefs, mangroves, and seagrass beds, coupled with developed watersheds adjacent to minimally developed watersheds, St. John provides a unique opportunity to compare data collected from sediment traps and nephelometers in a variety of environments and hydrodynamic conditions.

Coral Bay, located on the eastern end of St. John is $\sim 8 \mathrm{~km}^{2}$ and hosts a diversity of marine habitats, including coral reefs, seagrass beds, mangroves, and salt ponds (Rogers, 2009; Yates et al., 2014). Three watersheds drain into the western side of Coral Bay: the developed Coral Bay watershed $\left(\sim 4.5 \mathrm{~km}^{2}\right)$, the minimally developed Plantation Hill watershed $\left(0.56 \mathrm{~km}^{2}\right)$, and the developed Shipwreck watershed $\left(0.76 \mathrm{~km}^{2}\right)$ (Figure 3.1). Coral Bay Harbor, directly below the developed Coral Bay watersheds, is characterized by fine benthic substrate, seagrass beds, and mangroves along the northern shore. Sanders Bay, directly 
below the minimally developed Plantation Hill watershed, is characterized by relatively fine benthic sediment and abundance of seagrass beds. The marine environment directly below the developed Shipwreck watershed is relatively high energy and the benthic substrate is characterized by course sediment, and seagrass beds.

Great Lameshur and Little Lameshur watersheds are two adjacent minimally developed watersheds located within the Virgin Islands National Park on the south side of St. John, and drain into Great and Little Lameshur Bay, respectively. The two bays are separated by Yawzi Point, a narrow peninsula $\sim 0.5 \mathrm{~km}$ long. The benthic substrate in Little Lameshur Bay is characterized by course sediment and shallow rocky reef, while in Great Lameshur Bay the benthic substrate is relatively finer, and the shoreline is lined with mangroves.

\subsubsection{Data Collection}

Instrument packages including sediment traps (Figure 2.1) and nephelometers (Figure 2.2) were deployed at two shore sites (1.7-1.9m depth) in Lameshur Bays, and two shore sites (1.4-1.6m depth) and one reef site (11m depth) in Coral Bay from late July 2013 through December 2013 (Figure 1, Appendix A). Instrument packages were deployed at three additional sites, but data collected from these sites were not included in the analysis due to instrument fouling or delays between instrument recovery and re-deployment.

Sediment traps constructed from four $20.3 \mathrm{~cm}$ x $5.6 \mathrm{~cm}$ ID (internal diameter) sections of cylindrical PVC piping $(20.3 \mathrm{~cm}$ in height with an internal diameter of $5.6 \mathrm{~cm}$ ) were attached to a post and deployed so that the top of each 
tube was $60 \mathrm{~cm}$ above the seafloor (Figure 2.1). The design and collection interval (24-31 days, except the last two reef site deployments in Coral Bay which were 43 and 11 days, respectively) of sediment traps were consistent with previous studies and ongoing sediment trap monitoring (Kolupski, 2011; Gray et al., 2012; Sears, 2015).

Neph 1000 Series nephelometers, developed by the James Cook University Marine Geophysics Lab, and tested in multiple studies (Ridd and Larcombe, 1994; Ridd et al, 2001; Thomas et al., 2002; Thomas and Ridd, 2005, Whinney et al., 2017) were used for this project. Each nephelometer was deployed using zip ties to attach the instrument to a galvanized steel post, which was secured in a $\sim 22 \mathrm{~kg}$ block of concrete (Figure 2.2). At each site the turbidity sensor was aligned horizontal to the seafloor, while the sediment deposition sensor faced upwards approximately $60 \mathrm{~cm}$ above the seafloor. Battery life specifications theoretically allowed for deployment periods up to 6 months in duration, but actual deployments ranged from 1 to 3 months and were typically limited by the propensity of biofouling at

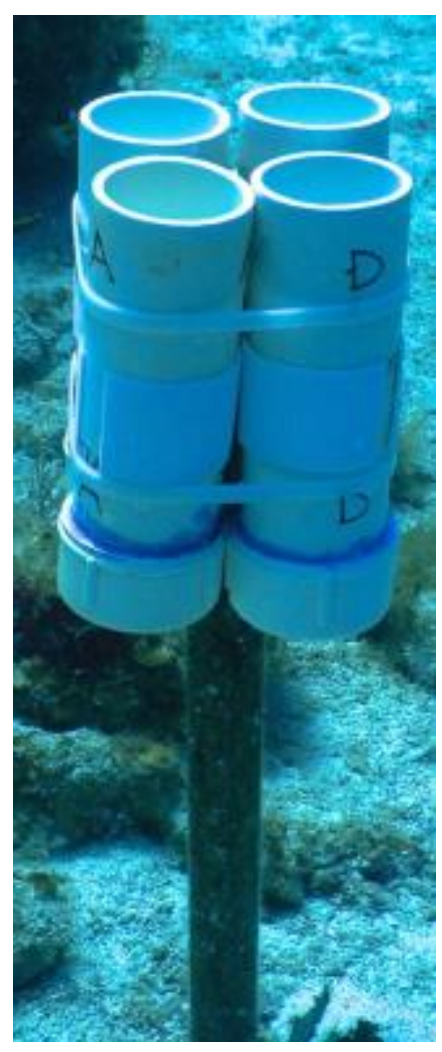

Figure 2.1. Example of a sediment trap

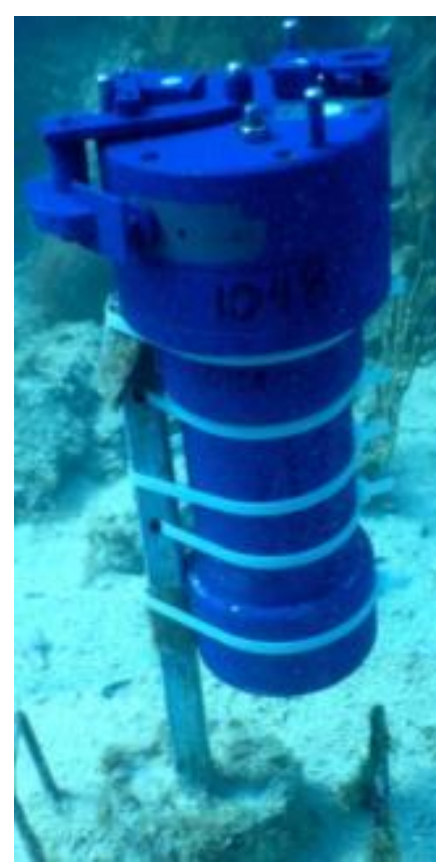

Figure 2.2. Example of a Neph 1000 Series nephelometer 
each sample site. For this study, Neph 1000 s were used to measure turbidity (0$350 \mathrm{NTU} \pm 2 \%)$ and deposition $\left(0-20 \mathrm{mg} \mathrm{cm}^{-2} \pm 5 \%\right)$ every ten minutes, with wipers activating every two hours prevent biofouling (JCU MGL, 2015). The Marine Geophysics Lab at James Cook University used benthic sediment samples from each respective site to calibrate the nephelometers and convert Nephelometric Turbidity Units to suspended sediment concentration (SSC) values in $\mathrm{mg} / \mathrm{L}$, and settled surface sediment density (SSSD) values to deposition values in $\mathrm{mg} / \mathrm{cm}^{2}$ (Thomas et al., 2002; Thomas and Ridd, 2004). While readings were taken every 10 minutes, instrument failure and biofouling (typically just one sensor), along with some delays between instrument recovery and re-deployment produced some gaps in the 5-month data set (Appendix A). Data that were affected by biofouling were not used for these analyses.

\subsubsection{Laboratory Methods}

Sediment samples collected from sediment traps were rinsed with fresh water to remove salt, dried, weighed, and the mass of sediment from each tube trap was divided by the cross-sectional area of the sediment trap mouth $\left(\sim 98 \mathrm{~cm}^{2}\right)$ and the deployment duration (typically $~ 26$ days) to determine the average trap sediment accumulation rate during the deployment in $\mathrm{mg} / \mathrm{cm}^{2} / \mathrm{day}$.

\subsubsection{Analysis of Data}

To compare time-integrated sediment trap accumulation data to highresolution nephelometer data, turbidity and deposition data from each nephelometer were grouped and the data were averaged according to the deployment interval of the corresponding sediment trap, to determine the average 
turbidity in $\mathrm{mg} / \mathrm{L}$ and average deposition in $\mathrm{mg} / \mathrm{cm} 2$ over the course of the sediment trap deployment. To quantify the strength of the relationship between the data collected by the two monitoring approaches, a Pearson $r$ Correlation test was used to compare the average accumulation rate $\left(\mathrm{mg} / \mathrm{cm}^{2} /\right.$ day $)$ from sediment traps with the average turbidity $(\mathrm{mg} / \mathrm{L})$ and deposition $\left(\mathrm{mg} / \mathrm{cm}^{2}\right)$ from nephelometers at each site (Table 2.1). An $\mathrm{r}$ value of 1 would indicate a perfect positive relationship, -1 would indicate a perfect negative correlation, and 0 would indicate no correlation. 


\subsection{Results}

Nephelometer turbidity and deposition data averaged over the course of 26-day sediment trap deployment periods were significantly correlated with sediment trap accumulation rates at the majority of the sites. Compared to the other sites, nephelometer and sediment trap data from the Shipwreck site were most strongly correlated, while nephelometer and sediment trap data from the Coral Bay site was most weakly correlated. Additionally, at all but the Coral Bay site, sediment trap accumulation rates were more strongly correlated with nephelometer turbidity rather than nephelometer deposition. Pearson $r$ values comparing averaged nephelometer turbidity and deposition to sediment trap accumulation ranged from 0.721 to 0.999 . P-values ranged from 0.0001 to 0.14 . (Table 2.1). Deployment intervals, time averaged nephelometer turbidity and deposition values, variance and range of turbidity and deposition values, and sediment trap accumulate rates at each site are presented in Appendix B. 


\begin{tabular}{|c|c|c|c|c|c|c|c|}
\hline \multirow[b]{2}{*}{ Nephelometer } & \multicolumn{6}{|c|}{ Pearson Correlation (R) } & \multirow[b]{2}{*}{ p-values } \\
\hline & $\begin{array}{l}\text { Shipwreck } \\
\text { Trap }\end{array}$ & $\begin{array}{c}\text { Coral Bay } \\
\text { Trap }\end{array}$ & $\begin{array}{c}\text { North Reef } \\
\text { Trap }\end{array}$ & $\begin{array}{l}\text { Little Lam } \\
\text { Trap }\end{array}$ & $\begin{array}{c}\text { Great Lam } \\
\text { Trap }\end{array}$ & Correlation & \\
\hline Shipwreck SSC & 0.999 & & & & & Strong & $<0.001$ \\
\hline Shipwreck Dep. & 0.963 & & & & & Strong & 0.009 \\
\hline Coral Bay SSC & & 0.721 & & & & Moderate & 0.106 \\
\hline Coral Bay Dep. & & 0.812 & & & & Strong & 0.049 \\
\hline North Reef SSC & & & 0.934 & & & Strong & 0.020 \\
\hline North Reef Dep. & & & 0.904 & & & Strong & 0.035 \\
\hline Little Lam. SSC & & & & $0.964 *$ & & Strong & 0.008 \\
\hline Little Lam. Dep. & & & & $0.884 *$ & & Strong & 0.047 \\
\hline Great Lam. SSC & & & & & $0.814^{*}$ & Strong & 0.094 \\
\hline Great Lam. Dep. & & & & & $0.754 *$ & Strong & 0.141 \\
\hline
\end{tabular}

Table 2.1. Pearson $R$ values, and correlation strength resulting from comparison between averaged nephelometer turbidity (SSC) and deposition (Dep.) data, and sediment trap accumulation data (Trap). Yellow highlights indicate significant relationships. *indicates gaps in data set due to delays between instrument deployment and recoveries. 


\subsection{Discussion}

\subsubsection{Interpretation of Sediment Trap Data}

Until now, there has not been a direct comparison of data collected from field deployed time-integrated sediment traps and high-resolution nephelometers monitoring turbidity and deposition. While our study showed that sediment traps and nephelometers record similar relative changes in marine sedimentation and turbidity, there are still considerations regarding the interpretation of sediment trap data. Strong and significant correlations between sediment trap accumulation and nephelometer turbidity and deposition values at the majority of sites indicate that sediment traps are effectively recording relative changes in some measure of sediment dynamics over longer periods (Table 2.1). However, the advantage of the high temporal resolution nephelometers becomes clear when looking at the range and variance of the data set. For example, during the $11 / 6 / 13$ to $12 / 7 / 13$ deployment period, time-averaged nephelometer turbidity and deposition were $5.84 \mathrm{mg} / \mathrm{L}$ and $0.17 \mathrm{mg} / \mathrm{cm}^{2}$, respectively. During this period, the range in turbidity was $553 \mathrm{mg} / \mathrm{L}$ and the variance was 214 , and the range in deposition was $141 \mathrm{mg} / \mathrm{cm}^{2}$ and the variance was 15 (Appendix B). The time-averaged or timeintegrated values of nephelometers and sediment traps cannot capture the highvariability of sediment dynamics that characterizes energetic coral reef environments. If one were to only use time-integrated sediment traps to characterize sediment dynamics in an energetic environment, the high-magnitude short-duration fluctuations in turbidity and deposition would be missed. 
Though sediment traps were conventionally interpreted to measure "gross" sediment deposition (Field et al., 2012), there were stronger correlations between sediment trap accumulation and nephelometer turbidity rather than sediment trap accumulation and nephelometer deposition at four of the five sites included in the analysis. Due to the hydrodynamic disturbance around the trap mouth and the quiescent zone with in the trap walls (Butman et al., 1986; Storlazzi et al., 2011), sediment traps can siphon in suspended sediment, and collect sediment even in net erosional environments (areas where sediment is removed rather from than deposited on the benthic substrate). For this reason, Storlazzi et al. (2011) has suggested that sediment trap accumulation rates may be more appropriately interpreted as a measure of suspended-sediment dynamics rather than sediment deposition. Essentially, sediment traps in energetic coastal environments collect sediment that would not have deposited on the seafloor near the trap. This may explain the stronger correlation between sediment trap accumulation and turbidity, rather than deposition.

While nephelometers and sediment traps record similar relative changes in sediment deposition and turbidity over longer periods, there is an important distinction between the two approaches. Sediment traps collect a sample that can be used for further sedimentological and geochemical analyses. The sediment can be analyzed to determine grain size distributions, which provide insight into the propensity for resuspension at a particular site. The composition of the sediment can be determined via loss on ignition (Heiri et al, 2001), allowing the sediment to be traced to its watershed or marine origins. The residence time of terrigenous 
sediment can be determined using short-lived radioisotopes (Larson et al., 2016), which can help discern the timeframe for terrigenous sediment to be worked out of the system. When combined with nephelometer turbidity and deposition data, and sediment trap accumulation data, these additional sedimentological and geochemical analyses can provide a more comprehensive picture of the system that would otherwise not be possible. 


\subsection{Conclusion}

Nephelometer turbidity and deposition values averaged over $~ 26$-day sediment trap deployment periods were significantly correlated with sediment trap accumulation rates at most sites. This indicates that sediment traps are effectively recording relative changes in sedimentation and turbidity over longer periods, but sediment traps cannot record variability in turbidity or deposition on time scales less than the sediment trap collection period ( 26 days). In addition, contributions to sediment trap accumulation from runoff vs. resuspension cannot be distinguished. This makes it challenging to monitor restoration induced changes in watershed runoff using sediment traps alone. The most promising approach would be one that combines a) high-resolution sediment deposition and turbidity data from nephelometers, b) sediment-trap sediment accumulation rates, c) sediment grain size, and d) the composition (\% terrigenous vs. \%carbonate) and geochemistry (particularly to track residence time) of the sediments. 


\subsection{Work Cited}

Almada-Villela, P.C., P.F. Sale, G. Gold-Bouchot, B. Kjerfve. 2003. Manual of methods for the Mesoamerican barrier reef systems synoptic monitoring program: Selected methods for monitoring physical and biological parameters for use in the Mesoamerican region. Mesoamerican Barrier Reef Systems Project Coordinating Unit, Belize City, Belize.

Alvarez-Filip, L., N.K. Dulvy, J.A. Gill, I.M. Cote, and A.R. Watkinson, 2009. Flattening of Caribbean coral reefs: region-wide declines in architectural complexity. Proceedings of the Royal Society 1822:1-7.

Anthony, K.R.N., and K.E. Fabricius, 2000. Shifting roles of heterotrophy and autotrophy in coral energetic under varying turbidity. Journal of Experimental Marine Biology and Ecology 252:221-253.

Bastidas, C., D. Bone, and E.M. Garcia. 1999. Sedimentation rates and metal content of sediments in a Venezuelan coral reef. Marine Pollution Bulletin 38(1):16-24.

Baker, E.T., H.B. Milburn, and D.A. Tennant. 1988. Field assessment of the sediment trap efficiency under varying flow conditions. Journal of Marine Research 46:573-592.

Brooks, G.R., B. Devine, R.A. Larson, and B.P. Rood. 2007. Sedimentary development of Coral Bay, St. John, USVI: A shift from natural to anthropogenic influences. Caribbean Journal of Science 43:226-243.

Browne, N.K., Tay, J., and P.A. Todd. 2015. Recreating pulsed turbidity events to determine coral-sediment thresholds for active management. Journal of Experimental Marine Biology and Ecology 466:98-109.

Butman, C.A., Grant W.D., and K.D. Stolzenbach. 1986. Prediction of sediment trap biases in turbulent flows: A theoretical analysis based on observations from the literature. Journal of Marine Research 44:601-644.

Edmunds, P.J., and S.C. Gray, 2014. The effects of storms, heavy rain, and sedimentation on the shallow coral reefs of St. John, US Virgin Islands. Hydrobiologia.

Fabricius, K.E., C. Wild, E. Wolanski, and D. Abele. 2003. Effects of transparent exopolymer particles and muddy terrigenous sediments on the survival of hard coral recruits. Estuarine, Coastal and Shelf Science 57:613-621.

Fabricius, K.E. 2005. Effects of terrestrial runoff on the ecology of corals and coral reefs: review and synthesis. Marine Pollution Bulletin 50:125-146.

Gardner, T.A., I.M. Côté, J.A. Gill, A. Grant, and A.R. Watkinson. 2003. Long- 
Term Region-Wide Declines in Caribbean Corals. Science 301:958-960.

Gray, S.C., C. Ramos-Scharrón, W. Sears, G. Brooks, R. Larson, M. LaFevor, and J. Roy. 2016. Ridge to reef integrated terrestrial-marine monitoring to assess the impact of watershed restoration on coral reef sedimentation in St. John, US Virgin Islands. $13^{\text {th }}$ International Coral Reef Symposium; 19-24 June 2016; Honolulu, Hawaii.

Gray, S.C., K.L. Gobbi, and P.V. Narwold. 2008. Comparison of Sedimentation in Bays and Reefs Below Developed versus Undeveloped Watersheds on St. John, US Virgin Islands. Proceedings of the $11^{\text {th }}$ International Coral Reef Symposium, $1-5$.

Gray, S.C., W. Sears, M.L. Kolupski, Z.C. Hastings, N.W. Przyuski, M.D. Fox, and A. DeGrood. 2012. Factors affecting land-based sedimentation in coastal bays, US Virgin Islands. Proceedings of the $12^{\text {th }}$ International Coral Reef Symposium, 9-13.

Hargrave, B.T., and N.M. Burns. 1979. Assessment of sediment trap collection efficiency. Limnology and Oceanography 24 (6), 1124- 1136.

Heiri, O., A. F. Lotter, and G. Lemcke. 2001. Loss on ignition as a method for estimating organic and carbonate content in sediments: reproducibility and comparability of results. Journal of Paleolimnology 25:101-110.

Hill, J., and C. Wilkinson. 2004. Methods for ecological monitoring of coral reefs, Version 1. Australian Institute of Marine Science.

James Cook University (JCU). Marine Geophysics Laboratory (MGL). Instruments. 2015. https://www.jcu.edu.au/marine-geophysicslaboratory/instruments

Kolupski, M.L. 2011. Sedimentation in coastal bays with coral reefs: Impacts of watershed development, St. John, USVI. Thesis. University of San Diego.

Larson, R.A., G. Brooks, S.C. Gray, C.E. Ramos-Scharron, S.E. Campbell, and N. Clark. 2016. 7Be as an Indicator of Terrigenous Sediment Input to Coastal Environments: St. John, US Virgin Islands, Presented at the 2016 Ocean Sciences Meeting, American Geophysical Union, New Orleans, LA 21-26 Feb.

MacDonald, L.H., D.M. Anderson, and W.E. Dietrich. 1997. Paradise threatened: Land use and erosion on St. John, US Virgin Islands. Environmental Management 21:851-863.

Nemeth, R.S. and J.S. Nowlis. 2001. Monitoring the effects of land development on the near-shore reef environment of St. Thomas, USVI. Bulletin of Marine Science 69(2): 759-775. 
Ramos-Scharrón, C.E., and L.H. MacDonald, 2007a. Measurement and prediction of natural and anthropogenic sediment sources, St. John, U.S. Virgin Islands. Catena 71:250-266.

Ramos-Scharrón, C.E., S. Atkinson, K. Day, B. Devine, K.R. Munroe, and B. Swanson. 2012. USVI Coastal Habitat Restoration through Watershed Stabilization Project, NOAA-ARRA: 2009-2012 Terrestrial Monitoring Component Final Report.

Ridd, P., G. Day, S. Thomas, J. Harradence, D. Fox, J. Bunt, O. Renagi, and C. Jago. 2001. Measurement of sediment deposition rates using an optical backscatter sensor. Estuarine, Coastal and Shelf Science 52:155-163.

Ridd, P., and P. Larcombe. 1994. Biofouling control for optical backscatter suspended sediment sensors. Marine Geology 116:225-258.

Rogers, C.S. 2009. High diversity and abundance of scleractinian corals growing on and near mangrove prop roots, St. John, US Virgin Islands. Coral Reefs 28:909.

Rogers, C.S. 1983. Sublethal and lethal effects of sediments applied to common Caribbean Reef corals in the field. Marine Pollution Bulletin 14:378-382.

Sears, W. 2015. Factors Affecting Terrigenous Sedimentation in Coastal Bays with Coral Reefs: Implications for Monitoring the Effective of Watershed Restoration. Thesis. University of San Diego.

Storlazzi, C.D., M.E. Field, and M.H. Bothner. 2011. The use (and misuse) of sediment traps in coral reef environments: theory, observations, and suggested protocols. Coral Reefs 30:23-38.

Thomas, S., and P.V. Ridd. 2005. Field assessment of innovative sensor for monitoring of sediment accumulation on inshore coral reefs. Marine Pollution Bulleting 51:470-480.

Thomas, S., and P.V. Ridd. 2004. Review of methods to measure short time scale sediment accumulation. Marine Geology 207:95-114.

Thomas, S., Ridd, P.V., and P.J. Smith. 2002. New instrumentation for sediment dynamics studies. Marine Technology Society 36(1):55-58.

Whinney, J., Jones, R., Duckworth, A., and P. Ridd. 2017. Continuous in situ monitoring of sediment deposition in shallow benthic environments. Coral Reefs $1-13 \mathrm{pp}$ 
Yates, K.K., C.S. Rogers, J.J. Herlan, G.R. Brooks, N.A. Smiley, and R.A.

Larson, 2014. Diverse coral communities in mangrove habitats suggest a novel refuge from climate change. Biogeosciences 11:4321-4377. 
Manuscript to be submitted to Estuarine, Coastal and Shelf Science

\section{Chapter 3: Watershed Runoff and Sediment Resuspension: Factors Affecting Turbidity and Sedimentation in Bays with Coral Reefs, St. John, USVI}

Authors: Stephen E. Campbell ${ }^{1}$, Sarah C. Gray ${ }^{1}$, James Whinney ${ }^{2}$, Carlos RamosScharrón ${ }^{3}$, Heidi Hirsh ${ }^{4}$, Sean Campbell ${ }^{2}$

${ }^{1}$ Univ. of San Diego Dept. of Environmental and Ocean Sciences, ${ }^{2}$ James Cook Univ. Marine Geophysics Laboratory, ${ }^{3}$ Univ. of Texas at Austin, Dept. of Geography and the Environment, ${ }^{4}$ Stanford Univ. Dept. of Earth System Science

stephencampbell@sandiego.edu, sgray@sandiego.edu, james.whinney@jcu.edu.au, cramos@austin.utexas.edu, hkhirsh@stanford.edu, sean.campbell@jcu.edu.au

\subsection{Abstract}

In the US Virgin Islands (USVI), land-based (terrigenous) sedimentation has been identified as a major cause of coral stress. Development, such as the building of unpaved roads in steep coastal watersheds, has increased sediment yields and marine terrigenous sedimentation by up to an order of magnitude above background levels. When activated during storm events, ephemeral streams transport sediment from the watershed to coastal waters. Once deposited on the seafloor, resuspension of benthic sediments can further increase turbidity and deposition. However, isolating the relative contributions of runoff and resuspension to turbidity and deposition using conventional sediment trap monitoring has been challenging. Here we describe the spatial and temporal variability of marine sediment dynamics in response to runoff and resuspension events in St. John, USVI. Between late July 2013 and January 2014, nephelometers were deployed at three reef and five shoreline sites next to 
ephemeral stream outfalls equipped with a water level sensor (10-min resolution) and peak crest gauges ( 13-day resolution). At each instrument site, benthic sediment samples were collected every $\sim 26$ days. While runoff events resulted in high-magnitude spikes in turbidity and deposition, which were up to 900 and 17,000 times background, respectively, they were short-lived (hours).

Resuspension-induced spikes in turbidity and deposition were lower in magnitude but of longer duration (days-weeks), particularly at sites with finer-grained benthic sediments, and were associated with increased wave height during low tides. While the relative contribution of runoff and resuspension to turbidity and deposition were spatially variable between our study sites, resuspension contributed at least 7 times more to turbidity and 3 times more to deposition than runoff during the 2013 rainy season at one of our coastal marine monitoring sites. Though previous studies have measured marine sedimentation over monthscenturies in St. John, no studies have monitored turbidity or the relative contributions to turbidity and deposition from runoff and resuspension at the time scale of minutes-days. Understanding the relative contribution of runoff vs. resuspension to marine turbidity and deposition is important to effectively manage land-based sedimentation, marine development, as well as evaluate the effectiveness of watershed restoration programs which aim to reduce marine terrigenous sedimentation. 


\subsection{Introduction:}

In recent decades, there has been a decline in coral condition and abundance (Gardner et al., 2003; Alvarev-Filip et al., 2009). Coral reef degradation can originate from a multitude of direct and indirect anthropogenic activity, including overfishing (McManus, 1997), dredging and trawling (Bak, 1978; Brown et al., 1990; McManus, 1997), ocean acidification (Anthony et al., 2008), ocean warming (Anthony et al., 2011), and watershed runoff (Fabricius, 2005, Prouty et al., 2014). Watershed runoff affects coral condition in four distinct ways: 1) elevated concentration of dissolved inorganic nutrients increase the abundance of macroalgae which can overgrow corals (Loya, 2004); 2) increased concentrations of particulate organic matter provide a competitive advantage to heterotrophic filter feeders over corals (Fabricius, 2005); 3) increased turbidity reduce light availability for photosynthetic zooxanthellae (Anthony and Fabricius, 2000; Browne et al., 2015); and 4) increased sedimentation can smother corals, particularly affecting growth and recruitment in early life stages, reduce the availability of hard benthic substrate (Fabricius et al., 2003; Fabricius, 2005; Browne et al., 2015), and reduce reef fish herbivory (Goatley and Bellwood, 2012). In the U.S. Virgin Islands (USVI), the acceleration of anthropogenic activity in coastal watersheds since the 1950 s, such as the building of unpaved roads, deforestation, and development on steep slopes has increased watershed erosion, sediment yield (e.g., Macdonald et al., 1997; RamosScharrón and Macdonald, 2007b; Ramos-Scharron et al., 2012), and marine terrigenous sedimentation by up to an order of magnitude above background 
levels below developed watersheds (Brooks et al., 2007; Gray et al., 2008; Gray et al., 2012).

Depending on the size of a watershed, sediment availability in the watershed, and the duration and intensity of rainfall, runoff-induced sediment plumes can cause temporary (hours-weeks) increases in marine turbidity and deposition (Fabricius et al., 2013; Fabricius et al., 2014). Once runoff has transported sediment into the marine environment, the sediment will deposit on the seafloor if there is not sufficient hydrodynamic energy to keep it in suspension. Recently deposited terrigenous sediment can then undergo repeated cycles of resuspension and deposition under the influence of waves, tides, and currents. In areas where resuspension is sediment-limited, watershed runoff and the resulting sediment plume will not only elevate turbidity during runoff events, but also during resuspension events after the dissipation of the sediment plume. In areas where resuspension is not sediment-limited, but rather limited by hydrodynamic energy, increased sediment supply from watershed runoff will not result in greater turbidity from resuspension (Larcombe and Woolfe, 1999a). In St. John, the prevalence of runoff events and resuspension events, and their relative contributions to turbidity and deposition are unknown.

St. John, USVI is an ideal location to study the effects of watershed runoff and resuspension, and the effects of watershed development and restoration, on marine turbidity and deposition. In many coastal marine environments, it is difficult to separate turbidity and deposition caused by resuspension from turbidity and deposition caused by runoff. This is because perennial streams and 
rivers continuously deposit terrigenous sediment into the marine environment. On St. John, however, there are no perennial streams. Watershed runoff and fluvial transport of sediment from the watersheds to the bays only occurs with the activation of ephemeral stream channels during storm events. During periods with runoff, contributions to turbidity and deposition result from both runoff and resuspension. However, during most of the year when ephemeral streams are not flowing, the only source of turbidity and deposition is resuspension of benthic sediments due to hydrodynamic energy generated by waves, currents, tides, or anthropogenic activity. The presence of protected watersheds within the Virgin Islands National Park adjacent to developed watersheds outside of the park boundaries allow for a direct comparison of marine sediment dynamics between sites located below developed watersheds and those located below minimally developed watersheds. To reduce terrigenous sediment yields and transport to the marine environment, watershed restoration funded by the American Reinvestment and Recovery Act (ARRA) was completed in 2011 in the Coral Bay and Shipwreck watersheds (Figure 3.1). Watershed modeling suggests restoration was highly effective at reducing sediment yields (Gray et al., 2016).

Sediment traps, along with compositional and textural analysis of trapped sediments, have been commonly used in the USVI to monitor spatial and temporal changes in marine sedimentation (Nemeth and Nowlis, 2001; Gray et al., 2008; Gray et al., 2012; Sears, 2015, Edmunds and Gray, 2014). However, from sediment trap data alone, it is challenging to separate primary (particles that undergo deposition for the first time after being introduced to the marine 
environment) and secondary deposition (particles that are resuspended from the seafloor, and redeposit) (Thomas and Ridd, 2005; Storlazzi et al., 2011).

Previous work in St. John, USVI, found terrigenous sediment accumulation rates in traps to be up to 60 times greater at marine sites below developed watersheds compared to minimally developed watersheds (Gray et al., 2012). However, there have been no studies in St. John investigating the effects of watershed development on marine turbidity. Due to the relatively long ( 26-day) deployment interval of the sediment traps compared to the short duration (minutes to days) of runoff and resuspension processes, the relative contribution of runoff vs. resuspension to turbidity and deposition is unknown. The interaction between watershed runoff and hydrodynamic processes that induce resuspension have not been examined in coral reef systems surrounding St. John. Additionally, highresolution monitoring has not been used to explore the spatial and temporal variability of turbidity and deposition in relation to watershed restoration, development, and runoff. To effectively monitor the impact of watershed and marine development on marine sediment dynamics and evaluate effectiveness of watershed restoration in reducing sediment transport to the marine environment, it is first necessary to understand the processes that affect coastal marine sediment dynamics in St. John, and determine the relative contribution to turbidity and deposition from runoff and resuspension.

This is the first study to use a high-resolution (10-min) monitoring to directly compare turbidity and deposition data collected below developed and minimally developed watersheds, and to isolate resuspension induced turbidity and 
deposition from runoff-resuspension induced turbidity and deposition. The specific objectives of this integrated terrestrial-marine monitoring study were to answer the following questions:

1) What is the general spatial variability of turbidity and deposition in relation to watershed development?

2) How does runoff and resuspension affect marine sediment dynamics (turbidity and deposition), and how are the process connected from the shore to reef?

3) What is the relative contribution to turbidity and deposition from runoff vs. resuspension?

4) What factors affect resuspension?

The results of this study will help to better understand the complex watershed-marine interaction in St. John. To evaluate the effectiveness of ARRA watershed restoration, it is necessary to determine the proportion of turbidity and deposition due to runoff compared to resuspension. While current management policies addressing terrigenous sedimentation in bays with coral reefs in St. John are focused on reducing sediment laden runoff during storm events, the findings of this study may influence management decisions by revealing the role of resuspension in reducing water quality. 


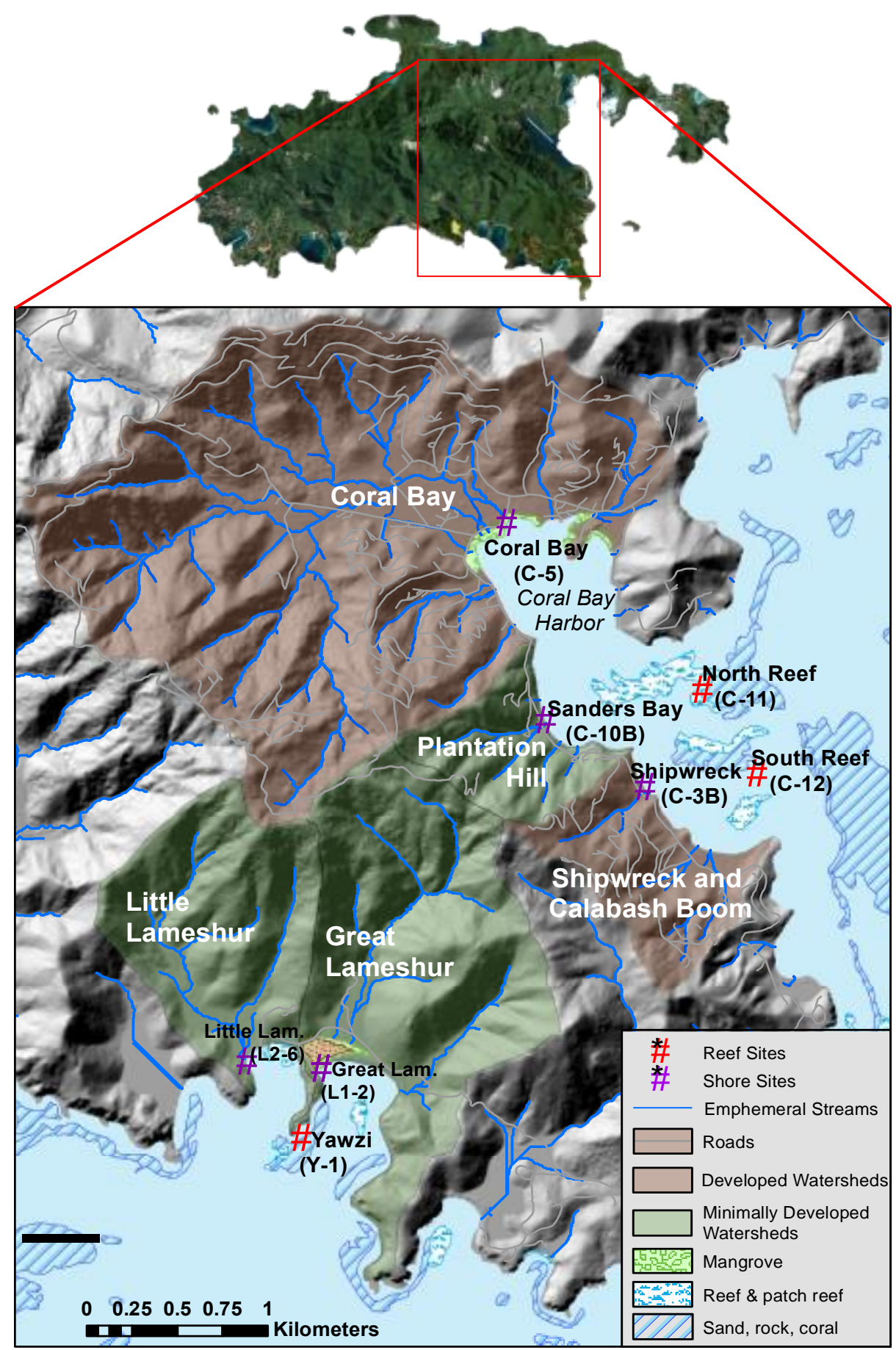

Figure 3.1. The island of St. John (top) and the study area (bottom) showing developed (brown shading) and minimally developed (green shading) watersheds, and marine sampling sites where sediment traps and nephelometers were deployed (triangles). Crest gauges were deployed at the shoreline outfalls of ephemeral streams and a stream gauge was deployed near an ephemeral stream outfall adjacent to the Shipwreck marine sampling site. Each site was assigned an alpha numeric identification code (e.g. Shipwreck=C-3B) which may be used to refer to the sites in subsequent text, figures or analyses. 


\subsection{Methods:}

\subsubsection{Study Area: St John, USVI}

St. John is a small $\left(50.8 \mathrm{~km}^{2}\right)$ high-relief island (slopes exceeding $\sim 17^{\circ}$ cover $80 \%$ of the island, with the highest peak reaching $377 \mathrm{~m}$ ) located $\sim 90 \mathrm{~km}$ east of Puerto Rico (CH2M Hill Inc., 1979). Typically, St. John receives between 89-140 cm of rain per year, with much of the precipitation concentrated between May and November when the trade winds are blowing from the southeast. During the drier winter months, the trade winds are strongest and blow from the east (Towle et al., 1976; Woodbury and Weaver, 1987).

With a small population of only 4,170 (2010 census), a subtropical climate, natural beauty, and a lack of natural resources to support manufacturing or industry, the economy of St. John is largely dependent on tourism (Sirius Marina Market Study and Financial Projections, 2013). The waters surrounding St. John host diverse marine life which attract tourists for snorkeling and diving, and both sustenance and commercial fishing. These marine resources have been extensively studied (Randall, 1963; Edmunds, 2002; Rogers and Miller, 2006). In 1956, the Virgin Islands National Park was established and now protects over 28 $\mathrm{km}^{2}$ of land on the island of St. John, and an additional $30 \mathrm{~km}^{2}$ plus of coastal waters surrounding the island. In addition to the national park, community organizations such as the Coral Bay Community Council have fought to protect the islands natural resources outside of the park boundaries.

Coral Bay, located on the eastern end of St. John, is $\sim 8 \mathrm{~km}^{2}$ and hosts a diversity of unique marine habitats, including coral reefs, seagrass beds, 
mangroves, and salt ponds (Rogers, 2009; Yates et al., 2014). Three watersheds drain into the western side of Coral Bay: Coral Bay watershed $\left(\sim 4.5 \mathrm{~km}^{2}\right)$, Plantation Hill watershed $\left(0.56 \mathrm{~km}^{2}\right)$, and Shipwreck watershed $\left(0.76 \mathrm{~km}^{2}\right)$. The Coral Bay watershed is a developed watershed with steep slopes surrounding a central valley (average slope: $10.2^{\circ}$ ) (Table 3.1). Within the watershed there are $11.5 \mathrm{~km}$ of unpaved roads. The ephemeral streams within the watershed drain into Coral Bay Harbor. Coral Bay Harbor is a subsection of Coral Bay, located at the northwestern-most end of Coral Bay, and is characterized by fine benthic substrate, seagrass beds, and mangroves along the northern shore (Figure 3.1). The Plantation Hill watershed is adjacent to Coral Bay and borders the southwestern boundary of the Coral Bay watershed (Figure 3.1). Plantation Hill watershed is relatively small and steep, and has undergone minimal development, with only $0.64 \mathrm{~km}$ of unpaved roads. Sanders Bay, a smaller bay within the larger Coral Bay, receives drainage from the Plantation Hill watershed, and is characterized by relatively fine benthic sediment, but an abundance of seagrass beds.

The Shipwreck watershed is a steep developed watershed that borders the southeastern boundary of the Plantation Hill watershed (Table 3.1). While of similar area to the Plantation Hill watershed, the Shipwreck watershed contains three times the length of unpaved roads. The coastal waters in Coral Bay that receive drainage from the Shipwreck watershed are characterized by relatively course benthic sediment and seagrass beds. 
Great Lameshur and Little Lameshur watersheds are two adjacent minimally developed watersheds located within the National Park on the south side of St. John, and drain into Great and Little Lameshur Bay, respectively. The two bays are separated by Yawzi Point, a narrow peninsula $\sim 0.5 \mathrm{~km}$ long. Within these two minimally developed watersheds there are only $1.42 \mathrm{~km}$ of unpaved roads. Although within the National Park, there is some development in the watersheds. An unpaved road (steep sections paved) provides beach access to both Little and Greater Lameshur bays, the Virgin Islands Environmental Resource Station (VIERS), and the Park Rangers residence. The ephemeral streams in Great Lameshur watershed pass through mangroves and mudflats prior to entering Great Lameshur Bay. The ephemeral stream in Little Lameshur watershed flows through mangroves and is then intersected by a beach berm before entering Little Lameshur Bay.

Based on the size and slope of these watersheds, the developed Coral Bay watershed is comparable to the minimally developed Lameshur watersheds, and the developed Shipwreck watershed is most comparable to the minimally developed Plantation Hill watersheds (Table 3.1). Essentially, these pairs of watersheds are geographically similar, but differ in the degree of development. 


\begin{tabular}{l|cc|ccc}
\multicolumn{1}{c}{ Lameshur Bay } & \multicolumn{3}{c}{ Coral Bay } \\
\hline \multicolumn{1}{c|}{ Watershed } & $\begin{array}{c}\text { Great } \\
\text { Lameshur }\end{array}$ & $\begin{array}{c}\text { Little } \\
\text { Lameshur }\end{array}$ & $\begin{array}{c}\text { Plantation } \\
\text { Hill }\end{array}$ & Shipwreck & $\begin{array}{c}\text { Coral } \\
\text { Bay }\end{array}$ \\
\hline $\begin{array}{l}\text { Development } \\
\text { Drainage Area } \\
\left(\mathrm{km}^{2}\right)\end{array}$ & Minimal & Minimal & Minimal & High & High \\
$\begin{array}{l}\text { Mean Slope** } \\
\text { Unpaved Road } \\
\text { length }(\mathrm{km})^{*}\end{array}$ & $11.3^{\circ}$ & $12.4^{\circ}$ & $23.6^{\circ}$ & $20.8^{\circ}$ & $10.2^{\circ}$ \\
Unpaved Road & 2.5 & 0.72 & 0.64 & 2.6 & 11.5 \\
Density $\left(\mathrm{km} / \mathrm{km}^{2}\right)^{*}$ & 1.04 & 0.38 & 1.14 & 3.42 & 2.56
\end{tabular}

Table 3.1. Physical characteristics of watersheds studied for this project (*Ramos-Scharrón unpublished, **Hubbard et al. 1987) (Table modified from Sears, 2015). 


\subsubsection{Data collection}

Marine monitoring was conducted using Neph 1000 series nephelometers at two shore sites (1.7-1.9 m depth) and one reef site (6.1 m depth) in Lameshur Bays, and three shore sites (1.4-1.6 m depth) and two reef sites (5.5-9.1 m depth) in Coral Bay from late July 2013 through December 2013 (Figure 3.1, Appendix A). These nephelometers were developed by the James Cook University Marine Geophysics Lab, and tested in multiple studies (Ridd and Larcombe, 1994; Ridd et al, 2001; Thomas et al., 2002; Thomas and Ridd, 2005). Each nephelometer was deployed using zip ties to attach the instrument to a galvanized steel fence post, which was secured in a $\sim 22 \mathrm{~kg}$ block of concrete (Figure 2.2). At each site the optical backscatter (OBS) turbidity sensor on the nephelometer was aligned horizontal to the seafloor, and the upward facing OBS sediment deposition sensor faced upwards approximately $60 \mathrm{~cm}$ above the seafloor. While battery life specifications allowed for deployment periods up to 6 months, actual deployment periods ranged from 1 to 3 months and were typically limited by biofouling. The Neph 1000's measured turbidity (0-350 NTU $\pm 2 \%)$, deposition $\left(0-20 \mathrm{mg} \mathrm{cm}^{-2}\right.$ $\pm 5 \%)$, and pressure (0-5 \pm 0.0005 atm., used to measure tidal fluctuations and as a proxy for wave energy) for 10 seconds every ten minutes, with wipers activating every 2 hours to prevent biofouling (JCU MGL, 2015). The Marine Geophysics Lab at James Cook University used benthic sediment samples from each respective site to calibrate the nephelometers and convert NTU values into suspended sediment concentration (SSC) values, and convert settled surface sediment density (SSSD) values to deposition values in $\mathrm{mg} / \mathrm{cm}^{2}$ (Thomas et al., 
2002; Thomas and Ridd, 2004). While readings were taken every 10 minutes, instrument failure and biofouling (typically just one sensor), along with some delays between instrument recovery and re-deployment produced some gaps in the 5-month data set (Appendix A). Data processing protocols were employed to identify, correct, or discard the data affected by biofouling. Data that were affected by biofouling were not used for these analyses.

Benthic sediment samples $(\sim 25 \mathrm{~mL})$ were collected from the upper $2 \mathrm{~cm}$ of the benthic substrate at each marine monitoring site approximately every 26 days.

Watershed runoff data were collected using peak crest gauges and a stream gauge. Peak crest gauges, which were deployed in ephemeral stream beds adjacent to the three shore sites in Coral Bay and the one shore site Little Lameshur Bay (Figure 3.1), provided data on the approximate maximum stage (maximum depth of flow) runoff events at relatively low temporal resolution (every 13 days or after each rain event exceeding $2 \mathrm{~cm}$ ). The stream gauge, located near an ephemeral stream outfall adjacent to the Shipwreck marine sampling site (C-3B) (Figure 3.1, Appendix A), collected high-resolution (10minute) stream-level data.

\subsubsection{Laboratory Methods}

A Beckman Coulter LS200 was used to determine grain size distributions, and loss on ignition (Heiri et al., 2001) was used to determine \%terrigenous and \%carbonate of benthic sediment samples from every deployment at each sample site (Figure 3.1, Appendix A). 


\subsubsection{Analysis of Data}

To compare the spatial variability of turbidity and deposition between sites below developed and minimally developed watersheds and between shore and reef sites, nephelometer turbidity and deposition data during "matching periods"1 were used to create box-and-whisker plots.

Runoff and resuspension periods during the 2013 sampling season were identified based on the peak crest gauge ( 13-day resolution or less) data from each respective site. These periods will be referred to as "crest gauge runoff periods" and "crest gauge resuspension periods". However, "crest gauge runoff periods" do include contributions to turbidity and deposition from resuspension in addition to runoff. Because the timing of runoff and resuspension periods varied between sites, to make inter-site comparisons it was necessary to identify time periods when all sites were determined to have runoff, and other time periods when all sites were determined to have no runoff (resuspension periods). Per the crest gauge data, $11 / 2 / 13-11 / 26 / 13$ was the only time during which runoff periods occurred simultaneously at all shore sites, and 10/12/13 - 10/23/13 was the only time during which resuspension periods occurred simultaneously at all shore sites for the 2013 sampling season (Appendix A, stippled).

In order to compare turbidity to benthic sediment grain size, nephelometer turbidity data from each site were averaged to determine the mean turbidity during the time series for each respective site. The percent benthic sediment less

\footnotetext{
${ }^{1}$ periods of time when data were available at all samples sites (due to limited deployment lengths, data from Greater Lameshur (L1-2) and Yawzi (Y-1) were not included in the analysis). Matching periods include 8/4/13 - 8/31/13, 9/15/13 $-11 / 6 / 13,11 / 11 / 13-12 / 1 / 13$, and 12/7/13 - 12/11/13.
} 
than $63 \mu \mathrm{m}$ from the five collections at each site were averaged together to compare the mean percent benthic sediment less $63 \mu \mathrm{m}$ from each site with mean turbidity.

The 10-minute resolution runoff stage data from the stream gauge deployed at Shipwreck ephemeral stream (Figure 3.1) was used to bin nephelometer turbidity and root mean square (RMS) water height (a proxy for wave energy) data from the Shipwreck marine sampling site (C-3B) into runoff and resuspension periods. These periods will be referred to as "stream gauge runoff periods" and "stream gauge resuspension periods". This analysis differs from the crest gauge runoff and resuspension periods discussed in the paragraph above, as those periods were binned based on the 13-day resolution crest gauges, not the 10-minute resolution stream-gauge. "Stream gauge runoff periods" start at the first runoff signal from the stream gauge, and end three hours following the last stream gauge runoff signal. Stream gauge resuspension periods always separated the stream gauge runoff periods. The inclusion of a three-hour window after runoff stopped was needed to account for the lingering effect runoff has on turbidity and deposition, as sediment introduced during a runoff event is not immediately advected away from the site nor does it immediately deposit on the seafloor at the conclusion of the runoff event. To investigate how RMS water height (proxy for wave energy) may affect minimum turbidity measurements, RMS water height values, and their corresponding turbidity values, were binned into $0.01 \mathrm{~m}$ increments (e.g. $0-<0.01 \mathrm{~m}, 0.01-<0.02 \mathrm{~m}, 0.02-<0.03 \mathrm{~m}$, etc.). For each $0.01 \mathrm{~m}$ bin, the $5^{\text {th }}$ percentile of turbidity data (proxy for minimum turbidity) 
was calculated. Bins with less than 25 data points were excluded from the minimum turbidity analysis.

To make an estimate of the relative contribution to turbidity and deposition from runoff vs. resuspension during the time series, nephelometer turbidity and deposition were binned into stream gauge runoff and resuspension periods using the same protocol as the RMS water height analysis above. Turbidity and deposition measured during the stream gauge resuspension periods were summed and compared to turbidity and deposition measurements during stream gauge runoff periods. 


\subsection{Results}

\subsubsection{General spatial variability in turbidity and deposition.}

Turbidity and deposition were highly variable in St. John. Across all sites during the time series, turbidity ranged from $0 \mathrm{mg} / \mathrm{L}$ to $\sim 550 \mathrm{mg} / \mathrm{L}$, and deposition ranged from $0 \mathrm{mg} / \mathrm{cm}^{2}$ to $140 \mathrm{mg} / \mathrm{cm}^{2}$. While median turbidity and deposition were greatest below the developed Coral Bay watershed $(6.4 \mathrm{mg} / \mathrm{L}$ and $0.05 \mathrm{mg} / \mathrm{cm}^{2}$, respectively), the greatest max turbidity and deposition measurements were recorded below the developed Shipwreck watershed (553 $\mathrm{mg} / \mathrm{L}$ and $141 \mathrm{mg} / \mathrm{cm}^{2}$, respectively) (Figure 3.2A, 3.2B). Among reef sites (North Reef and South Reef), median turbidity and deposition were 2.9 and 6 times greater, respectively, at North Reef compared to South Reef (1.2 mg/L vs. $0.4 \mathrm{mg} / \mathrm{L}$, and $0.012 \mathrm{mg} / \mathrm{cm}^{2}$ vs. $0.002 \mathrm{mg} / \mathrm{cm}^{2}$, respectively). However, maximum turbidity was 1.3 times greater at South Reef than at North Reef (Figure 3.2A, 3.2B). Turbidity and deposition were compared between pairs of sites below geographically similar (area, slope) developed and minimally developed watersheds (Table 3.1, Table 3.2). Median and max turbidity and deposition were greater below both developed watersheds, compared to the respective minimally developed watersheds (Table 3.2).

When data were available at Yawzi reef in Lameshur Bay (August through October), turbidity and deposition were on average 3 and 2 times greater, respectively, at the reef sites below the developed watersheds in Coral Bay (North Reef and South Reef) compared to the minimally developed reef site in Lameshur Bay (Yawzi). 

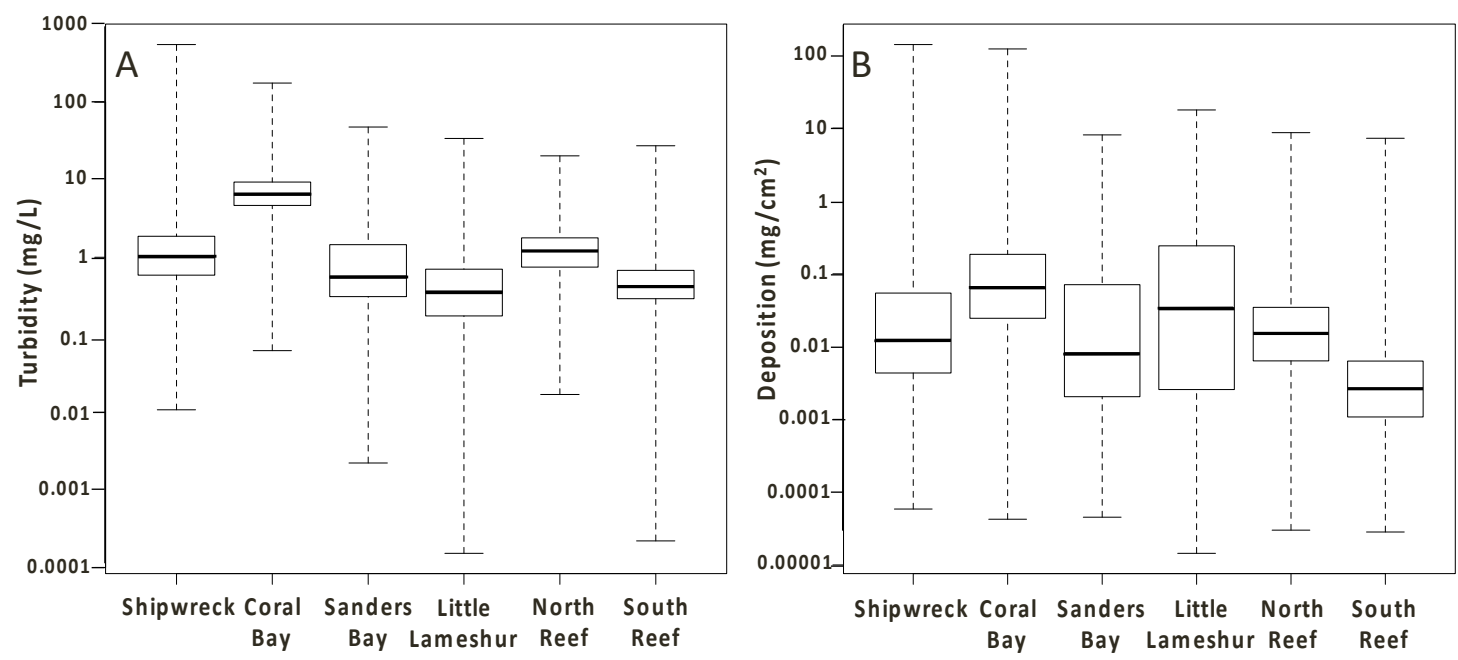

Figure 3.2. Range of turbidity (A. left) and deposition (B. right) at developed (brown) and minimally developed (green) shore and reef sites. Boxes indicate $25^{\text {th }}$ and $75^{\text {th }}$ percentiles, whiskers indicate minimum and maximum values, bold lines indicate median values. 
SHIPWRECK /

SANDERS BAY
CORAL BAY / LAMESHUR BAY

\begin{tabular}{l|cc|cc}
\hline & Turbidity & Deposition & Turbidity & Deposition \\
MEDIAN & 2 & 2 & 18 & 3 \\
MAX & 12 & 17 & 5 & 7
\end{tabular}

Table 3.2. Ratio of median and max turbidity and deposition below pairs of comparable developed (brown) and minimally developed (green) watersheds. The large developed Coral Bay watershed was paired with the large minimally developed Lameshur watershed, and the small developed Shipwreck watershed was paired with the small minimally developed Sanders Bay watershed. 


\subsubsection{Runoff induced sedimentation}

\subsubsection{Rainfall and runoff at the Shipwreck ephemeral stream}

Watershed runoff on St. John is characterized by ephemeral flow typically lasting only a few hours. For example, 21 separate runoff pulses spanned $6.5 \%$ of the 102 days (9/21/13-12/31/13) of high-resolution (10-min) watershed runoff monitoring. Runoff coincided with as little as $2.8 \mathrm{~mm}$ of rainfall and runoff lasted for as short as 20 minutes (Appendix C). However, some runoff events were not sufficient to produce a turbidity or deposition response in the marine environment. The minimum runoff stage threshold observed to produce a marine turbidity response was $0.2 \mathrm{~m}$, which was exceeded during 12 separate runoff pulses totaling $1.2 \%$ of the 102 days of runoff monitoring. These short (hours) periods of runoff were separated by periods with no runoff of up to 14 days in duration (Appendix C).

\subsubsection{Sedimentary response to runoff}

To characterize the spatial and temporal variability of marine turbidity and deposition in response to the highest magnitude runoff events, 10-minute resolution runoff stage data from the stream gauge are presented with nephelometer turbidity and deposition data during the three greatest runoff event of the monitoring period (Figure 3.3, Figure 3.4, and Figure 3.5). The marine sedimentary response to runoff was highly variable between sites and between runoff events. The greatest rainfall event of the monitoring period occurred on the morning of $11 / 21 / 13$, and resulted in $86 \mathrm{~mm}$ of rainfall over 9 hours. The resulting runoff lasted $\sim 21$ hours. Excluding Hurricane Otto in 2010, which resulted in 
$175 \mathrm{~mm}$ of rainfall in a single day, this storm event was comparable to maximum daily precipitation events over the previous 5 years. During the 11/21/13 runoff event at the Shipwreck site (C-3B), there were two distinct runoff flushes. The first flush peaked at $0.7 \mathrm{~m}$ at 3:13am, and second flush peaked $0.65 \mathrm{~m}$ at 6:33am. During the first flush, turbidity and deposition peaked at $553 \mathrm{mg} / \mathrm{L}$ (the greatest magnitude turbidity peak of 2013) and $141 \mathrm{mg} / \mathrm{cm}^{2}$, respectively, below the small developed Shipwreck watershed, while turbidity and deposition below the much larger Coral Bay watershed, peaked at $99 \mathrm{mg} / \mathrm{L}$ and $95 \mathrm{mg} / \mathrm{cm}^{2}$, respectively. Turbidity below the small minimally developed Sanders Bay watershed peaked at $6.4 \mathrm{mg} / \mathrm{L}$ (98\% lower magnitude than Shipwreck), and no deposition was measured. While the second flush at 6:33am was of almost equal magnitude to the first $(0.7 \mathrm{~m}$ vs. $0.65 \mathrm{~m})$, the turbidity response below the developed watersheds Shipwreck and Coral Bay were only $51 \mathrm{mg} / \mathrm{L}$ and $61 \mathrm{mg} / \mathrm{L}$, respectively, and turbidity peaked at $8 \mathrm{mg} / \mathrm{L}$ below the minimally developed Sanders Bay watershed (no deposition peaks were recorded following the second runoff pulse) (Figure 3.3A, 3.3B).

The 11/4/13 and 12/24/13 runoff events were a result of $29 \mathrm{~mm}$ and 35 $\mathrm{mm}$ of rainfall, respectively, and runoff stage height peaked at $0.38 \mathrm{~m}$ during both rainfall/runoff events. While the peak runoff stage height during these two runoff events were about half the magnitude of the peak stage heights on 11/21/13, the marine turbidity response was 8.2 (on 11/4/13) and 3.4 (on 12/24/13) times less compared to the first flush during the 11/21/13 event (Figure 3.4, Figure 3.5). 
To characterize how short-term (hours) runoff events may affect turbidity and deposition over longer periods (weeks), nephelometer turbidity and deposition data were binned into crest-gauge runoff and resuspension periods as described in the methods. Maximum turbidity measurements were greater at every site during runoff periods compared to resuspension periods. However, compared to resuspension periods, median turbidity was only slightly greater during runoff periods at Coral Bay (1.2x), North Reef (1.1x), and South Reef (1.2x), while median deposition was less during runoff periods at Coral Bay (0.06x) and South Reef (0.8x) (Figure 3.6A, 3.6B). 

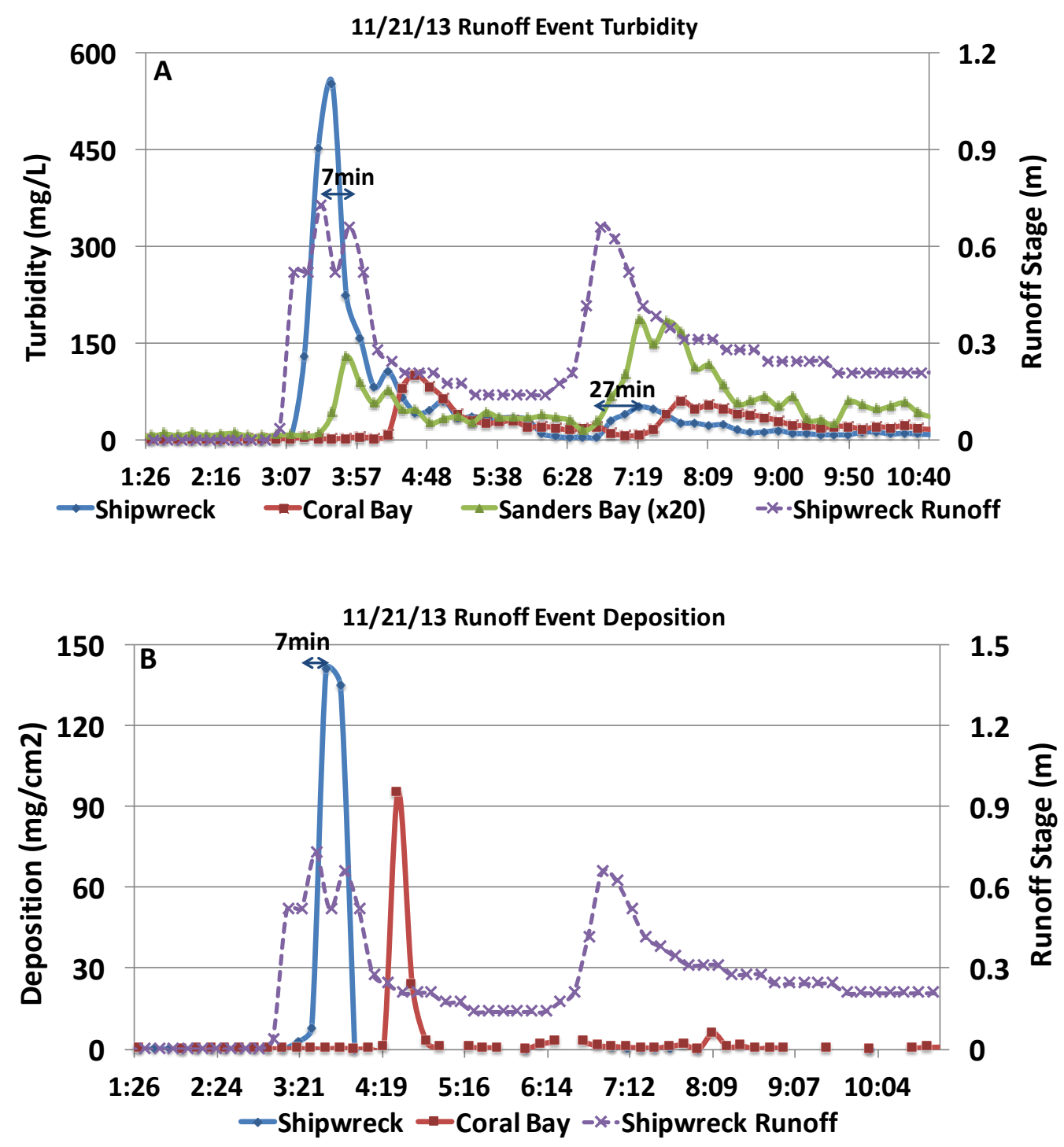

Figure 3.3. Turbidity (A. Top) and deposition (B. Bottom) at shore sites, and Shipwreck runoff stage height vs. local time during the 11/21/13 runoff event. 

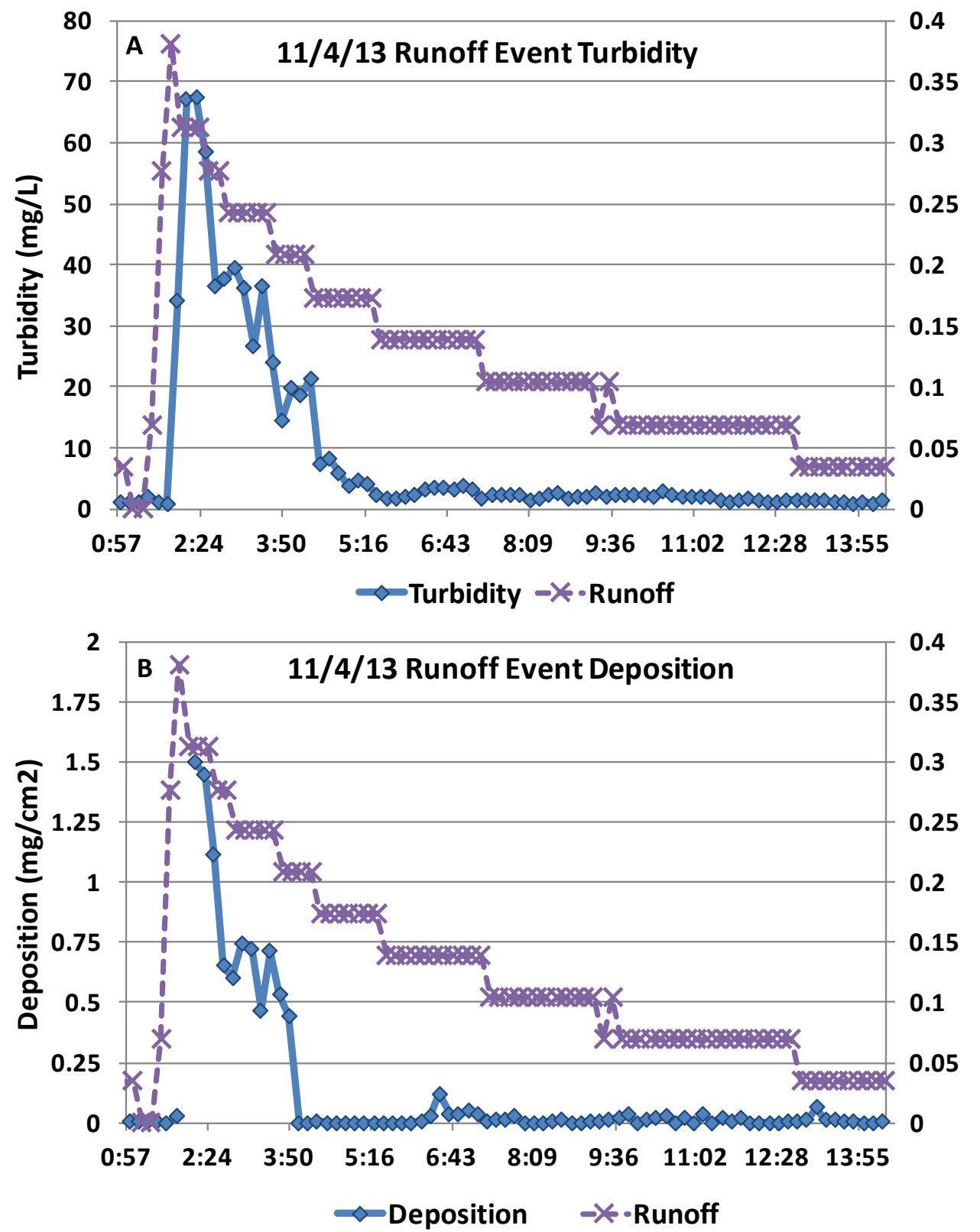

Figure 3.4. Turbidity (A. Top) and deposition (B. Bottom) at the Shipwreck marine shore sites, and Shipwreck runoff stage height vs. local time during the 11/4/13 runoff event. 

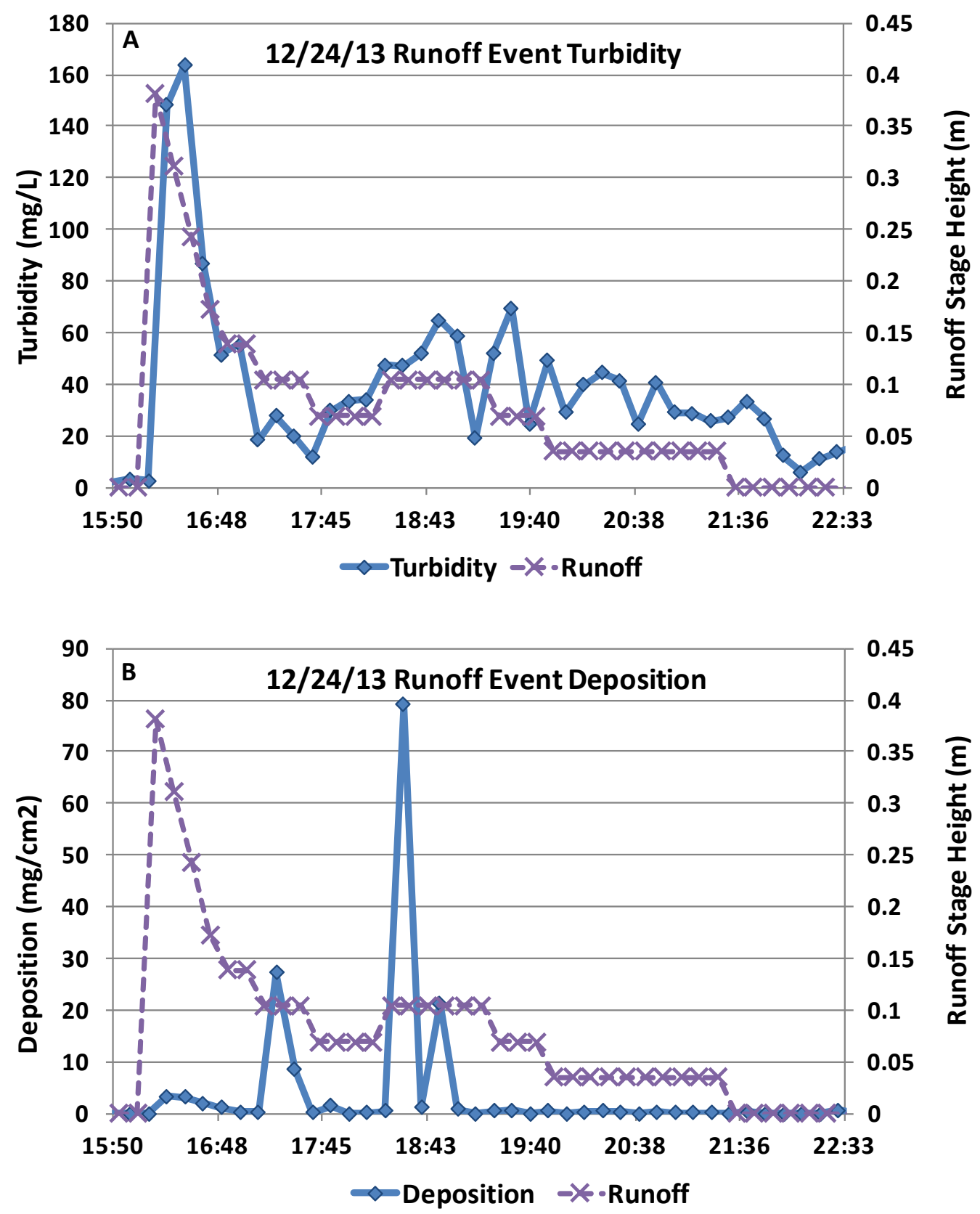

Figure 3.5. Turbidity (A. Top) and deposition (B. Bottom) at the Shipwreck marine shore sites, and Shipwreck runoff stage height vs. local time during the 12/24/13 runoff event. 

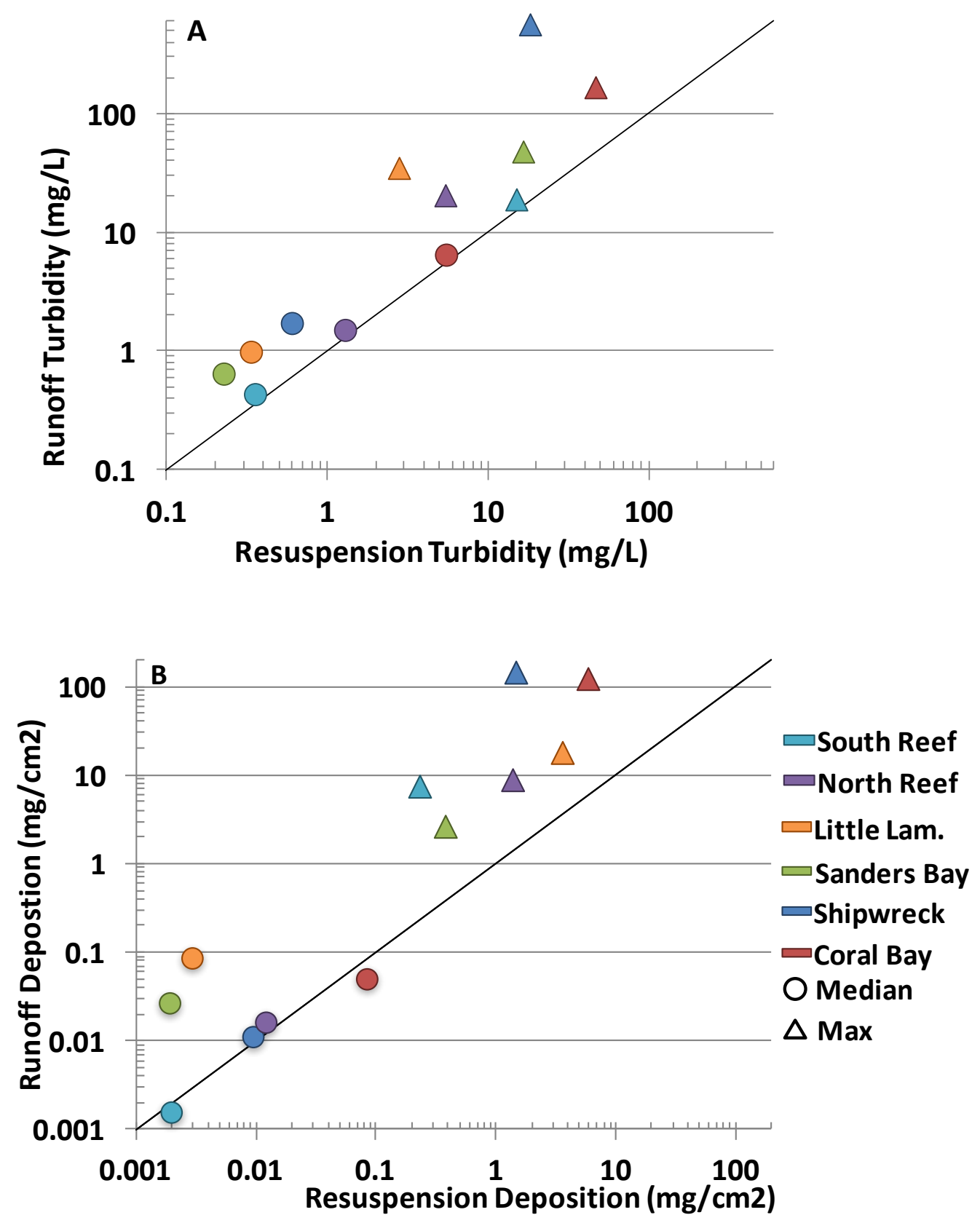

Figure 3.6. Median and max turbidity (A. Top), and deposition (B. Bottom) during crest gauge runoff and resuspension periods at shore and reef sites, and an $x=y$ line. 


\subsubsection{Factors affecting resuspension}

While isolated runoff events directly affect turbidity for short periods (hours), resuspension of benthic sediment occurs over much longer periods (weeks-months), and is affected by increased hydrodynamic energy and decreased benthic grain size.

\subsubsection{Benthic sediment grain size}

To characterize the spatial variability of turbidity in relation to benthic sediment grain size, mean turbidity at each site was compared to mean percent abundance of silt and clay in the benthic sediment at each respective site. Mean turbidity over the time series was generally greater at sites with finer benthic grain sizes. While the average percent of benthic silt and clay $(\%<63 \mu \mathrm{m})$ explained $80 \%(\mathrm{p}$-value $=0.004)$ of the variability in turbidity between sites, benthic grain size was variable between sites and sampling periods (Figure 3.7). Across all sites and sampling periods, the abundance of silt and clay $(\%<63 \mu \mathrm{m})$ in benthic sediment ranged from as low as $1.8 \%$ at North Reef in October, to has high as $42 \%$ at Coral Bay in December. On average, turbidity was greatest at the developed site Coral Bay $(7 \mathrm{mg} / \mathrm{L})$, with silt+clay $(\%<63 \mu \mathrm{m})$ composing $36 \%$ of the benthic sediment, while at Yawzi Reef, turbidity was lowest $(0.3 \mathrm{mg} / \mathrm{L})$, and the benthic sediment was composed of $4 \%$ silt+clay (Figure 3.7). At the other developed site, Shipwreck, silt+clay accounted for $14 \%$ of the benthic sediment. 


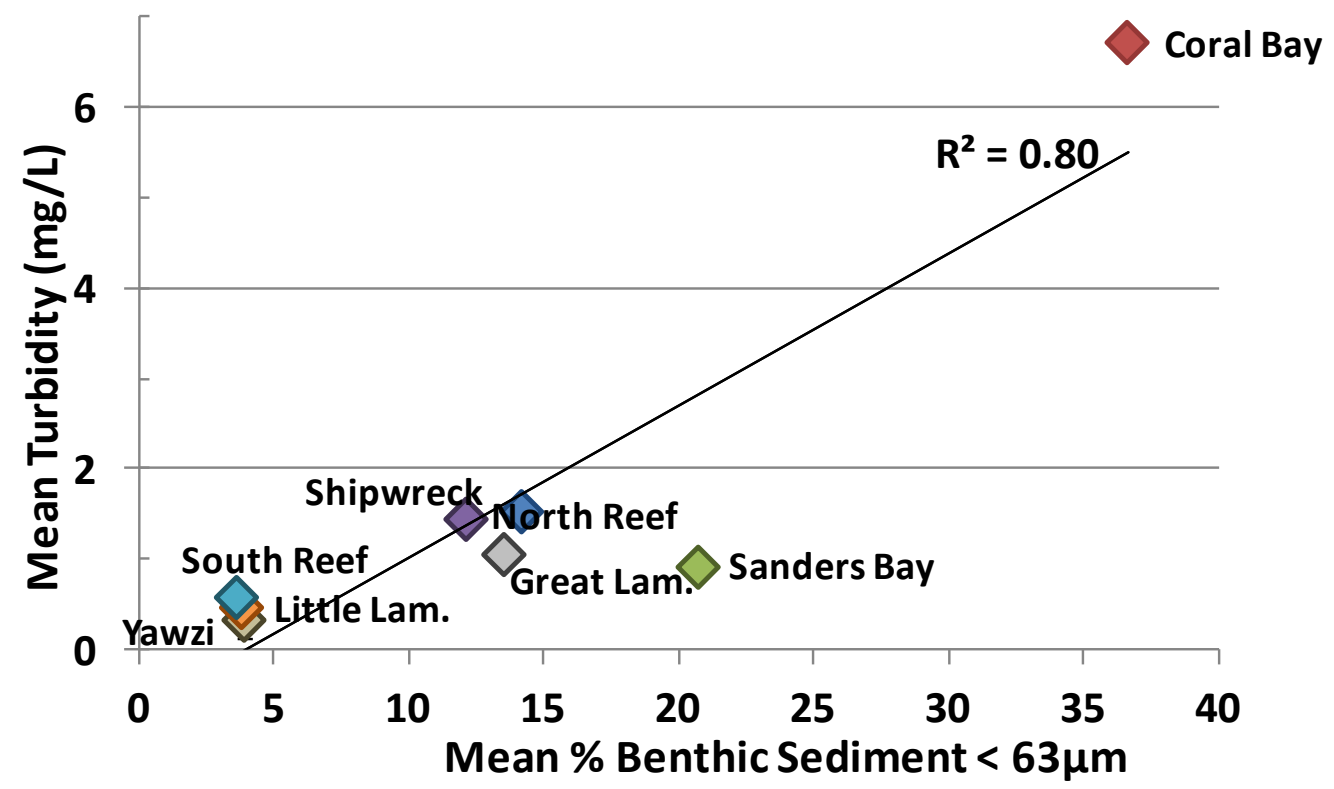

Figure 3.7. Mean turbidity vs. mean \% fine grained $(<63 \mu \mathrm{m})$ benthic sediment during the fall of 2013, at 5 shore and 3 reef sites. 


\subsubsection{Wave energy and tides}

To characterize the effect of wave energy on turbidity, RMS water height (a proxy for wave energy) values were compared to their respective turbidity values during stream gauge runoff and resuspension periods (Figure 3.8). Turbidity typically did not exceed $100 \mathrm{mg} / \mathrm{L}$, except during periods with runoff (Figure 3.8). Maximum turbidity (550 $\mathrm{mg} / \mathrm{L})$ during runoff periods was 5.3 times greater than during resuspension periods (104 $\mathrm{mg} / \mathrm{L})$ and maximum RMS water height during runoff periods was half as great as maximum RMS water height during resuspension periods. Minimum turbidity measurements increased exponentially (a linear increase as seen on the log-scale in Figure 3.8) with increasing RMS water height during both runoff $(\mathrm{R}=0.97)$ periods and resuspension ( $\mathrm{R}=0.99$ ) periods (Figure 3.8). However, given the same RMS water height, minimum turbidity measurements during runoff periods were significantly $(50-100 \%)$ greater than during resuspension periods $(\mathrm{p}-\mathrm{value}=0.002)$. Additionally, RMS water height values above $0.06 \mathrm{~m}$ during runoff periods, and $0.09 \mathrm{~m}$ during resuspension periods were associated with minimum turbidity measurements exceeding the Class B water quality threshold of $6.3 \mathrm{mg} / \mathrm{L}$ (converted from 3 NTU) (Figure 3.8) (EPA, 2016).

Wave energy combined with tidal fluctuations can also result in high magnitude turbidity and deposition spikes. To characterize the effect of tidal fluctuations on marine sediment dynamics, nephelometer turbidity and deposition measurements from the Shipwreck site were compared to water height (tides) values between 12/15/13 and 12/21/13 (Figure 3.9). During that week there was 
no runoff, regional wave height was $50-100 \%$ greater than the time series mean, and turbidity and deposition peaked on a diurnal cycle during low tides. Tidal cycles were not associated with turbidity or deposition fluctuations during periods of average or below average wave height. While turbidity ranged from $2 \mathrm{mg} / \mathrm{L}$ to $104 \mathrm{mg} / \mathrm{L}$ (58 times background) during these 7 days, turbidity was only below the Class B water quality threshold of $6.3 \mathrm{mg} / \mathrm{L}$ for a total of 17.5 hours (Figure 3.8). Hydrodynamic energy generated by waves will directly resuspend benthic sediment if the water depth is shallow enough for wave orbitals to reach the benthic substrate. Relative to mean tide level, fluctuations in water depth caused by tides have the effect of reducing (at high tide) and increasing (at low tide) wave orbital energy contacting the benthic substrate and thus inducing resuspension. 


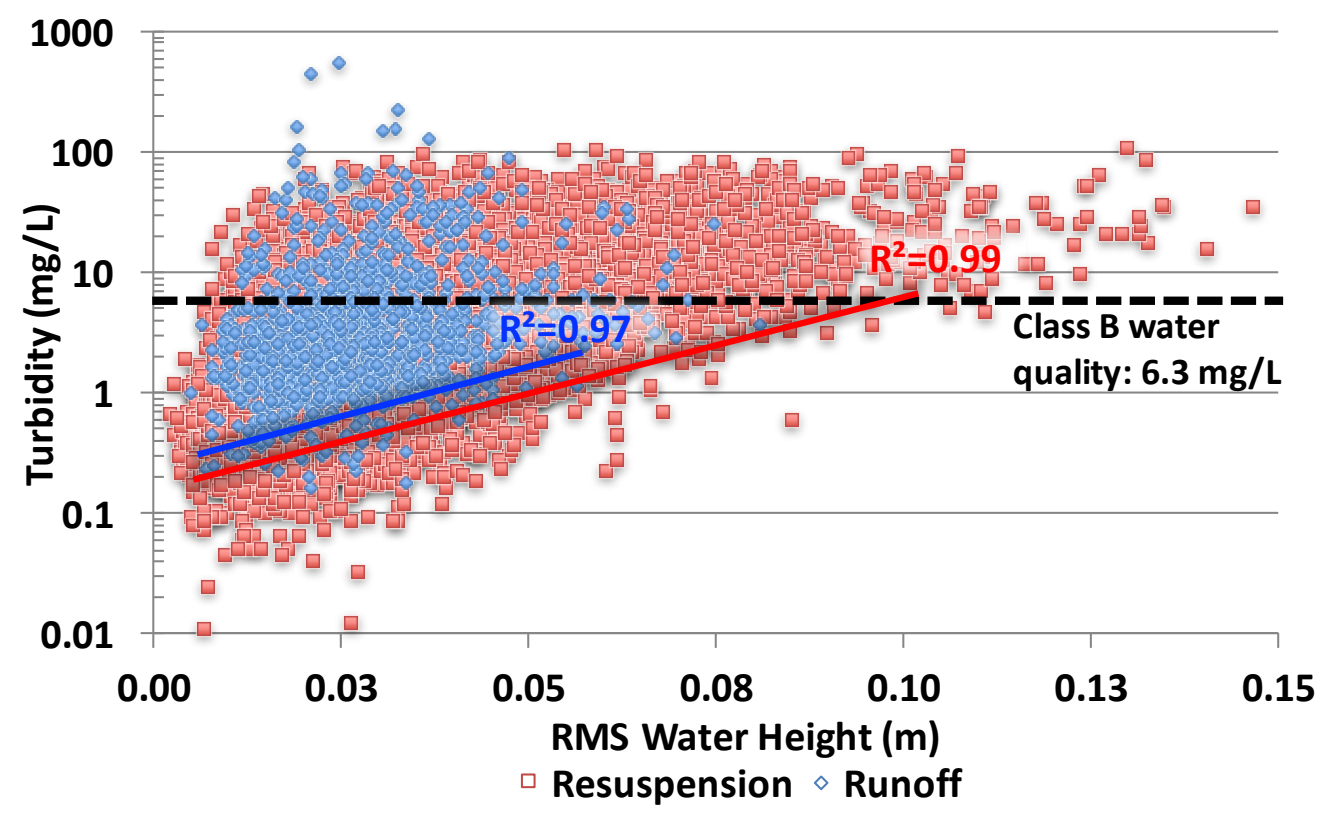

Figure 3.8. RMS water height (proxy for wave energy) vs. turbidity during stream-gauge runoff periods (blue) and stream gauge resuspension periods (red) at Shipwreck. Minimum turbidity $\left(5^{\text {th }}\right.$ percentile) trend-lines during runoff periods (blue line) and resuspension periods (red line), with corresponding $R^{2}$ values. The dashed black line indicates the Class $B$ water quality threshold. 


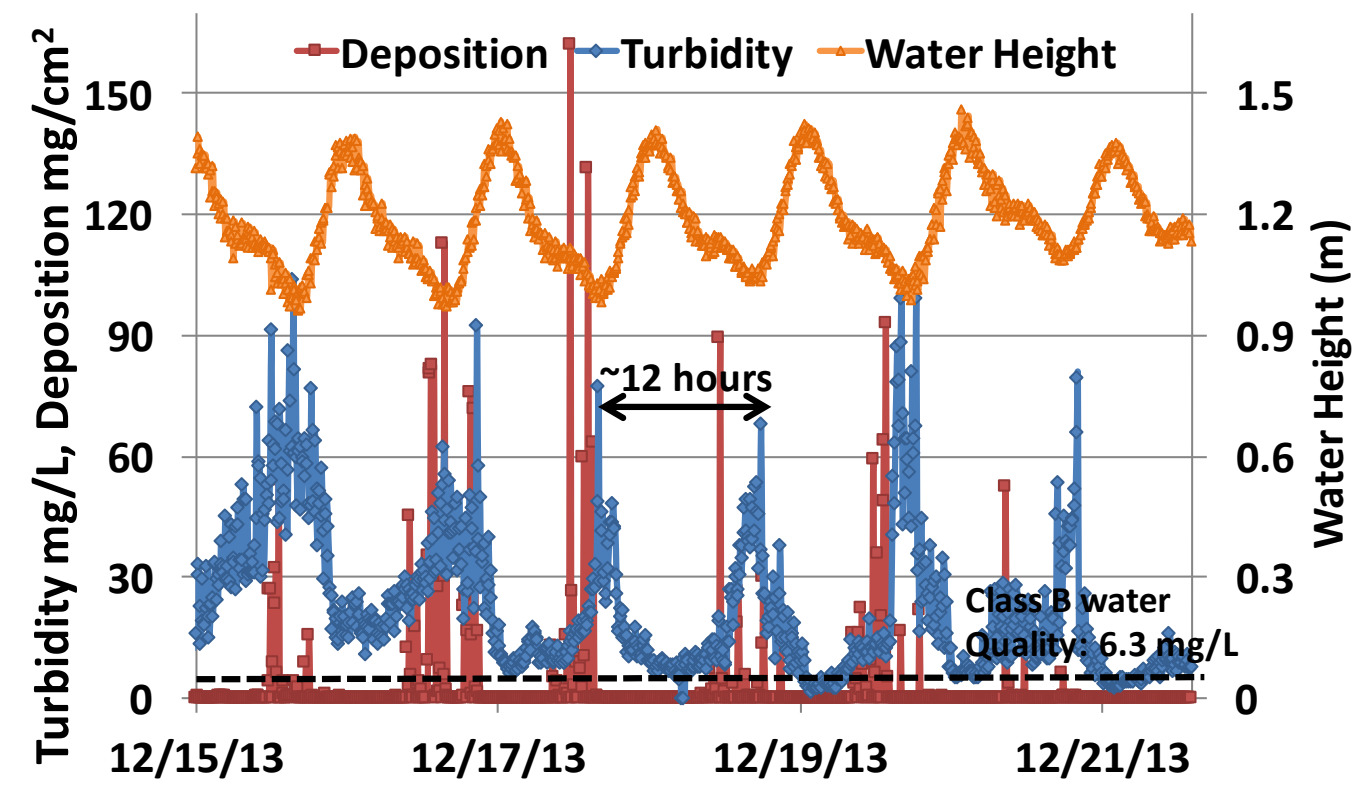

Figure 3.9. Turbidity, deposition, and water height (tides) at Shipwreck, during period of elevated regional wave height in December of 2013. 


\subsubsection{Contributions to turbidity and deposition from runoff vs. resuspension.}

To make an estimate of the relative contributions to turbidity and deposition from runoff vs. resuspension, nephelometer turbidity and deposition data were binned into runoff and resuspension periods based the high-resolution stream gauge at the Shipwreck ephemeral stream outfall. Between 9/20/13 and $12 / 31 / 13$, resuspension contributed at least 7 times more to turbidity and 3 times more to deposition than runoff at the Shipwreck marine monitoring site (Figure $3.10)$. 


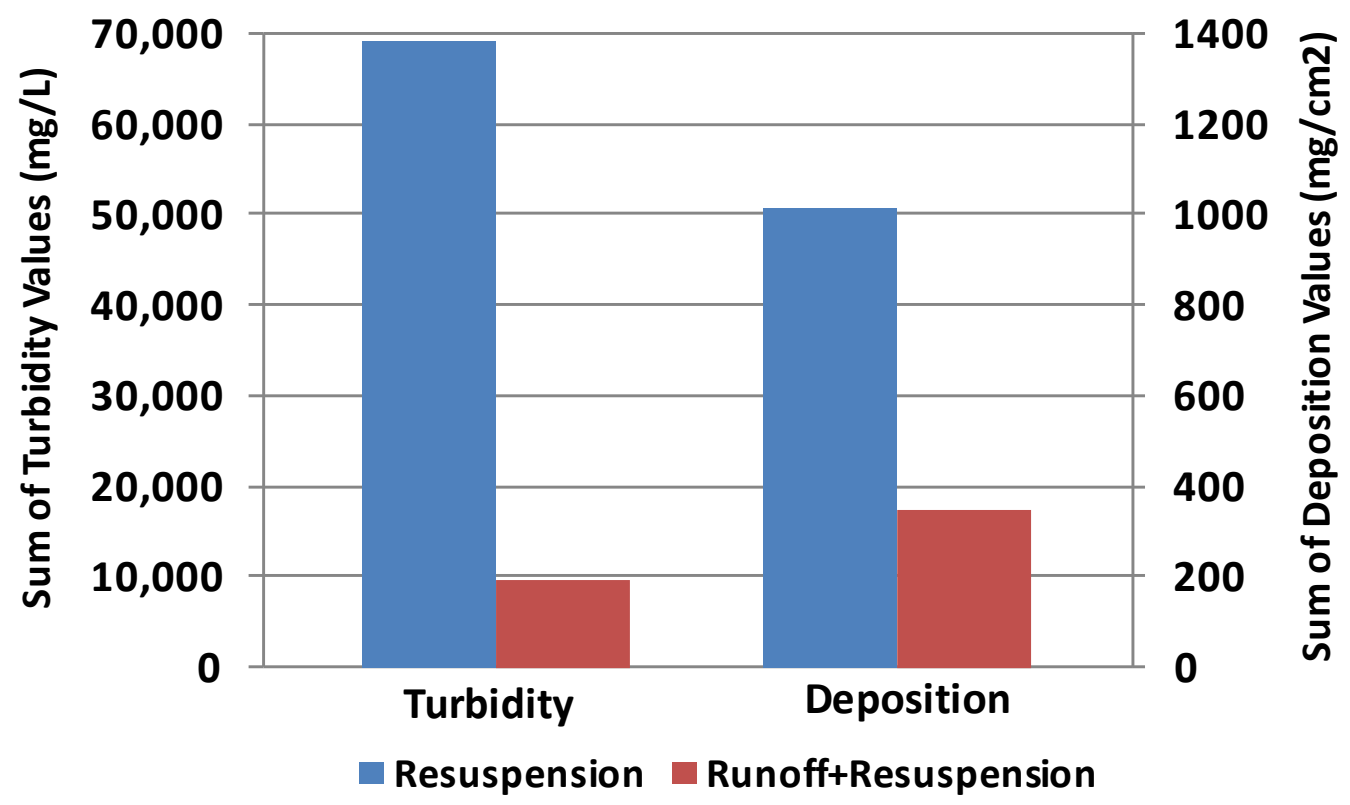

Figure 3.10. Contributions to turbidity and deposition from only resuspension (blue) and from runoff+resuspension (red) during the fall of 2013. 


\subsection{Discussion}

\subsubsection{Processes affecting sediment dynamics at the shore and reef in St. John}

In coastal marine areas surrounding small islands like St. John, sediment can be introduced into the water column via two general processes: runoff and resuspension. Transport of terrigenous sediment from the watershed to the marine environment is affected by sediment availability in the watershed and stream discharge (Fabricius et al., 2014; Ramos-Scharrón and Macdonald, 2007b). By introducing new terrigenous sediment to the marine environment, runoff can increase turbidity, and subsequently deposition if there is not sufficient energy in the water column to keep the particles in suspension (Hjulström, 1939).

\subsubsection{Runoff}

Runoff to the marine environment was relatively infrequent because of St.

John's temperate climate and small watersheds. Runoff consisted of short (median runoff duration: 2.5 hours) flushes separated by up to two weeks with no runoff. During runoff events, turbidity and deposition at shore sites adjacent to ephemeral stream outfalls increased by up to three orders of magnitude above background, but only remained elevated for short (minutes to hours) periods (Figure 3.3, Figure 3.4, Figure 3.5). In contrast, elevated turbidity and deposition were not observed at reef sites ( $\sim 0.6 \mathrm{~km}$ from ephemeral stream outfalls) during and immediately following (within hours) runoff events. However, benthic sediment composition at the reef sites were up to $30 \%$ terrigenous, so land-based sediment is eventually transported and deposited on the reefs, even if not immediately (minutes-hours-days) following runoff events. It is possible that terrigenous 
sediment carried by runoff is either a) deposited in an area near the ephemeral stream outfall before reaching the reefs, or b) transported seaward of the reef monitoring sites prior to deposition. The latter scenario is unlikely because a temporary turbidity signal resulting from sediment transport across the reef monitoring sites was not observed following runoff. It is therefore more plausible that sediment introduced during runoff initially accumulates near the ephemeral stream outfall before some of this terrigenous sediment is resuspended, then transported and deposited at the reef sites.

\subsubsection{Runoff and Resuspension}

Though the nephelometers did not record elevated turbidity measurements immediately following (within hours) runoff events at the reefs, during 13-day resolution crest gauge runoff periods median turbidity measurements were greater at both shore and reefs sites (compared to crest gauge resuspension periods); median turbidity measurements were $\sim 2.8$ times greater at Shipwreck, Sanders Bay, and Little Lameshur, and 1.1-1.2 times greater at Coral Bay, North Reef, and South Reef during crest gauge runoff periods compared to resuspension periods. Greater median turbidity measurements during 13-day crest gauge runoff periods could theoretically be caused by 1) increased resuspension due to greater wave energy, 2) the high-magnitude but short-duration runoff induced sediment plumes (shore sites only), and/or 3) increased resuspension due to increased availability of recently introduced fine-terrigenous sediment. Because regional wave height was not elevated during the 13-day crest gauge runoff

periods (relative to 13-day crest gauge resuspension periods), elevated turbidity 
during runoff periods was not due to increased resuspension from greater wave energy. Additionally, short-duration high-magnitude runoff-induced turbidity spikes alone cannot explain the persistent elevated median turbidity over the 13day crest gauge runoff periods. When runoff events occur, marine turbidity can increase by over and order of magnitude but only for short (minutes-hours) periods. When short-duration runoff-induced turbidity spikes are averaged over the course of 13-day periods, the effect of runoff on turbidity is negligible. Studies on the Great Barrier Reef have suggested that resuspension of recently introduced terrigenous sediment can increase turbidity and deposition for days to weeks following a runoff event (Fabricius et al., 2013; Wolanski et al., 2008). However, elevated turbidity following the dissipation of a runoff induced sediment plume would only occur if sediment availability (rather than hydrodynamic energy) is the limiting factor for resuspension (Larcombe and Woolfe, 1999a). Our observations coupled with these findings on the Great Barrier Reef, suggest that increased availability of fine terrigenous sediment is the most plausible explanation to account for greater median turbidity during 13-day crest gauge runoff periods. In summary, after a runoff-induced sediment plume dissipates (within hours) turbidity may be elevated for weeks due to resuspension of fine terrigenous sediment introduced by runoff. In St. John, this means that even if watershed restoration efforts succeeded in eliminating the transport of sediment from the watershed to the marine environment, there may not be measureable improvements in water quality until the fine terrigenous sediment in 
is removed from the system through advection or burial and is no longer available for resuspension.

\subsubsection{Factors affecting resuspension}

\subsubsection{Wave energy}

The relationship between increased wave energy (wave orbital velocity/wave period/wave height) and increased resuspension (turbidity and deposition) is well documented (Fabricius et al., 2013; Larcombe and Woolfe, 1999b; Ogston et al., 2004; Storlazzi et al., 2004). As we expected, there were strong significant relationships between minimum turbidity values $\left(5^{\text {th }}\right.$ percentile $)$ and RMS water height (a proxy for wave energy) (Figure 3.8) during both runoff and resuspension periods, with minimum turbidity measurements during runoff periods being greater than those during resuspension periods. This suggests that during runoff periods, contributions to turbidity are a result of both resuspension and runoff. Accordingly, during resuspension periods, resuspension is the only process contributing to turbidity. Wave energy is not the only factor that affects resuspension/turbidity. Turbidity values greater than the minimum turbidity predicted by the RMS water height (wave energy) values suggest added contributions to turbidity from other factors that also affect resuspension/turbidity, such as currents, benthic grain size, and tides.

\subsubsection{Wave-tide interaction}

The effect of tides on turbidity is well documented. On the Great Barrier Reef, turbidity was $13 \%$ lower during weeks with the lowest tidal range compared to weeks with the highest tidal range (Fabricius et al., 2013) and in Molokai, 
Hawaii, turbidity was highly correlated with tidal range (Ogston et al., 2004). We expected greater tidal range (and thus greater tidal currents) to increase sediment resuspension at our shallow shore sites. At one site (Shipwreck) turbidity and deposition peaked diurnally at low tide, but only during periods of above average regional wave height (Figure 3.9), and was not associated with tidal range. This pattern was observed at Shipwreck and not the other shoreline sites because the Shipwreck shoreline is located closer to the inlet of Coral Bay than other sites and is oriented facing the prevailing swell (Figure 3.1).

When elevated wave height and low tide occur simultaneously, greater wave orbital velocities contact the seafloor and resuspend benthic sediments. Because wave orbital velocities decay exponentially with depth, the $0.5 \mathrm{~m}$ increase in water height from low tide to high tide is sufficient to attenuate wave orbitals so that they do not have sufficient energy to resuspend benthic sediment when they reach the seafloor (Figure 3.9). During periods of average or below average wave height, even during low tide, sufficiently strong wave orbitals do not reach the seafloor and thus do not resuspend benthic sediment. Given a greater tidal range, and thus a lower low tide, it is probable that lower wave heights would result in resuspension. Similar to our findings, on reefs surrounding Ishigaki Island, Japan, turbidity and deposition increased during low tides, but not systematically at every low tide (Thomas and Ridd 2005). However, an association between high wave heights coupled with low tide, and turbidity and deposition spikes were not investigated (Thomas and Ridd, 2005). The pattern of peak resuspension at low tide (during periods of above average wave height) 
observed in the USVI is opposite to the pattern of peak resuspension at high tides in Molokai, HI (Ogston et al., 2004; Presto et al., 2006; Storlazzi et al., 2004). The different patterns may be related to the presence of a shallow, partially exposed fringing reef crest in Molakai. During low tide the reef crest reduces wave energy on the reef flat. However, during high tide, the reef crest is submerged and waves are able to pass over the reef crest and onto the reef flat (Ogston et al., 2004; Presto et al., 2006; Storlazzi et al., 2004). In contrast, on St. John during low tides, wave orbitals contact the shallow seafloor and resuspend sediment because there are no physical structures to attenuate wave energy. On St. John, low tides effectively result in lower water depth. During low tides, greater wave orbitals can make contact with the seafloor and resuspend sediment.

\subsubsection{Benthic sediment grain size}

In addition to hydrodynamic energy, our study associated finer benthic sediments with increased turbidity. The strong significant correlation $\left(R^{2}=0.80\right.$, $\mathrm{p}$-value $=0.004)$ between percent benthic sediment less than $63 \mu \mathrm{m}$ (percent silt+clay) and turbidity at each site suggest that benthic sediment texture is an important factor contributing to turbidity (Figure 3.7). Finer grains are more easily resuspended than coarser grains and stay in suspension longer. Interestingly, out of the 8 sites, benthic sediment at Sanders bay contained the second highest fraction of silt and clay, yet mean turbidity measured at Sanders Bay was lower than 4 sites (Figure 3.7). This may be because dense rhizome networks from the macrophyte beds at Sanders Bay reduces resuspension by holding the fine sediment in place on the seafloor, and the macrophyte blades 
attenuate hydrodynamic energy, which also reduces resuspension (Madsen et al., 2001). While finer benthic sediments were associated with greater turbidity, confounding factors including macrophyte abundance and exposure to hydrodynamic energy also affected variability in turbidity between sites.

\subsubsection{Contributions to turbidity and deposition from runoff vs. resuspension}

The relative contributions of resuspension and runoff to turbidity and deposition varied spatially. While median turbidity and deposition were greatest at Coral Bay, max turbidity and deposition were greatest at Shipwreck (Figure 3.2A, 3.2B). As the marine sedimentary response to runoff is very short-lived (minutes-hours), the greater median turbidity and deposition measured at Coral Bay indicate that resuspension contributes relatively more to turbidity and deposition than at Shipwreck. Compared to Coral Bay, the greater max turbidity and deposition at Shipwreck is a result of high magnitude spikes in turbidity and deposition caused by runoff. While max turbidity and deposition were greater during crest gauge runoff periods compared to resuspension periods at every site, at Coral Bay median turbidity was only slightly greater during runoff periods and deposition was less during runoff periods compared to resuspension periods (Figure 3.6A, 3.6B). Again, this indicates that runoff contributes relatively less to turbidity and deposition over longer periods (weeks to months) in Coral Bay, possibly because of effective watershed restoration and/or the presence of mangroves along the shoreline of Coral Bay Harbor.

A more precise approach (use of the 10-min resolution stream gauge instead of the 13-day resolution crest gauges) to determine the relative 
contributions from resuspension and runoff to turbidity and deposition was only possible at the Shipwreck site. At Shipwreck, resuspension contributed at least 7 times more to turbidity, and 3 times more to deposition than runoff (Figure 3.10). Because turbidity and deposition spikes during runoff events were greatest at the Shipwreck site, resuspension likely contributed relatively more to turbidity and deposition than runoff at the other monitoring sites on St. John. Data for this study was collected post restoration, so it is possible that prior to restoration, contributions to turbidity and deposition from runoff were greater than this study shows. Unfortunately, it has not been possible to determine that from pre and post restoration sediment trap time series.

\subsubsection{Impact of watershed development and restoration, and environmental implications of a proposed mega-yacht marina}

Previous studies on St. John have used techniques such as sediment traps (Gray et al., 2008; Gray et al., 2012; Gray et al., 2016), and sediment cores (Brooks et al., 2007) to associate watershed development with increased marine sedimentation on time scales ranging from centuries to months. However, no published studies assessed the effect of watershed development on marine turbidity over shorter time scales. Our study is the first to use high-resolution (10minute) instruments to monitor marine turbidity and deposition below geographically similar developed and minimally developed watersheds (Figure 3.1, Figure 8 ). We found median turbidity and deposition were up to 18 and 3 times greater, respectively, and max turbidity and deposition were up to 12 and 17 times greater, respectively, below developed watersheds compared to sites below 
geographically similar minimally developed watersheds (Table 3.2). Over the course of our 5-month time series, differences of this magnitude from sites below developed vs. minimally developed watersheds were expected. Numerous studies corroborate this link between watershed development on St. John and increases in watershed erosion and marine sedimentation by up to an order of magnitude above background (Macdonald et al., 1997; Brooks et al., 2007; Gray et al., 2008; Gray et al., 2012; Gray et al., 2016; Ramos-Scharrón and Macdonald, 2007a; Ramos-Scharrón and Macdonald, 2007b; Ramos-Scharron et al., 2012). Turbidity and deposition were also greater at reef sites in a bay adjacent to developed watersheds (Coral Bay) compared to a bay below minimally developed watersheds (Lameshur Bay). Over short time periods (minutes) during runoff events, turbidity was up to $\sim 90$ times greater below the developed Shipwreck watershed compared to the geographically similar minimally developed Sanders Bay watershed (Figure 3.3). Marine areas below developed watersheds receive greater sediment loads during runoff events than areas below minimally developed watersheds. Therefor there is more fine sediment available for resuspension below developed watersheds, which leads to persistently elevated turbidity and deposition relative to areas below minimally developed watersheds.

With the goal of reducing marine turbidity and sedimentation by decreasing sediment-laden watershed runoff, watershed restoration in the developed Coral Bay and Shipwreck watersheds were completed in 2011. The restoration efforts included paving unpaved roads, installing water-bars on unpaved roads, and building retention ponds (Ramos-Scharrón et al., 2012). 
Watershed modeling suggested that the installation of retention ponds, such as those in Coral Bay, accounted for $90 \%$ of the reduction in sediment yield (Gray et al., 2016). Restoration efforts in the Shipwreck watershed consisted of constructing water-bars on unpaved roads to divert runoff into an ephemeral stream channel, rather than letting the unpaved roads serve as a conduit for runoff. The water-bars in the Shipwreck watershed likely reduced watershed-scale sediment yields to coastal waters. However, the water-bars channeled sedimentrich runoff water from an unpaved road segment into the ephemeral stream channel with an outlet adjacent to our Shipwreck marine monitoring site. Without water-bars, road runoff would have otherwise ended up in another ephemeral stream. This may have caused localized increases in marine turbidity and deposition at our Shipwreck marine sampling site, while watershed-scale sediment yield was reduced.

Although the Coral Bay watershed is $\sim 6$ times larger than the watershed above Shipwreck and contains over 4 times the length of unpaved roads, peak turbidity measured at Coral Bay was over 5 times lower than at Shipwreck during the 11/21/13 runoff event (Figure 3.3). This result is consistent with watershed studies suggesting restoration in the Coral Bay watershed was effective in reducing the marine turbidity response to runoff, and that watershed restoration resulted in sediment being diverted and concentrated in the Shipwreck ephemeral stream. The apparent success of watershed restoration in Coral Bay, relative to the Shipwreck watershed, may have also been enhanced by the presence of mangroves along the shoreline of Coral Bay Harbor, the gentle sloping central 
valley of the Coral Bay watershed, and the effect of water-bar placement on unpaved road segments in the Shipwreck watershed. The above-ground roots of mangroves slow down surface runoff and promote deposition of sediments, and the gentle slope of the central valley slow down surface runoff and reduce suspended load.

While watershed modeling and anecdotal evidence suggest that ARRA watershed restoration reduced sediment yields, its effect on short-term marine turbidity and deposition is inconclusive due to the lack of data prior to restoration. Continued monitoring of marine turbidity and deposition would allow us to see improvements in water quality as land-based sediment introduced prior to restoration is removed from the system. However, sediment trap monitoring at our study sites during a pre-restoration period (2009-2011) to the post-restoration period (2012-2016) indicate significant declines post-restoration in \% terrigenous sediment as well as the \% clay (Gray et al., in prep). These preliminary findings may indicate that the first stages of recovery are occurring.

Although we would generally expect to see more rapid improvements in water quality at sites with greater hydrodynamic energy due to high sediment removal rates, the residence time of terrigenous sediment at any particular site on St. John is unknown. In the Corsica River, a $\sim 5$-year lag time between watershed restoration and decreased sediment deposition was observed (Palinkas, 2013), but in coastal marine environments like St. John that have been exposed to over a century of degradation, it could take a minimum of $15-25$ years for a full recovery (Borja et al., 2010). This highlights the need for long (decades) time series 
monitoring to separate natural variability of marine sediment dynamics from the effects of watershed development and restoration, and to evaluate the potential effectiveness of restoration.

Anthropogenic activity associated with marine construction and marina use, such as dredging, and boat/ship traffic, would also increase turbidity and deposition (Bak, 1978, Brown et al., 1990; Jones, 2011). While watershed restoration appears to have reduced sediment transport to the marine environment, the proposed Summer's End Group Mega Yacht Marina and The Sirius Resort and Marina would likely negate these improvements in water quality by indefinitely increasing resuspension and temporarily (6-17 months) increasing sediment laden watershed runoff (Summer's End Group EAR, 2014a; Sirius Marina EAR, 2015). Construction of the proposed mega yacht marina would temporarily increase turbidity and deposition during both the land and marine phases of construction. Marine construction-related activities, such as the dredging and removal of $1,300 \mathrm{~m}^{3}$ of material, and the installation of 1,333 concrete pilings, would increase resuspension by disturbing the fine benthic sediments found in Coral Bay (PIANC Report, 2010; Summer's End Group EAR, 2014b; Sirius Marina EAR, 2015). Over 35\% of benthic sediment in Coral Bay Harbor is composed of silt and clay (Figure 3.7), and the mean current velocity in Coral Bay is $0.95 \mathrm{~cm} / \mathrm{s}$ but can reach as high as $0.28 \mathrm{~cm} / \mathrm{s}$. When these fine particles are resuspended during construction, natural currents speeds in Coral Bay are sufficient to keep the finer particles in suspension indefinitely (Hjulström, 1939). Although sediment runoff mitigation protocols would be employed, 
vegetation removal and land clearing during the land phase of construction would expose large sources of easily erodible sediment, which would increase the potential for runoff induced sediment plumes (PIANC Report, 2010).

Additionally, the developers have proposed to dispose of the sediment dredged from Coral Bay by dumping it on an upland parcel adjacent to Coral Bay (Sirius Marina EAR, 2015). This would provide another a large (thousands of cubic meters) source of fine, unconsolidated, easily-erodible sediment which would increase the potential for runoff-induced sediment plumes during rainfall events. From the proposed marina construction, we would expect higher magnitude spikes in turbidity and deposition following runoff events, and persistently elevated turbidity year round from prop-wash induced resuspension.

Areas protected from strong currents and waves can accumulate large loads of fine sediment due to low removal rates (Larcombe and Wolfe, 1999a; Larcombe et al., 1995, Orpin et al., 2004). Of the eight sites in eastern St. John in which benthic sediment samples were collected during the Fall of 2013, the samples collected from Coral Bay contained the greatest fraction of silt and clay, due to low hydrodynamic energy in the bay and thus low removal rates. (Figure 3.7). After construction is complete and the marina is in use, increased boat traffic (including mega-yachts) would also result in increased turbidity and deposition due to greater resuspension from prop-wash (the disturbed mass of water pushed by the propeller of a watercraft) induced scouring of fine benthic sediment (PIANC Report, 2010). Due to the relatively low (lowest mean RMS water height of shore sites in St. John) hydrodynamic energy in Coral Bay Harbor, benthic 
sediments resuspended by prop-wash scouring are unlikely to be advected to another area outside of the bay, and instead would either stay in suspension or deposit back on the seafloor. With regular traffic of large boats such as megayachts, this would result in repeated cycles of resuspension and deposition. At 6.4 $\mathrm{mg} / \mathrm{L}$, median turbidity in Coral Bay is above the Class B water quality threshold of $5.8 \mathrm{mg} / \mathrm{L}$. An increase in boat traffic and thus resuspension, would push turbidity levels in Coral Bay further above the Class B water quality threshold for turbidity.

Although studies have concluded that watershed scale sediment yield has decreased since restoration was completed in 2011 (Gray et al., 2016), statistically significant decreases in sediment trap accumulation rates have not yet been measured (Sears, 2015). Due to the dominating role of resuspension in St. John (Figure 3.10), which produce high variability (and thus a low signal to noise ratio) in sediment accumulation, it is difficult to resolve statistically significant postrestoration decreases in sediment accumulation. Reducing sediment yield though improved watershed management practices should lead to improved coastal water quality in St. John, but on a time-frame that is currently not fully understood. 


\subsection{Future research}

Research to investigate the residence time of terrigenous sediments in bays would provide crucial data to determine the lag time between watershed restoration and improved water quality at marine shore and reef areas. It would also be beneficial to measure the turbidity and discharge of ephemeral stream effluent in order to quantify the total mass of land-based sediment transported to the marine environment. 


\subsection{Conclusion}

To monitor the impact of marine and watershed development and the effectiveness of watershed restoration on marine sedimentation we must first understand the processes that affect marine sediment dynamics. Though previous studies have used sediment traps and sediment cores to measure marine sedimentation over longer periods (weeks-centuries), this is the first study to monitor marine turbidity and determine the relative contributions to turbidity and deposition from runoff and resuspension at the time-scale of minutes-days in St. John.

Our analysis supports the following conclusions:

1. Compared to marine areas below minimally developed watersheds, watershed development was associated with greater marine turbidity and deposition, likely due to greater rates of erosion on abundant unpaved roads in the developed watersheds and the subsequent transport of sediment to the marine environment where fine terrigenous grains are easily resuspended. While other studies have found marine deposition to be greater below developed watersheds over longer periods (months-years) in St. John, this is the first study to demonstrate that turbidity and deposition were greater below developed watersheds during short-lived (minutes-hours) runoff events.

2. Runoff events were characterized by high-magnitude but short-duration (minutes-hours) spikes in turbidity (SSC) and deposition which were up to $550 \mathrm{mg} / \mathrm{L}$ and $140 \mathrm{mg} / \mathrm{cm}^{2}$ (900 and 17,000 times background), respectively. Compared to runoff, resuspension of benthic sediment typically resulted in 
lower-magnitude but longer-term (hours-weeks-months) turbidity and deposition which were up to $104 \mathrm{mg} / \mathrm{L}$ and $160 \mathrm{mg} / \mathrm{cm}^{2}(60$ and 4500 times background), respectively.

3. Though spatially variable, data from our study show that resuspension contributed at least seven times more to turbidity and three times more to deposition than runoff. Because resuspension is the primary mechanism contributing to turbidity and deposition, watershed restoration may not immediately result in statistically significant reductions in marine sedimentation. We would not expect to see improved water quality until the terrigenous sediment has worked its way out of the system through advection or burial and is no longer available for resuspension. However, this study of marine sediment dynamics was conducted after completion of the ARRA watershed restoration. It is possible that prior to restoration, contributions to turbidity and deposition from runoff, relative to resuspension, were greater. Activities that increase resuspension, such as marina construction related destruction of macrophyte beds and boat prop-wash, could potentially negate improvements from ARRA watershed restoration.

4. The main factors that explained the spatial variability in the magnitude of the marine sedimentary response to runoff included the degree of watershed development, and possibly ARRA watershed restoration. Resuspensioninduced turbidity and deposition were associated with hydrodynamic energy caused by waves during low tides, finer benthic sediment grain size, and also low macrophyte abundance. 
Finally, this study highlights the need for long time-series monitoring using multiple lines of evidence to separate the effects of watershed development and restoration from the natural variability of marine sediment dynamics. 


\subsection{Work Cited}

Alvarez-Filip, L., N.K. Dulvy, J.A. Gill, I.M. Cote, and A.R. Watkinson, 2009. Flattening of Caribbean coral reefs: region-wide declines in architectural complexity. Proceedings of the Royal Society 1822:1-7.

Anthony, K.R.N., and K.E. Fabricius, 2000. Shifting roles of heterotrophy and autotrophy in coral energetic under varying turbidity. Journal of Experimental Marine Biology and Ecology 252:221-253.

Anthony, K.R.N., J.A. Maynard, G. Diaz-Pulido, P.J. Mumby, P.A. Marshall, L. Cao, and O. Hoegh-Guldberg. 2011. Ocean acidification and warming will lower coral reef resilience. Global Change Biology17:1798-1808.

Anthony, KRN., D.I. Kline, G. Diaz-Pulido, S. Dove, and O. Hoegh-Guldberg. 2008. Ocean acidification causes bleaching and productivity loss in coral reef builders. PNAS 105(45): 17442-17446.

Applied Technology \& Management Inc., Bioimpact Inc., and Cairone and Kaupp Inc., Submitted by The Summer's End Group LLC. 2014a. Earth Change Plan \& Environmental Assessment Report for the Development of the Upland Areas of St. John Marina, Coral Bay, St. John, USVI.

Applied Technology \& Management Inc., Bioimpact Inc., and Cairone and Kaupp Inc., Submitted by The Summer's End Group LLC. 2014b. Environmental Assessment Report for the Development of the St. John Marina, Coral Bay, St. John, USVI.

Bak, R.P.M. 1978. Lethal and sublethal effects of dredging on reef corals. Marine Pollution Bulletin 9, 14-16.

Borja, A., D.M. Dauer, M. Elliot, and C.A. Simenstad. 2010. Medium-and longterm recovery of estuarine and coastal ecosystems: Patterns, Rates, and Restoration Effectiveness. Estuaries and Coasts 33 (6):1249-1260.

Brooks, G.R., B. Devine, R.A. Larson, and B.P. Rood. 2007. Sedimentary development of Coral Bay, St. John, USVI: A shift from natural to anthropogenic influences. Caribbean Journal of Science 43:226-243.

Brown, B.E., Le Tissier, M.D.A., Scoffin, T.P., and A.W. Tudhope. 1990.

Evaluation of the environmental impact of dredging on intertidal coral reefs at Ko Phuket, Thailand, using ecological and physiological parameters. Marine Ecology Progress Series 65:273-281.

Browne, N.K., Tay, J., and P.A. Todd. 2015. Recreating pulsed turbidity events to determine coral-sediment thresholds for active management. Journal of Experimental Marine Biology and Ecology 466:98-109. 
CH2M Hill Inc. 1979. A sediment reduction program. Report submitted to the Department of Conservation and Cultural Affairs, Government of the U.S. Virgin Islands.

Edmunds, P.J., 2002. Long-term dynamics of coral reefs in St. John, US Virgin Islands. Coral Reefs 21(4):357-367.

Edmunds, P.J., and S.C. Gray, 2014. The effects of storms, heavy rain, and sedimentation on the shallow coral reefs of St. John, US Virgin Islands. Hydrobiologia.

Environmental Protection Agency (EPA). 2016. U.S. Virgin Islands Water Quality Standards. Chapter 7: Water Pollution Control. Subchapter 186: Water Quality Standards for Waters of the Virgin Islands.

Fabricius, K.E., C. Wild, E. Wolanski, and D. Abele. 2003. Effects of transparent exopolymer particles and muddy terrigenous sediments on the survival of hard coral recruits. Estuarine, Coastal and Shelf Science 57:613-621.

Fabricius, K.E., G. De'ath, C. Humphrey, I. Zagorskis, and B. Schaffelke. 2013. Intra-annual variation in turbidity in response to terrestrial runoff on near-shore coral reefs of the Great Barrier Reef. Estuarine, Coastal and Shelf Science 116:5765.

Fabricius, K.E., M. Logan, S. Weeks, and J. Brodie. 2014. The effects of river runoff on water clarity across the central Great Barrier Reef. Marine Pollution Bulletin 84:191-200.

Fabricius, K.E. 2005. Effects of terrestrial runoff on the ecology of corals and coral reefs: review and synthesis. Marine Pollution Bulletin 50:125-146.

Gardner, T.A., I.M. Côté, J.A. Gill, A. Grant, and A.R. Watkinson. 2003. LongTerm Region-Wide Declines in Caribbean Corals. Science 301:958-960.

Goatley, C.H., and D.R. Bellwood. 2012. Sediment suppresses herbivory across a coral reef depth gradient. Biology Letters 8, 1016-1018.

Gray, S.C., C. Ramos-Scharrón, W. Sears, G. Brooks, R. Larson, M. LaFevor, and J. Roy. 2016. Ridge to reef integrated terrestrial-marine monitoring to assess the impact of watershed restoration on coral reef sedimentation in St. John, US Virgin Islands. 13 ${ }^{\text {th }}$ International Coral Reef Symposium; 19-24 June 2016; Honolulu, Hawaii.

Gray, S.C., K.L. Gobbi, and P.V. Narwold. 2008. Comparison of Sedimentation in Bays and Reefs Below Developed versus Undeveloped Watersheds on St. John, US Virgin Islands. Proceedings of the $11^{\text {th }}$ International Coral Reef Symposium, $1-5$. 
Gray, S.C., W. Sears, M.L. Kolupski, Z.C. Hastings, N.W. Przyuski, M.D. Fox, and A. DeGrood. 2012. Factors affecting land-based sedimentation in coastal bays, US Virgin Islands. Proceedings of the $12^{\text {th }}$ International Coral Reef Symposium, 9-13.

Heiri, O., A. F. Lotter, and G. Lemcke. 2001. Loss on ignition as a method for estimating organic and carbonate content in sediments: reproducibility and comparability of results. Journal of Paleolimnology 25:101-110.

Hjulström, F. 1939. Part 1. Transportation: Transportation of detritus by moving water. Published in Recent Marine Sediments. 1955.

Hubbard, D.K., J.D. Stump, and B. Carter. 1987. Sedimentation and reef development in Hawksnest, Fish and Reef Bays, St. John, U.S. Virgin Islands. In: Virgin Islands Resource Management Cooperative. Biosphere Research Reserve Report 21:99.

HVS Valuation \& Consulting. Submitted to Linwood Gilbert Jr., MAI Sirius Development LLC. 2013. MARKET STUDY AND FINANCIAL PROJECTIONS of the Proposed Coral Bay Marina Resort.

James Cook University (JCU). Marine Geophysics Laboratory (MGL). Instruments. 2015. https://www.jcu.edu.au/marine-geophysicslaboratory/instruments

Jones, R.J. 2011. Environmental Effects of the cruise tourism boom: sediment resuspension from cruise ships and the possible effects of increased turbidity and sediment deposition on corals (Bermuda). Bulletin of Marine Science 87(3):659679.

Larcombe, P., P.V. Ridd, A. Prytz, and B. Wilson. 1995. Factors controlling suspended sediment on inner-shelf coral reefs, Townsville, Australia. Coral Reefs 14:163-171.

Larcombe, P., and K.J. Woolfe. 1999a. Increased sediment supply to the Great Barrier Reef will not increase sediment accumulation at most coral reefs. Coral Reefs18:163-171.

Larcombe, P., and K.J. Woolfe. 1999b. Terrigenous sediments as influence upon Holocene nearshore coral reefs, central Great Barrier Reef, Australia. Australian Journal of Earth Sciences 46:141-154.

Loya, Y. 2004. The coral reefs of Eilat — past, present and future: three decades of coral community structure studies. In: Rosenberg, E., Loya, Y. (Eds.), Coral Reef Health and Disease. Springer, Berlin, p. 396. 
MacDonald, L.H., D.M. Anderson, and W.E. Dietrich. 1997. Paradise threatened: Land use and erosion on St. John, US Virgin Islands. Environmental Management 21:851-863.

Madsen, J.D., P.A. Chambers, W.F. James, E.W. Koch, and D.F. Westlake. 2001. The interaction between water movement, sediment dynamics, and submersed macrophytes. Hydrobiologia 444:71-84.

McManus, J.W. 1997, Tropical marine fisheries and the future of coral reefs: a brief review with emphasis on Southeast Asia. Coral Reefs 16:121-127.

Nemeth, R.S. and J.S. Nowlis. 2001. Monitoring the effects of land development on the near-shore reef environment of St. Thomas, USVI. Bulletin of Marine Science 69(2): 759-775.

Ogston, A.S., C.D. Storlazzi, M.E. Field, and M.K. Presto. 2004. Sediment resuspension and transport patterns on a fringing reef flat, Molokai, Hawaii. Coral Reefs 23:559-569.

Orpin, A.R., G.J. Brunskill, I. Zagorskis, and K.J. Woolfe. 2004. Patterns of mixed siliciclastic-carbonate sedimentation adjacent to a large dry-tropics river on the central Great Barrier Reef shelf, Australia. Australian Journal of Earth Sciences 51:665-683.

Palinkas, C.M., 2013. Seasonal and interannual patterns of sedimentation in the Corsica River (MD): Evaluating the potential influence of watershed restoration. Estuarine, Coastal and Shelf Science 127:37-45.

PIANC Report $N^{\circ}$ 10. 2010. Dredging and Port Construction Around Coral Reefs. The World Association for Waterborne Transport Infrastructure.

Prouty, N.G., C. D. Storlazzi, A.L. McCutcheon, and J.W. Jenson. 2014. Historic impact of watershed change and sedimentation to reefs along west-central Guam. Coral Reefs 33:733-749.

Ramos-Scharrón, C.E., and L.H. MacDonald, 2007a. Measurement and prediction of natural and anthropogenic sediment sources, St. John, U.S. Virgin Islands. Catena 71:250-266.

Ramos-Scharrón, C.E., and L.H. MacDonald, 2007b. Runoff and suspended sediment yields from an unpaved road segment, St John, US Virgin Islands. Hydrological Processes 21:35-50.

Ramos-Scharrón, C.E., S. Atkinson, K. Day, B. Devine, K.R. Munroe, and B. Swanson. 2012. USVI Coastal Habitat Restoration through Watershed Stabilization Project, NOAA-ARRA: 2009-2012 Terrestrial Monitoring Component Final Report. 
Randall, J.E., 1963. An analysis of fish populations of artificial and natural reefs in the Virgin Islands. Caribbean Journal of Science 3(1):31-47.

Ridd, P., G. Day, S. Thomas, J. Harradence, D. Fox, J. Bunt, O. Renagi, and C. Jago. 2001. Measurement of sediment deposition rates using an optical backscatter sensor. Estuarine, Coastal and Shelf Science 52:155-163.

Ridd, P., and P. Larcombe. 1994. Biofouling control for optical backscatter suspended sediment sensors. Marine Geology 116:225-258.

Rogers, C.S., and J. Miller. 2006. Permanent 'phase shifts' or reversible declines incoral cover? Lack of recovery of two coral reefs inSt. John, US Virgin Islands. Marine Ecology Progress Series 306:103-114.

Rogers, C.S. 2009. High diversity and abundance of scleractinian corals growing on and near mangrove prop roots, St. John, US Virgin Islands. Coral Reefs 28:909.

Sears, W. 2015. Factors Affecting Terrigenous Sedimentation in Coastal Bays with Coral Reefs: Implications for Monitoring the Effective of Watershed Restoration. Thesis. University of San Diego.

Storlazzi, C.D., M.E. Field, and M.H. Bothner. 2011. The use (and misuse) of sediment traps in coral reef environments: theory, observations, and suggested protocols. Coral Reefs 30:23-38.

Storlazzi, C.D., A.S. Ogston, M.H. Bothner, M.E. Field, and M.K. Presto. 2004. Wave- and tidally-driven flow and sediment flux across a fringing coral reef: Southern Molokai, Hawaii. Continental Shelf Research 24:1397-1419.

Thomas, S., and P.V. Ridd. 2005. Field assessment of innovative sensor for monitoring of sediment accumulation on inshore coral reefs. Marine Pollution Bulleting 51:470-480.

Thomas, S., and P.V. Ridd. 2004. Review of methods to measure short time scale sediment accumulation. Marine Geology 207:95-114.

Thomas, S., Ridd, P.V., and P.J. Smith. 2002. New instrumentation for sediment dynamics studies. Marine Technology Society 36(1):55-58.

Towle, E., D. Grigg, and W. Rainey. 1976. Marine Environments of the Virgin Islands. Technical Supplement No. 1, Prepared for U.S. Virgin Islands Planning Office, St. Thomas.

T-Rex St. John LLC, and Moravian Church VI Conference, Prepared by McComb, W.F., 2015. Environmental Assessment Report for Sirius Marina Lease Area "A" - Parcel 10A, Estate Emmaus St. John, USVI. 
Woodbury, R.0., and P.L. Weaver. 1987. The vegetation of Saint John and Hassel Island, U.S. Virgin Islands. National Park Service. Research/Resources

Management Report Ser-83

Yates, K.K., C.S. Rogers, J.J. Herlan, G.R. Brooks, N.A. Smiley, and R.A. Larson, 2014. Diverse coral communities in mangrove habitats suggest a novel refuge from climate change. Biogeosciences 11:4321-4377. 


\section{Chapter 4: Conclusion}

Previous studies in St. John have measured marine sedimentation over time scales of months-centuries. However, this is the first study in St. John to monitor turbidity and deposition over shorter time-scales (minutes-days), to isolate contributions to turbidity and deposition from runoff and resuspension, and to directly compare time-integrated sediment trap monitoring to high-resolution nephelometer monitoring.

- Consistent with previous studies, our data show that there was greater turbidity and deposition at shore and reef sites below developed watersheds over short duration (min-days) runoff events, and over longer periods (months) due to high availability of fine easily resuspended sediment.

- Resuspension was associated with above average wave height during low tides and finer benthic sediment, and contributed at least 7 times more to turbidity and 3 times more to deposition than runoff.

o This study of marine sediment dynamics was conducted post restoration, so prior to restoration contributions to turbidity and deposition from runoff may have been greater than this study shows. Unfortunately, we have been able to determine that from our pre and post restoration sediment trap time series because any reductions in contributions to sediment trap accumulation from runoff are lost in the variability of sediment trap accumulation from resuspension. o Watershed restoration may not immediately result in measureable reductions in marine sedimentation. We would not expect to see 
improved water quality until the terrigenous sediment has worked its way out of the system through advection or burial and is no longer available for resuspension.

o A key question is how long it will take for fine sediment to work their way out of the system. Ongoing studies in St. John are using shortlived radio isotopes to determine the residence time of sediment at our shore and reef sites.

- Activities that increase resuspension, such as marina construction related destruction of macrophyte beds and boat prop-wash, could potentially negate improvements from ARRA watershed restoration by remobilizing and resuspending buried sediment.

- While sediment traps are effectively recording relative changes in sedimentation over longer periods, sediment traps cannot record important short time-scale variability, and cannot separate contributions to sediment trap accumulation from runoff vs resuspension.

o This makes it difficult to monitor restoration induced changes in watershed runoff using sediment traps. However, anecdotal evidence suggests there has been a noticeable improvement in water quality following major storms, and preliminary data shows that there have been significant declines in \% terrigenous sediment as well as the $\%$ clay. These findings may indicate that fine terrigenous sediments are being worked out of the system, however, this stage of recovery has yet to be reflected in sediment trap accumulation rates. 
Finally, this study highlights the need for long time-series monitoring using multiple lines of evidence to separate the effects of watershed development and restoration from the natural variability of marine sediment dynamics. 


\section{Appendix}

Appendix A. Data availability of Sediment Traps (and collection/deployment dates), Nephelometers, Crest Gauges, and the stream gauge during the Fall of 2013. *L1-2 deposition sensor saturation during low tides at mid-day. Stipled areas correspond to matching crest gauge runoff $(11 / 2 / 13-11 / 26 / 13)$ and resuspension $(10 / 12 / 13-10 / 23 / 13)$ periods used for inter-site comparison. $* * \mathrm{C}$ 12 deposition sensors used for turbidty measurements from $9 / 11 / 13$ on. $* * * \mathrm{C}-10 \mathrm{~B}$ turbidty data removed from $11 / 26 / 13$ on, and deposition data removed from $12 / 11 / 13$ on. $* * * *$ C -5 deposition sensor saturation during low tides at mid day, deposition sensors used for turbidty measurements from 11/26/13 on. Due to intermentent neph deployment, data from Y-1 and L1-2 were not used for some analyses.

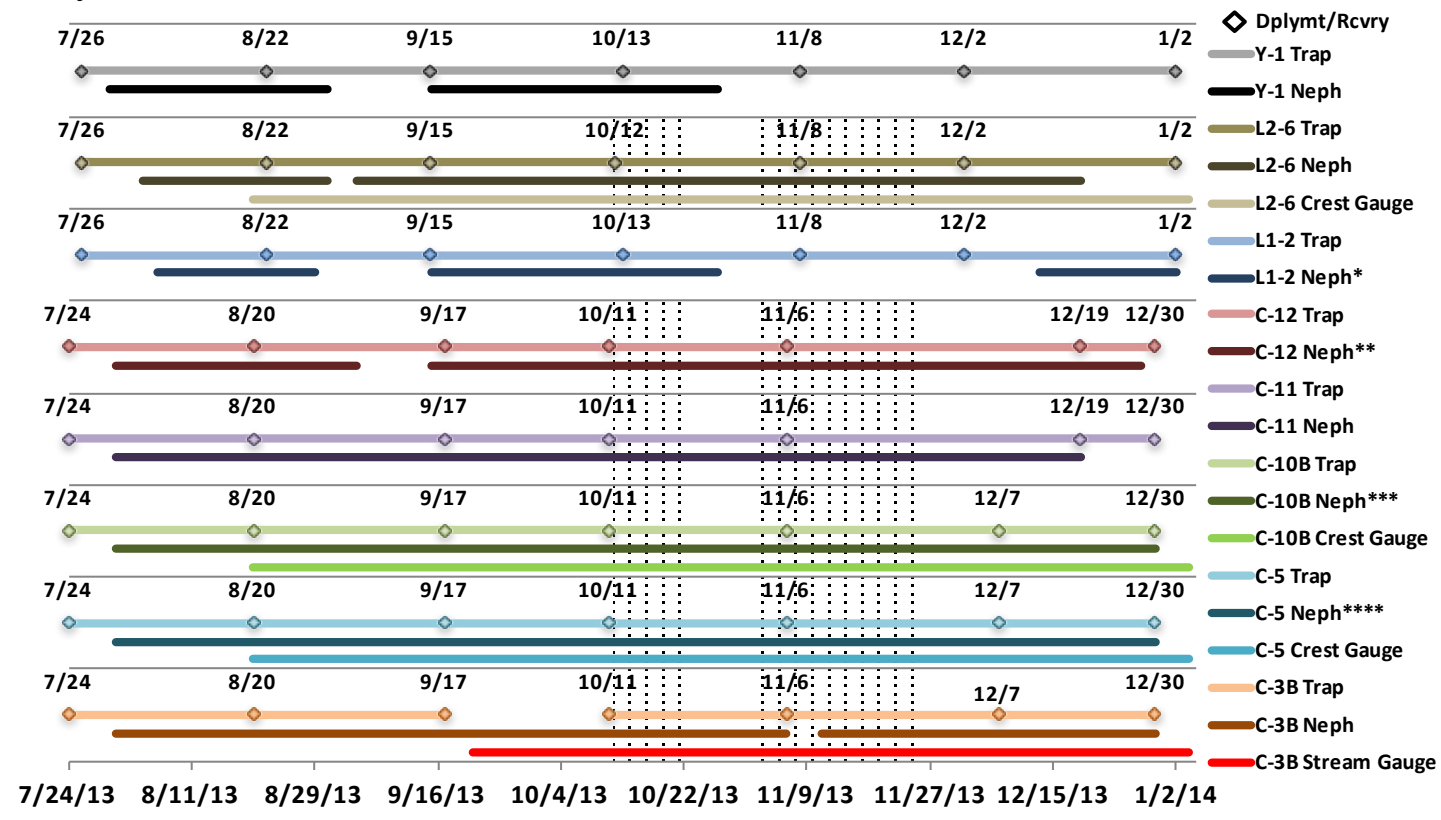


Appendix B. Deployment intervals, time averaged nephelometer turbidity and deposition values, variance and range of turbidity and deposition values, and sediment trap accumulate rates at each site during the Fall of 2013

\begin{tabular}{|c|c|c|c|c|c|c|c|c|c|}
\hline \multirow[b]{2}{*}{ Site } & \multirow[b]{2}{*}{$\begin{array}{c}\text { Deployment } \\
\text { Date }\end{array}$} & \multirow[b]{2}{*}{$\begin{array}{c}\text { Recovery } \\
\text { Date }\end{array}$} & \multicolumn{4}{|c|}{ Nephelometer } & \multirow[b]{2}{*}{$\begin{array}{c}\text { Deposition } \\
\text { Variance }\end{array}$} & \multirow[b]{2}{*}{$\begin{array}{c}\text { Deposition } \\
\text { Range }\end{array}$} & \multirow{2}{*}{$\begin{array}{c}\text { Sediment Trap } \\
\text { Accumulation } \\
\text { Rate } \\
\left(\mathrm{mg} / \mathrm{cm}^{2} / \mathrm{day}\right)\end{array}$} \\
\hline & & & $\begin{array}{c}\text { Average } \\
\text { Turbidity } \\
\text { (mg/L) }\end{array}$ & $\begin{array}{l}\text { Turbidity } \\
\text { Variance }\end{array}$ & $\begin{array}{c}\text { Turbidity } \\
\text { Range }\end{array}$ & $\begin{array}{c}\text { Average } \\
\text { Deposition } \\
(\mathrm{mg} / \mathrm{cm} 2)\end{array}$ & & & \\
\hline \multirow{6}{*}{ क्ष } & $7 / 24 / 13$ & $8 / 20 / 13$ & 1.73 & 1.47 & 10.32 & 0.03 & 0.004 & 0.77 & 28.84 \\
\hline & $8 / 20 / 13$ & 9/17/13 & 1.16 & 0.70 & 8.35 & 0.15 & 0.24 & 18.79 & 10.20 \\
\hline & $9 / 17 / 13$ & $10 / 11 / 13$ & 0.88 & 0.54 & 15.62 & 0.05 & 0.04 & 5.80 & \\
\hline & $10 / 11 / 13$ & $11 / 6 / 13$ & 2.62 & 16.55 & 67.47 & 0.07 & 0.62 & 36.65 & 50.99 \\
\hline & $11 / 6 / 13$ & $12 / 7 / 13$ & 5.84 & 214.06 & 553.21 & 0.17 & 14.60 & 140.98 & 143.54 \\
\hline & $12 / 7 / 13$ & $12 / 30 / 13$ & 13.53 & 228.88 & 163.42 & 1.31 & 68.41 & 162.25 & 415.79 \\
\hline \multirow{6}{*}{ 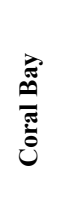 } & $7 / 24 / 13$ & $8 / 20 / 13$ & 8.00 & 19.79 & 53.00 & 0.07 & 0.02 & 3.47 & 8.28 \\
\hline & $8 / 20 / 13$ & $9 / 17 / 13$ & 7.61 & 13.87 & 44.48 & 0.10 & 0.07 & 4.23 & 6.95 \\
\hline & $9 / 17 / 13$ & $10 / 11 / 13$ & 7.75 & 107.42 & 176.54 & 0.28 & 0.44 & 5.95 & 8.18 \\
\hline & $10 / 11 / 13$ & $11 / 6 / 13$ & 9.59 & 103.33 & 163.44 & 0.34 & 0.62 & 5.88 & 18.72 \\
\hline & $11 / 6 / 13$ & $12 / 7 / 13$ & 28.53 & 2372.39 & 488.66 & 0.69 & 3.65 & 95.16 & 20.22 \\
\hline & $12 / 7 / 13$ & $12 / 30 / 13$ & 19.30 & 337.77 & 222.12 & 0.18 & 0.12 & 3.14 & 13.74 \\
\hline \multirow{5}{*}{ 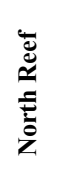 } & $7 / 24 / 13$ & $8 / 20 / 13$ & 1.59 & 0.83 & 7.84 & 0.04 & 0.01 & 2.11 & 5.20 \\
\hline & $8 / 20 / 13$ & $9 / 17 / 13$ & 0.99 & 0.39 & 5.17 & 0.03 & 0.02 & 3.00 & 2.52 \\
\hline & $9 / 17 / 13$ & $10 / 11 / 13$ & 0.97 & 0.33 & 4.84 & 0.03 & 0.04 & 7.67 & 2.88 \\
\hline & $10 / 11 / 13$ & $11 / 6 / 13$ & 1.60 & 0.93 & 15.22 & 0.04 & 0.01 & 7.67 & 7.32 \\
\hline & $11 / 6 / 13$ & $12 / 19 / 13$ & 1.99 & 2.18 & 20.13 & 0.19 & 0.16 & 8.68 & 12.64 \\
\hline \multirow{5}{*}{ 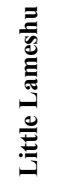 } & $7 / 26 / 13^{\square}$ & $8 / 22 / 13$ & 0.58 & 0.49 & 5.64 & 0.38 & 1.19 & 8.71 & 1.49 \\
\hline & $8 / 22 / 13$ & $9 / 15 / 13^{\square}$ & 0.15 & 0.03 & 4.65 & 0.22 & 0.54 & 8.33 & 1.26 \\
\hline & 9/15/13 & 10/13/13 & 0.24 & 0.03 & 3.44 & 0.05 & 0.09 & 10.60 & 1.14 \\
\hline & $10 / 13 / 13$ & $11 / 8 / 13$ & 0.64 & 0.21 & 4.52 & 0.10 & 0.13 & 11.50 & 2.15 \\
\hline & $11 / 8 / 13$ & $12 / 2 / 13$ & 2.00 & 7.29 & 33.94 & 2.29 & 29.34 & 51.08 & 3.28 \\
\hline \multirow{6}{*}{ 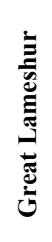 } & $7 / 26 / 13$ & $8 / 22 / 13$ & 0.98 & 3.86 & 39.58 & 0.02 & 0.00 & 0.98 & 3.35 \\
\hline & $8 / 22 / 13$ & $9 / 15 / 13^{\wedge}$ & 0.87 & 3.67 & 38.87 & 0.05 & 0.09 & 4.35 & 2.76 \\
\hline & $9 / 15 / 13$ & $10 / 13 / 13$ & 0.86 & 1.33 & 41.49 & 0.03 & 0.01 & 2.93 & 4.20 \\
\hline & $10 / 13 / 13$ & $11 / 8 / 213$ & 1.04 & 0.93 & 11.77 & 0.03 & 0.02 & 2.10 & 5.49 \\
\hline & $11 / 8 / 13$ & $12 / 2 / 13$ & & & & & & & 8.98 \\
\hline & $12 / 2 / 13 \bullet$ & $1 / 2 / 14$ & 2.83 & 1.05 & 13.24 & 0.30 & 0.33 & 6.03 & 6.81 \\
\hline \multicolumn{10}{|c|}{ neph data starts $8 / 6 / 13$} \\
\hline \multicolumn{10}{|c|}{ neph data ends $8 / 31 / 13$} \\
\hline \multicolumn{10}{|c|}{ neph data stars $8 / 6 / 13$} \\
\hline \multicolumn{10}{|c|}{$\Delta$ neph data ends $8 / 31 / 13$} \\
\hline \multicolumn{10}{|c|}{ - neph data ends $10 / 27 / 13$} \\
\hline \multicolumn{10}{|c|}{ - neph data starts $12 / 13 / 17$} \\
\hline
\end{tabular}


Appendix C. Timing, total duration, max stage height, mean stage height, and total rainfall during runoff events of the Fall 2013 rainy season. *no rain data available

\begin{tabular}{|c|c|c|c|c|c|}
\hline $\begin{array}{l}\text { Date-Time } \\
\text { (Begin) }\end{array}$ & $\begin{array}{l}\text { Date-Time } \\
\quad \text { (End) }\end{array}$ & $\begin{array}{c}\text { Duration } \\
\text { (hours) }\end{array}$ & $\begin{array}{c}\text { Max } \\
\text { Stage (m) }\end{array}$ & $\begin{array}{c}\text { Mean } \\
\text { Stage }(m)\end{array}$ & $\begin{array}{c}\text { Rainfall } \\
\text { During Runoff } \\
\text { Event }(\mathbf{m m}) \\
\end{array}$ \\
\hline 10/5/13 1:13 & $10 / 5 / 131: 33$ & 0.33 & 0.17 & 0.10 & $*$ \\
\hline 10/9/13 20:43 & $10 / 9 / 1322: 33$ & 1.83 & 0.21 & 0.11 & $*$ \\
\hline $10 / 10 / 137: 23$ & 10/10/13 8:33 & 1.17 & 0.28 & 0.11 & $*$ \\
\hline 10/29/13 3:03 & $10 / 29 / 133: 53$ & 0.83 & 0.21 & 0.12 & 18.2 \\
\hline 11/1/13 1:43 & $11 / 1 / 132: 13$ & 0.50 & 0.10 & 0.09 & 3.4 \\
\hline $11 / 2 / 137: 53$ & 11/2/13 10:33 & 2.67 & 0.17 & 0.12 & 8.8 \\
\hline $11 / 2 / 1313: 53$ & 11/2/13 21:03 & 7.17 & 0.24 & 0.07 & 18.6 \\
\hline $11 / 2 / 1321: 43$ & $11 / 3 / 136: 33$ & 8.83 & 0.17 & 0.04 & 15.2 \\
\hline $11 / 3 / 13$ 7:23 & 11/4/13 1:03 & 17.67 & 0.31 & 0.07 & 19.8 \\
\hline $11 / 4 / 131: 33$ & 11/5/13 0:03 & 22.50 & 0.38 & 0.09 & 29.2 \\
\hline $11 / 6 / 1310: 33$ & $11 / 6 / 13$ 18:23 & 7.83 & 0.24 & 0.04 & 14.0 \\
\hline 11/21/13 3:03 & $11 / 21 / 1323: 43$ & 20.67 & 0.73 & 0.17 & 86.4 \\
\hline 11/25/13 9:13 & $11 / 25 / 139: 43$ & 0.50 & 0.07 & 0.04 & 2.8 \\
\hline $11 / 28 / 13$ 7:03 & $11 / 28 / 137: 33$ & 0.50 & 0.07 & 0.04 & 2.8 \\
\hline 11/29/13 8:13 & $11 / 29 / 1310: 43$ & 2.50 & 0.10 & 0.06 & 6.0 \\
\hline $11 / 30 / 135: 33$ & $11 / 30 / 13$ 7:43 & 2.17 & 0.10 & 0.04 & 3.8 \\
\hline $11 / 30 / 1318: 23$ & $12 / 1 / 1322: 33$ & 28.17 & 0.38 & 0.14 & 43.6 \\
\hline $12 / 3 / 1313: 53$ & $12 / 3 / 13 \quad 14: 33$ & 0.67 & 0.14 & 0.08 & 5.2 \\
\hline $12 / 5 / 136: 23$ & $12 / 6 / 137: 43$ & 25.33 & 0.24 & 0.07 & 13.4 \\
\hline $12 / 8 / 134: 53$ & $12 / 8 / 135: 23$ & 0.50 & 0.14 & 0.09 & 8.0 \\
\hline $12 / 24 / 1316: 13$ & $12 / 24 / 1321: 23$ & 5.17 & 0.38 & 0.10 & 39.6 \\
\hline
\end{tabular}


Appendix D. Location, water depth, environment, watershed classification, and runoff monitoring instruments at each monitoring site

\begin{tabular}{|c|c|c|c|c|c|c|c|}
\hline Site Name & Site ID & Latitude & Longitude & $\begin{array}{c}\text { Water } \\
\text { Depth (m) }\end{array}$ & Environment & $\begin{array}{c}\text { Watershed } \\
\text { Classification } \\
\end{array}$ & $\begin{array}{c}\text { Runoff } \\
\text { Monitoring }\end{array}$ \\
\hline Coral Bay & $\mathrm{C}-5$ & 18.34658 & -64.71415 & 0.6 & Shore & Developed & Crest Gauge \\
\hline Sanders Bay & $\mathrm{C}-10 \mathrm{~B}$ & 18.33645 & -64.71222 & 1.3 & Shore & $\begin{array}{l}\text { Minimally } \\
\text { Developed }\end{array}$ & Crest Gauge \\
\hline Shipwreck & C-3B & 18.33025 & -64.70707 & 1.6 & Shore & Developed & Stream Gauge \\
\hline North Reef & $\mathrm{C}-11$ & 18.33797 & -64.70402 & 11 & Reef & Developed & NA \\
\hline South Reef & $\mathrm{C}-12$ & 18.33363 & -64.70120 & 7 & Reef & Developed & NA \\
\hline Little Lameshur & L2-6 & 18.31910 & -64.72802 & 1.4 & Shore & $\begin{array}{l}\text { Minimally } \\
\text { Developed }\end{array}$ & Crest Gauge \\
\hline Great Lameshur & L1-2 & 18.31872 & -64.72413 & 1.7 & Shore & $\begin{array}{l}\text { Minimally } \\
\text { Developed }\end{array}$ & Crest Gauge \\
\hline Yawzi & Y-1 & 18.31517 & -64.72520 & 6.1 & Reef & $\begin{array}{l}\text { Minimally } \\
\text { Developed }\end{array}$ & NA \\
\hline
\end{tabular}


Appendix E. $\%$ of benthic sediment $<63 \mu \mathrm{m}$ (silt+clay) at each site during each collection/deployment

\begin{tabular}{|c|c|c|c|c|c|c|c|c|c|}
\hline \multicolumn{2}{|c|}{ Collection Dates } & \multicolumn{5}{|c|}{ Coral Bay Sites $(\%<63 \mu m)$} & \multicolumn{3}{|c|}{ Lameshur Bay Sites $(\%<63 \mu \mathrm{m})$} \\
\hline $\begin{array}{c}\text { Lameshur } \\
\text { Bays }\end{array}$ & Coral Bay & $\begin{array}{c}\text { Coral } \\
\text { Bay } \\
(\mathrm{C}-5)\end{array}$ & $\begin{array}{c}\text { Shipwreck } \\
\text { (C-3B) }\end{array}$ & $\begin{array}{l}\text { Sanders } \\
\text { Bay } \\
\text { (C-10B) }\end{array}$ & $\begin{array}{l}\text { North } \\
\text { Reef } \\
(\mathrm{C}-11)\end{array}$ & $\begin{array}{l}\text { South } \\
\text { Reef } \\
(\mathrm{C}-12)\end{array}$ & $\begin{array}{c}\text { Little } \\
\text { Lameshur } \\
\text { (L2-6) }\end{array}$ & $\begin{array}{c}\text { Great } \\
\text { Lameshur } \\
(\text { L1-2) }\end{array}$ & $\begin{array}{l}\text { Yawzi } \\
(\mathrm{Y}-1)\end{array}$ \\
\hline $8 / 22 / 13$ & $8 / 20 / 13$ & 29.3 & 15.8 & 25.9 & 15.5 & 5.6 & 15.5 & 25.5 & 2.9 \\
\hline $9 / 15 / 13$ & $9 / 17 / 13$ & 32.0 & 10.6 & 19.0 & 15.6 & 4.5 & 8.6 & 13.2 & 4.3 \\
\hline $10 / 13 / 13$ & $10 / 11 / 13$ & 37.3 & 12.7 & 37.3 & 15.9 & 1.8 & 5.7 & 63.6 & 6.5 \\
\hline $11 / 8 / 13$ & $11 / 6 / 13$ & 43.0 & 14.1 & 11.3 & 17.7 & 5.3 & 6.1 & 21.8 & 2.3 \\
\hline $12 / 2 / 13$ & $* 12 / 7 / 13$ & 35.9 & 10.9 & 17.2 & 17.9 & 1.2 & 3.3 & 14.7 & 3.4 \\
\hline $1 / 2 / 14$ & $12 / 30 / 13$ & 42.6 & 20.9 & 14.0 & 5.6 & & 4.2 & 7.7 & 4.0 \\
\hline & Average: & 36.7 & 14.2 & 20.8 & 14.7 & 3.7 & 7.2 & 24.4 & 3.9 \\
\hline
\end{tabular}


Appendix F. Crest gauge periods with and without runoff

*Brown bold font indicates dates when crest gauges in Coral Bay were checked, green bold font indicate dates when the Lameshur crest gauge was checked

Runoff Period? Yes(y)/No(n)

\begin{tabular}{|c|c|c|c|c|}
\hline Date* & $\begin{array}{c}\text { Shipwreck } \\
\text { (C-3B) }\end{array}$ & $\begin{array}{l}\text { Coral Bay } \\
\text { (C-5) }\end{array}$ & $\begin{array}{l}\text { Sanders Bay } \\
\quad(\mathrm{C}-10 \mathrm{~B})\end{array}$ & $\begin{array}{c}\text { Little Lameshur } \\
\text { (L2-6) }\end{array}$ \\
\hline $8 / 20 / 13$ & $\mathrm{y}$ & $\mathrm{n}$ & $\mathrm{y}$ & $\mathrm{y}$ \\
\hline $8 / 21 / 13$ & $\mathrm{y}$ & $\mathrm{n}$ & $\mathrm{n}$ & $\mathrm{y}$ \\
\hline $8 / 22 / 13$ & $\mathrm{y}$ & $\mathrm{n}$ & $\mathrm{n}$ & $\mathrm{y}$ \\
\hline $8 / 23 / 13$ & $\mathrm{y}$ & $\mathrm{n}$ & $\mathrm{n}$ & $\mathrm{y}$ \\
\hline $8 / 24 / 13$ & $\mathrm{y}$ & $\mathrm{n}$ & $\mathrm{n}$ & $\mathrm{y}$ \\
\hline $8 / 25 / 13$ & $\mathrm{y}$ & $\mathrm{n}$ & $\mathrm{n}$ & $\mathrm{y}$ \\
\hline $8 / 26 / 13$ & $\mathrm{y}$ & $\mathrm{n}$ & $\mathrm{n}$ & $\mathrm{y}$ \\
\hline $8 / 27 / 13$ & $\mathrm{y}$ & $\mathrm{n}$ & $\mathrm{n}$ & $\mathrm{y}$ \\
\hline $8 / 28 / 13$ & $\mathrm{y}$ & $\mathrm{n}$ & $\mathrm{n}$ & $\mathrm{y}$ \\
\hline $8 / 29 / 13$ & $\mathrm{y}$ & $\mathrm{n}$ & $\mathrm{n}$ & $\mathrm{y}$ \\
\hline $8 / 30 / 13$ & $\mathrm{n}$ & $\mathrm{n}$ & $\mathrm{n}$ & $\mathrm{y}$ \\
\hline $8 / 31 / 13$ & $\mathrm{n}$ & $\mathrm{n}$ & $\mathrm{n}$ & $\mathrm{y}$ \\
\hline $9 / 1 / 13$ & $\mathrm{n}$ & $\mathrm{n}$ & $\mathrm{n}$ & $\mathrm{y}$ \\
\hline $9 / 2 / 13$ & $\mathrm{n}$ & $\mathrm{n}$ & $\mathrm{n}$ & $\mathrm{y}$ \\
\hline $9 / 3 / 13$ & $\mathrm{y}$ & $\mathrm{n}$ & $\mathrm{y}$ & $\mathrm{y}$ \\
\hline $9 / 4 / 13$ & $\mathrm{y}$ & $\mathrm{n}$ & $\mathrm{y}$ & $\mathrm{y}$ \\
\hline $9 / 5 / 13$ & $\mathrm{y}$ & $\mathrm{n}$ & $\mathrm{y}$ & $\mathrm{y}$ \\
\hline $9 / 6 / 13$ & $\mathrm{y}$ & $\mathrm{n}$ & $\mathrm{y}$ & $\mathrm{y}$ \\
\hline $9 / 7 / 13$ & $\mathrm{y}$ & $\mathrm{n}$ & $\mathrm{y}$ & $\mathrm{y}$ \\
\hline $9 / 8 / 13$ & $\mathrm{y}$ & $\mathrm{n}$ & $\mathrm{y}$ & $\mathrm{y}$ \\
\hline $9 / 9 / 13$ & $\mathrm{y}$ & $\mathrm{n}$ & $\mathrm{y}$ & $\mathrm{y}$ \\
\hline $9 / 10 / 13$ & $\mathrm{y}$ & $\mathrm{n}$ & $\mathrm{y}$ & $\mathrm{y}$ \\
\hline $9 / 11 / 13$ & $\mathrm{y}$ & $\mathrm{n}$ & $\mathrm{y}$ & $\mathrm{y}$ \\
\hline $9 / 12 / 13$ & $\mathrm{y}$ & $\mathrm{n}$ & $\mathrm{y}$ & $\mathrm{y}$ \\
\hline $9 / 13 / 13$ & $\mathrm{y}$ & $\mathrm{n}$ & $\mathrm{y}$ & $\mathrm{y}$ \\
\hline $9 / 14 / 13$ & $\mathrm{y}$ & $\mathrm{n}$ & $\mathrm{y}$ & $\mathrm{y}$ \\
\hline $9 / 15 / 13$ & $\mathrm{y}$ & $\mathrm{n}$ & $\mathrm{y}$ & $\mathrm{y}$ \\
\hline $9 / 16 / 13$ & $\mathrm{y}$ & $\mathrm{n}$ & $\mathrm{y}$ & $\mathrm{y}$ \\
\hline $9 / 17 / 13$ & $\mathrm{y}$ & $\mathrm{n}$ & $\mathrm{y}$ & $\mathrm{y}$ \\
\hline $9 / 18 / 13$ & $\mathrm{y}$ & $\mathrm{n}$ & $\mathrm{y}$ & $\mathrm{y}$ \\
\hline 9/19/13 & $\mathrm{y}$ & $\mathrm{n}$ & $\mathrm{y}$ & $\mathrm{y}$ \\
\hline $9 / 20 / 13$ & $\mathrm{y}$ & $\mathrm{n}$ & $\mathrm{y}$ & $\mathrm{n}$ \\
\hline $9 / 21 / 13$ & $\mathrm{y}$ & $\mathrm{n}$ & $\mathrm{y}$ & $\mathrm{n}$ \\
\hline $9 / 22 / 13$ & $\mathrm{y}$ & $\mathrm{n}$ & $\mathrm{y}$ & $\mathrm{n}$ \\
\hline
\end{tabular}


Runoff Period? Yes(y)/No(n)

\begin{tabular}{|c|c|c|c|c|}
\hline Date* & $\begin{array}{c}\text { Shipwreck } \\
\text { (C-3B) }\end{array}$ & $\begin{array}{l}\text { Coral Bay } \\
\text { (C-5) }\end{array}$ & $\begin{array}{l}\text { Sanders Bay } \\
\quad(\mathrm{C}-10 \mathrm{~B})\end{array}$ & $\begin{array}{c}\text { Little Lameshur } \\
\text { (L2-6) }\end{array}$ \\
\hline $9 / 23 / 13$ & $\mathrm{y}$ & $\mathrm{n}$ & $\mathrm{y}$ & $\mathrm{n}$ \\
\hline $9 / 24 / 13$ & $\mathrm{y}$ & $\mathrm{n}$ & $\mathrm{y}$ & $\mathrm{n}$ \\
\hline $9 / 25 / 13$ & $\mathrm{y}$ & $\mathrm{n}$ & $\mathrm{y}$ & $\mathrm{n}$ \\
\hline $9 / 26 / 13$ & $\mathrm{y}$ & $\mathrm{n}$ & $\mathrm{y}$ & $\mathrm{n}$ \\
\hline $9 / 27 / 13$ & $\mathrm{y}$ & $\mathrm{n}$ & $\mathrm{y}$ & $\mathrm{n}$ \\
\hline $9 / 28 / 13$ & $\mathrm{y}$ & $\mathrm{n}$ & $\mathrm{y}$ & $\mathrm{n}$ \\
\hline $9 / 29 / 13$ & $\mathrm{y}$ & $\mathrm{n}$ & $\mathrm{y}$ & $\mathrm{n}$ \\
\hline $9 / 30 / 13$ & $\mathrm{y}$ & $\mathrm{n}$ & $\mathrm{y}$ & $\mathrm{n}$ \\
\hline $10 / 1 / 13$ & $\mathrm{y}$ & $\mathrm{n}$ & $\mathrm{y}$ & $\mathrm{n}$ \\
\hline $10 / 2 / 13$ & $\mathrm{y}$ & $\mathrm{n}$ & $\mathrm{y}$ & $\mathrm{n}$ \\
\hline $10 / 3 / 13$ & $\mathrm{y}$ & $\mathrm{n}$ & $\mathrm{y}$ & $\mathrm{n}$ \\
\hline $10 / 4 / 13$ & $\mathrm{y}$ & $\mathrm{n}$ & $\mathrm{y}$ & $\mathrm{n}$ \\
\hline $10 / 5 / 13$ & $\mathrm{y}$ & $\mathrm{n}$ & $\mathrm{y}$ & $\mathrm{n}$ \\
\hline $10 / 6 / 13$ & $\mathrm{y}$ & $\mathrm{n}$ & $\mathrm{y}$ & $\mathrm{n}$ \\
\hline $10 / 7 / 13$ & $\mathrm{y}$ & $\mathrm{n}$ & $\mathrm{y}$ & $\mathrm{n}$ \\
\hline $10 / 8 / 13$ & $\mathrm{y}$ & $\mathrm{n}$ & $\mathrm{y}$ & $\mathrm{n}$ \\
\hline $10 / 9 / 13$ & $\mathrm{y}$ & $\mathrm{n}$ & $\mathrm{y}$ & $\mathrm{n}$ \\
\hline $10 / 10 / 13$ & $\mathrm{y}$ & $\mathrm{n}$ & $\mathrm{y}$ & $\mathrm{n}$ \\
\hline $10 / 11 / 13$ & $\mathrm{y}$ & $\mathrm{n}$ & $\mathrm{y}$ & $\mathrm{n}$ \\
\hline $10 / 12 / 13$ & $\mathrm{n}$ & $\mathrm{n}$ & $\mathrm{n}$ & $\mathrm{n}$ \\
\hline $10 / 13 / 13$ & $\mathrm{n}$ & $\mathrm{n}$ & $\mathrm{n}$ & $\mathrm{n}$ \\
\hline $10 / 14 / 13$ & $\mathrm{n}$ & $\mathrm{n}$ & $\mathrm{n}$ & $\mathrm{n}$ \\
\hline $10 / 15 / 13$ & $\mathrm{n}$ & $\mathrm{n}$ & $\mathrm{n}$ & $\mathrm{n}$ \\
\hline $10 / 16 / 13$ & $\mathrm{n}$ & $\mathrm{n}$ & $\mathrm{n}$ & $\mathrm{n}$ \\
\hline $10 / 17 / 13$ & $\mathrm{n}$ & $\mathrm{n}$ & $\mathrm{n}$ & $\mathrm{n}$ \\
\hline $10 / 18 / 13$ & $\mathrm{n}$ & $\mathrm{n}$ & $\mathrm{n}$ & $\mathrm{n}$ \\
\hline $10 / 19 / 13$ & $\mathrm{n}$ & $\mathrm{n}$ & $\mathrm{n}$ & $\mathrm{n}$ \\
\hline $10 / 20 / 13$ & $\mathrm{n}$ & $\mathrm{n}$ & $\mathrm{n}$ & $\mathrm{n}$ \\
\hline $10 / 21 / 13$ & $\mathrm{n}$ & $\mathrm{n}$ & $\mathrm{n}$ & $\mathrm{n}$ \\
\hline $10 / 22 / 13$ & $\mathrm{n}$ & $\mathrm{n}$ & $\mathrm{n}$ & $\mathrm{n}$ \\
\hline $10 / 23 / 13$ & $\mathrm{n}$ & $\mathrm{n}$ & $\mathrm{n}$ & $\mathrm{n}$ \\
\hline $10 / 24 / 13$ & $\mathrm{n}$ & $\mathrm{n}$ & $\mathrm{n}$ & $\mathrm{y}$ \\
\hline $10 / 25 / 13$ & $\mathrm{y}$ & $\mathrm{n}$ & $\mathrm{n}$ & $\mathrm{y}$ \\
\hline $10 / 26 / 13$ & $\mathrm{y}$ & $\mathrm{n}$ & $\mathrm{n}$ & $\mathrm{y}$ \\
\hline $10 / 27 / 13$ & $\mathrm{y}$ & $\mathrm{n}$ & $\mathrm{n}$ & $\mathrm{y}$ \\
\hline $10 / 28 / 13$ & $\mathrm{y}$ & $\mathrm{n}$ & $\mathrm{n}$ & $\mathrm{y}$ \\
\hline $10 / 29 / 13$ & $\mathrm{y}$ & $\mathrm{n}$ & $\mathrm{n}$ & $\mathrm{y}$ \\
\hline
\end{tabular}


Runoff Period? Yes(y)/No(n)

\begin{tabular}{|c|c|c|c|c|}
\hline Date* & $\begin{array}{c}\text { Shipwreck } \\
\text { (C-3B) }\end{array}$ & $\begin{array}{c}\text { Coral Bay } \\
\text { (C-5) }\end{array}$ & $\begin{array}{c}\text { Sanders Bay } \\
\text { (C-10B) }\end{array}$ & $\begin{array}{l}\text { Little Lameshur } \\
\text { (L2-6) }\end{array}$ \\
\hline $10 / 30 / 13$ & $\mathrm{y}$ & $\mathrm{n}$ & $\mathrm{n}$ & $\mathrm{y}$ \\
\hline $10 / 31 / 13$ & $\mathrm{y}$ & $\mathrm{n}$ & $\mathrm{n}$ & $\mathrm{y}$ \\
\hline $11 / 1 / 13$ & $\mathrm{y}$ & $\mathrm{n}$ & $\mathrm{n}$ & $\mathrm{y}$ \\
\hline $11 / 2 / 13$ & $\mathrm{y}$ & $\mathrm{y}$ & $\mathrm{y}$ & $\mathrm{y}$ \\
\hline $11 / 3 / 13$ & $\mathrm{y}$ & $\mathrm{y}$ & $\mathrm{y}$ & $\mathrm{y}$ \\
\hline $11 / 4 / 13$ & $\mathrm{y}$ & $\mathrm{y}$ & $\mathrm{y}$ & $\mathrm{y}$ \\
\hline $11 / 5 / 13$ & $\mathrm{y}$ & $\mathrm{y}$ & $\mathrm{y}$ & $\mathrm{y}$ \\
\hline $11 / 6 / 13$ & $\mathrm{y}$ & $\mathrm{y}$ & $\mathrm{y}$ & $\mathrm{y}$ \\
\hline $11 / 7 / 13$ & $\mathrm{y}$ & $\mathrm{y}$ & $\mathrm{y}$ & $\mathrm{y}$ \\
\hline $11 / 8 / 13$ & $\mathrm{y}$ & $\mathrm{y}$ & $\mathrm{y}$ & $\mathrm{y}$ \\
\hline $11 / 9 / 13$ & $\mathrm{y}$ & $\mathrm{y}$ & $\mathrm{y}$ & $\mathrm{y}$ \\
\hline $11 / 10 / 13$ & $\mathrm{y}$ & $\mathrm{y}$ & $\mathrm{y}$ & $\mathrm{y}$ \\
\hline $11 / 11 / 13$ & $\mathrm{y}$ & $\mathrm{y}$ & $\mathrm{y}$ & $\mathrm{y}$ \\
\hline $11 / 12 / 13$ & $\mathrm{y}$ & $\mathrm{y}$ & $\mathrm{y}$ & $\mathrm{y}$ \\
\hline $11 / 13 / 13$ & $\mathrm{y}$ & $\mathrm{y}$ & $\mathrm{y}$ & $\mathrm{y}$ \\
\hline $11 / 14 / 13$ & $\mathrm{y}$ & $\mathrm{y}$ & $\mathrm{y}$ & $\mathrm{y}$ \\
\hline $11 / 15 / 13$ & $\mathrm{y}$ & $\mathrm{y}$ & $\mathrm{y}$ & $\mathrm{y}$ \\
\hline $11 / 16 / 13$ & $\mathrm{y}$ & $\mathrm{y}$ & $\mathrm{y}$ & $\mathrm{y}$ \\
\hline $11 / 17 / 13$ & $\mathrm{y}$ & $\mathrm{y}$ & $\mathrm{y}$ & $\mathrm{y}$ \\
\hline $11 / 18 / 13$ & $\mathrm{y}$ & $\mathrm{y}$ & $\mathrm{y}$ & $\mathrm{y}$ \\
\hline $11 / 19 / 13$ & $\mathrm{y}$ & $\mathrm{y}$ & $\mathrm{y}$ & $\mathrm{y}$ \\
\hline $11 / 20 / 13$ & $\mathrm{y}$ & $\mathrm{y}$ & $\mathrm{y}$ & $\mathrm{y}$ \\
\hline $11 / 21 / 13$ & $\mathrm{y}$ & $\mathrm{y}$ & $\mathrm{y}$ & $\mathrm{y}$ \\
\hline $11 / 22 / 13$ & $\mathrm{y}$ & $\mathrm{y}$ & $\mathrm{y}$ & $\mathrm{y}$ \\
\hline $11 / 23 / 13$ & $\mathrm{y}$ & $\mathrm{y}$ & $\mathrm{y}$ & $\mathrm{y}$ \\
\hline $11 / 24 / 13$ & $\mathrm{y}$ & $\mathrm{y}$ & $\mathrm{y}$ & $\mathrm{y}$ \\
\hline $11 / 25 / 13$ & $\mathrm{y}$ & $\mathrm{y}$ & $\mathrm{y}$ & $\mathrm{y}$ \\
\hline $11 / 26 / 13$ & $\mathrm{y}$ & $\mathrm{y}$ & $\mathrm{y}$ & $\mathrm{y}$ \\
\hline $11 / 27 / 13$ & $\mathrm{y}$ & $\mathrm{y}$ & $\mathrm{y}$ & $\mathrm{y}$ \\
\hline $11 / 28 / 13$ & $\mathrm{y}$ & $\mathrm{y}$ & $\mathrm{y}$ & $\mathrm{y}$ \\
\hline $11 / 29 / 13$ & $\mathrm{y}$ & $\mathrm{y}$ & $\mathrm{y}$ & $\mathrm{y}$ \\
\hline $11 / 30 / 13$ & $\mathrm{y}$ & $\mathrm{y}$ & $\mathrm{y}$ & $\mathrm{y}$ \\
\hline $12 / 1 / 13$ & $\mathrm{y}$ & $\mathrm{y}$ & $\mathrm{y}$ & $\mathrm{y}$ \\
\hline $12 / 2 / 13$ & $\mathrm{y}$ & $\mathrm{y}$ & $\mathrm{y}$ & $\mathrm{y}$ \\
\hline $12 / 3 / 13$ & $\mathrm{y}$ & $\mathrm{n}$ & $\mathrm{n}$ & $\mathrm{y}$ \\
\hline $12 / 4 / 13$ & $\mathrm{y}$ & $\mathrm{n}$ & $\mathrm{n}$ & $\mathrm{y}$ \\
\hline $12 / 5 / 13$ & $\mathrm{y}$ & $\mathrm{n}$ & $\mathrm{n}$ & $\mathrm{y}$ \\
\hline
\end{tabular}


Runoff Period? Yes(y)/No(n)

\begin{tabular}{|c|c|c|c|c|}
\hline Date* & $\begin{array}{c}\text { Shipwreck } \\
\text { (C-3B) }\end{array}$ & $\begin{array}{c}\text { Coral Bay } \\
\text { (C-5) }\end{array}$ & $\begin{array}{c}\text { Sanders Bay } \\
\quad(\mathrm{C}-10 \mathrm{~B})\end{array}$ & $\begin{array}{l}\text { Little Lameshur } \\
\text { (L2-6) }\end{array}$ \\
\hline $12 / 6 / 13$ & $\mathrm{y}$ & $\mathrm{n}$ & $\mathrm{n}$ & $\mathrm{y}$ \\
\hline $12 / 7 / 13$ & $\mathrm{y}$ & $\mathrm{n}$ & $\mathrm{n}$ & $\mathrm{y}$ \\
\hline $12 / 8 / 13$ & $\mathrm{y}$ & $\mathrm{n}$ & $\mathrm{n}$ & $\mathrm{y}$ \\
\hline $12 / 9 / 13$ & $\mathrm{y}$ & $\mathrm{n}$ & $\mathrm{n}$ & $\mathrm{y}$ \\
\hline $12 / 10 / 13$ & $\mathrm{y}$ & $\mathrm{n}$ & $\mathrm{n}$ & $\mathrm{y}$ \\
\hline $12 / 11 / 13$ & $\mathrm{y}$ & $\mathrm{n}$ & $\mathrm{n}$ & $\mathrm{y}$ \\
\hline $12 / 12 / 13$ & $\mathrm{y}$ & $\mathrm{n}$ & $\mathrm{n}$ & $\mathrm{y}$ \\
\hline $12 / 13 / 13$ & $\mathrm{y}$ & $\mathrm{n}$ & $\mathrm{n}$ & $\mathrm{y}$ \\
\hline $12 / 14 / 13$ & $\mathrm{y}$ & $\mathrm{n}$ & $\mathrm{n}$ & $\mathrm{y}$ \\
\hline $12 / 15 / 13$ & $\mathrm{y}$ & $\mathrm{n}$ & $\mathrm{n}$ & $\mathrm{y}$ \\
\hline $12 / 16 / 13$ & $\mathrm{y}$ & $\mathrm{n}$ & $\mathrm{y}$ & $\mathrm{y}$ \\
\hline $12 / 17 / 13$ & $\mathrm{y}$ & $\mathrm{n}$ & $\mathrm{y}$ & $\mathrm{y}$ \\
\hline $12 / 18 / 13$ & $\mathrm{y}$ & $\mathrm{n}$ & $\mathrm{y}$ & $\mathrm{y}$ \\
\hline $12 / 19 / 13$ & $\mathrm{y}$ & $\mathrm{n}$ & $\mathrm{y}$ & $\mathrm{y}$ \\
\hline $12 / 20 / 13$ & $\mathrm{y}$ & $\mathrm{n}$ & $\mathrm{y}$ & $\mathrm{y}$ \\
\hline $12 / 21 / 13$ & $\mathrm{y}$ & $\mathrm{n}$ & $\mathrm{y}$ & $\mathrm{y}$ \\
\hline $12 / 22 / 13$ & $\mathrm{y}$ & $\mathrm{n}$ & $\mathrm{y}$ & $\mathrm{y}$ \\
\hline $12 / 23 / 13$ & $\mathrm{y}$ & $\mathrm{n}$ & $\mathrm{y}$ & $\mathrm{y}$ \\
\hline $12 / 24 / 13$ & $\mathrm{y}$ & $\mathrm{n}$ & $\mathrm{y}$ & $\mathrm{y}$ \\
\hline $12 / 25 / 13$ & $\mathrm{y}$ & $\mathrm{n}$ & $\mathrm{y}$ & $\mathrm{y}$ \\
\hline $12 / 26 / 13$ & $\mathrm{y}$ & $\mathrm{n}$ & $\mathrm{y}$ & $\mathrm{y}$ \\
\hline $12 / 27 / 13$ & $\mathrm{y}$ & $\mathrm{n}$ & $\mathrm{y}$ & $\mathrm{y}$ \\
\hline $12 / 28 / 13$ & $\mathrm{y}$ & $\mathrm{n}$ & $\mathrm{y}$ & $\mathrm{y}$ \\
\hline $12 / 29 / 13$ & $\mathrm{y}$ & $\mathrm{n}$ & $\mathrm{y}$ & $\mathrm{y}$ \\
\hline $12 / 30 / 13$ & $\mathrm{y}$ & $\mathrm{n}$ & $\mathrm{y}$ & $\mathrm{y}$ \\
\hline $12 / 31 / 13$ & $\mathrm{y}$ & $\mathrm{n}$ & $\mathrm{y}$ & $\mathrm{y}$ \\
\hline $1 / 1 / 14$ & $\mathrm{y}$ & $\mathrm{n}$ & $\mathrm{y}$ & $\mathrm{y}$ \\
\hline $1 / 2 / 14$ & $\mathrm{y}$ & $\mathrm{n}$ & $\mathrm{y}$ & $\mathrm{y}$ \\
\hline $1 / 3 / 14$ & $\mathrm{y}$ & $\mathrm{n}$ & $\mathrm{y}$ & $\mathrm{y}$ \\
\hline $1 / 4 / 14$ & $\mathrm{y}$ & $\mathrm{n}$ & $\mathrm{y}$ & $\mathrm{y}$ \\
\hline $1 / 5 / 14$ & $\mathrm{y}$ & $\mathrm{n}$ & $\mathrm{y}$ & $\mathrm{y}$ \\
\hline $1 / 6 / 14$ & $\mathrm{y}$ & $\mathrm{n}$ & $\mathrm{y}$ & $\mathrm{y}$ \\
\hline $1 / 7 / 14$ & $\mathrm{y}$ & $\mathrm{n}$ & $\mathrm{y}$ & $\mathrm{y}$ \\
\hline $1 / 8 / 14$ & $\mathrm{y}$ & $\mathrm{n}$ & $\mathrm{y}$ & $\mathrm{y}$ \\
\hline $1 / 9 / 14$ & $\mathrm{y}$ & $\mathrm{n}$ & $\mathrm{y}$ & $\mathrm{y}$ \\
\hline $1 / 10 / 14$ & $\mathrm{y}$ & $\mathrm{n}$ & $\mathrm{y}$ & $\mathrm{y}$ \\
\hline 1/11/14 & $\mathrm{y}$ & & $\mathrm{y}$ & $\mathrm{y}$ \\
\hline
\end{tabular}


